\title{
Mapping Canada's Rangeland and Forage Resources using Earth Observation
}

by

\author{
Emily Jane Lindsay
}

A thesis submitted to the Faculty of Graduate and Postdoctoral Affairs in partial fulfillment of the requirements for the degree of

Master of Science

in

Geography

Carleton University

Ottawa, Ontario

(C) 2016, Emily Jane Lindsay 


\begin{abstract}
This thesis implements a pixel-based random forest classifier for differentiating rangeland, pastureland, and forage crops using multi-temporal optical and radar Earth observation (EO) data. Previous efforts to create an inventory of rangeland and forage resources across the Canadian Prairies using EO have not achieved desired accuracies due to spectral reflectance similarities amongst the classes and partly as a result of the regional variability of climate, soil type and management practices. Field data related to land cover type and dominant species composition were collected during the 2015 growing season at study areas west of Brandon, MB and near Lethbridge, AB. Landsat-8 (LS8) multispectral and derived phenological variables, as well as mid-summer RADARSAT-2 (RS2) backscatter data were integrated into a Random Forest (RF) classification. The results of this study highlight the importance of spring optical image acquisitions to differentiate between rangeland and seeded forage in multi-date optical land cover classifications, as well as low performance of mid-summer RS2 backscatter for differentiating rangeland and seeded forage alone and in combination with LS8. Keywords: rangeland, seeded forage, land cover classification, random forest, Landsat 8 OLI, RADARSAT-2, vegetation indices, phenology
\end{abstract}




\section{Acknowledgements}

I would like to express my deepest appreciation for the support of my co-supervisors, Dr. Doug J. King, and Dr. Andrew M. Davidson, without the wisdom, attention to detail, and occasional emotional support, this project would not have been possible.

I am grateful for the many individuals who contributed to this project with their wisdom and experience who were either directly or indirectly involved. The many AAFC-AAC collaborators on the project team under the leadership of Bill Houston, as well as the daily support of the members of the Earth Observation Team of the Science and Technology Branch (STB) at AAFC-AAC.

I greatly appreciate the assistance of Mae Elsinger and Gary Larson, for their time and experience during my field work in Brandon, $\mathrm{MB}$ and Lethbridge, $\mathrm{AB}$. Without the combined encyclopedic knowledge between the two of them the difference between common range plants would still elude me. I would also like to thank all the kind producers and land managers who allowed access to their land and time as well as their individual perspectives on land stewardship which contributed immensely to this project.

I would like to thank those within the Department of Geography and Environmental Studies at Carleton University, including the staff, faculty, and fellow students who have encouraged my academic pursuits over the past 7 years.

Nobody has been more important to me in the pursuit of this research than the members of my family and loved ones. I would like to thank my parents for their unfailing support and guidance throughout this adventure and all those to come. 


\section{Table of Contents}

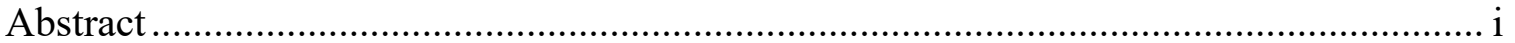

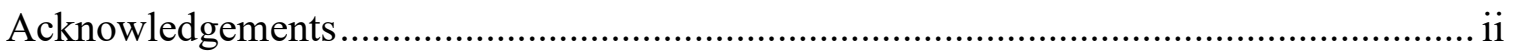

List of Tables.................................................................................................... vi

List of Figures ................................................................................................. viii

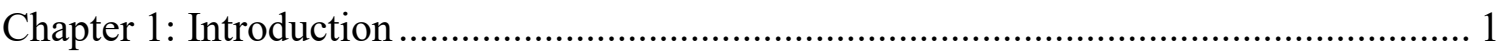

1.1 Research Context and Justification ........................................................... 2

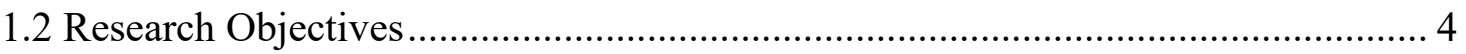

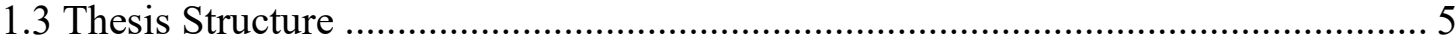

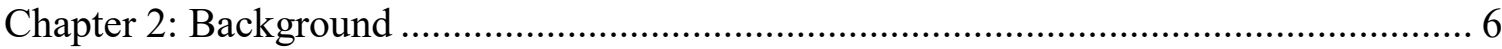

2.1 Canada's Rangeland and Forage Resources ................................................... 6

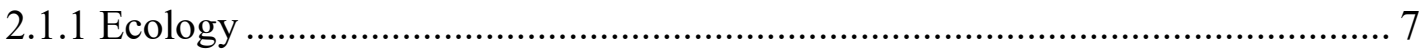

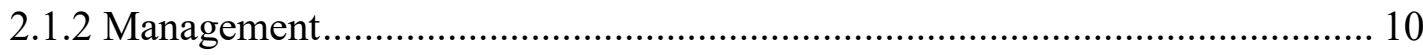

2.2 Remote Sensing of Rangeland and Forage ...............................................11

2.2.1 Multi-temporal Remote Sensing and Vegetation Phenology ........................ 13

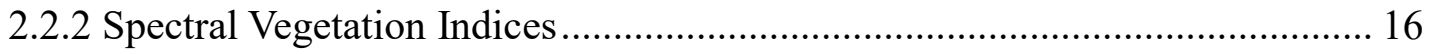

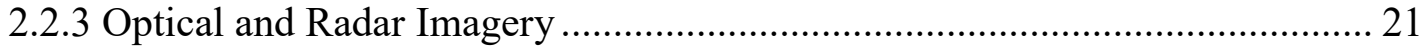

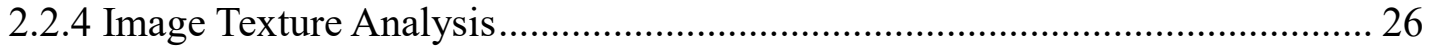

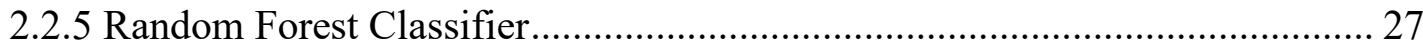

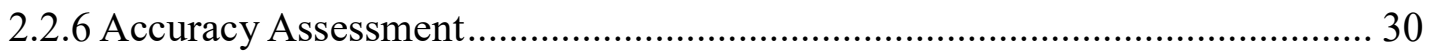

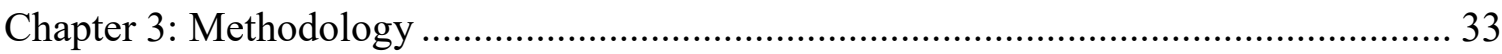

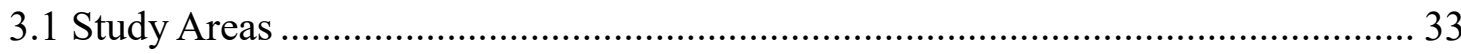

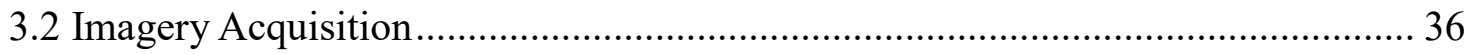

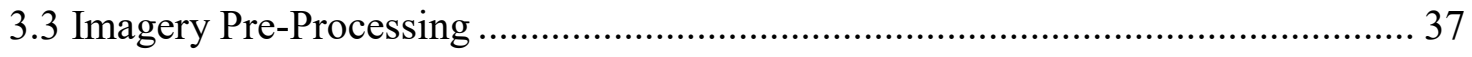

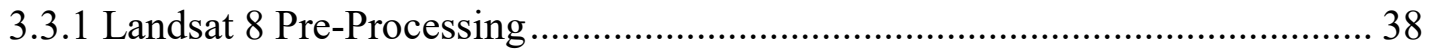


3.3.2 RADARSAT-2 Pre-Processing 39

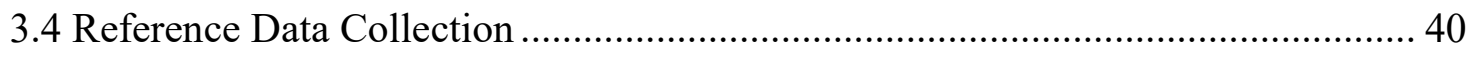

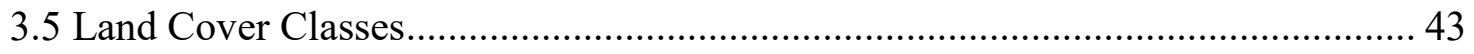

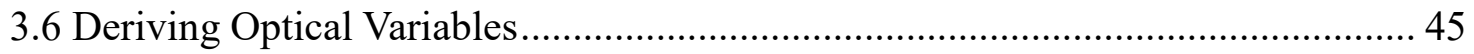

3.6.1 Vegetation Indices and Time-Series NDVI Variables ....................................... 46

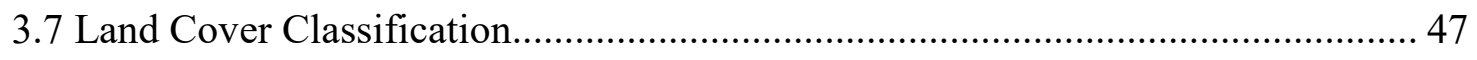

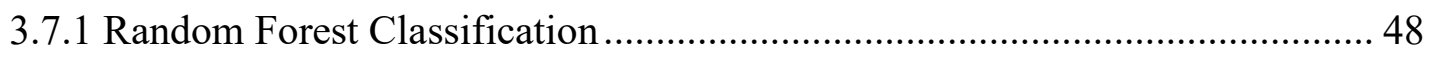

3.7.2 Classification Accuracy Assessment .............................................................. 48

3.8 Assessing Variable Importance …………………............................................ 49

3.8.1 Predictor Variable Performance …………………………........................... 49

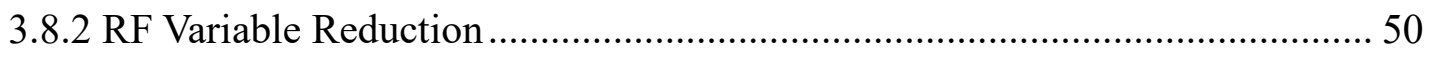

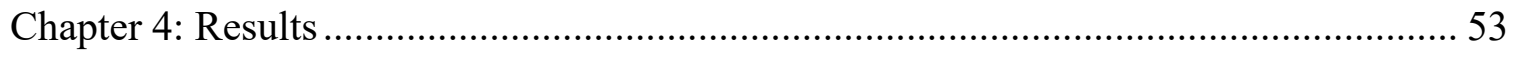

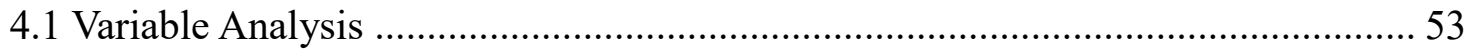

4.1.1 Multitemporal Multispectral Analysis ........................................................... 53

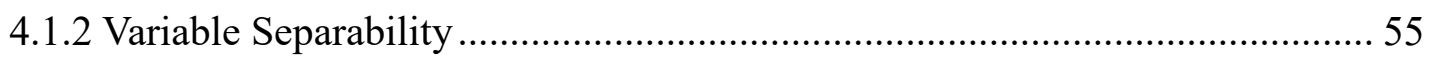

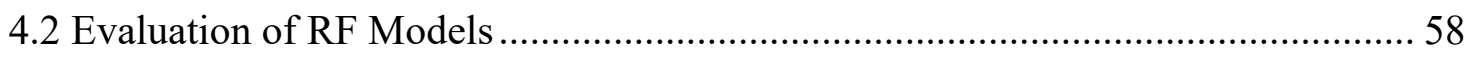

4.2.1 Evaluation of MS Acquisition Dates............................................................ 58

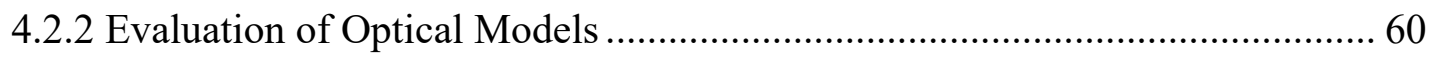

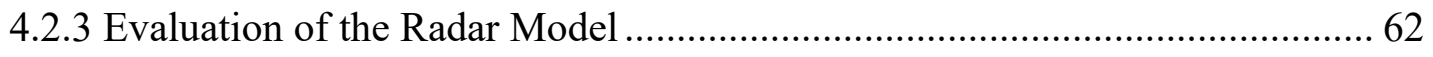

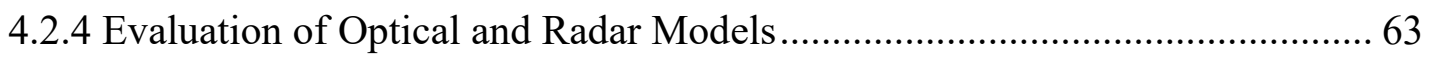

4.3 Evaluation of RF Variable Importance ………................................................. 70

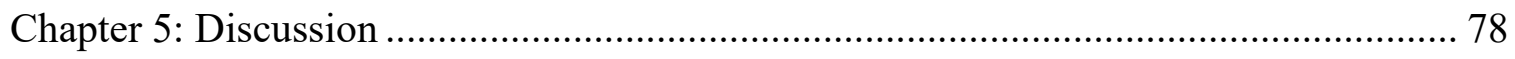

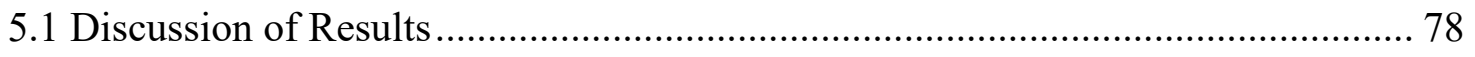

5.1.1 Random Forest Classification ...................................................................... 78

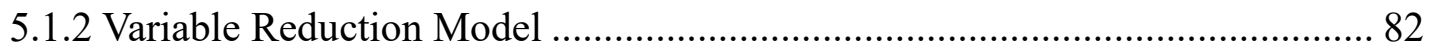


5.2 Limitations and Future Work

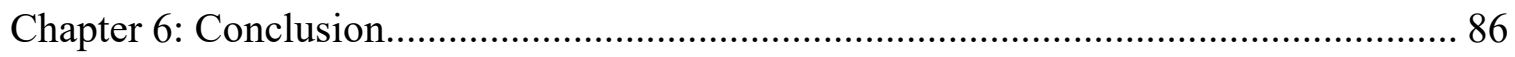

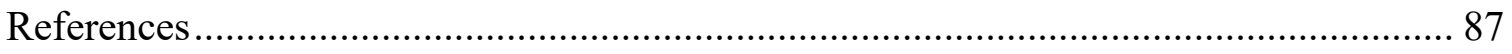

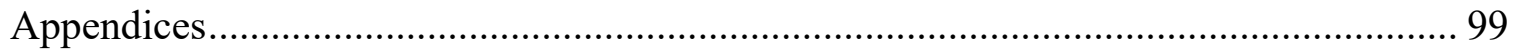

APPENDIX A - Separability Analysis for Radar Speckle Filter Selection................. 99

APPENDIX B - Classification Error Matrices and Accuracy Statistics .................. 100

APPENDIX C - McNemar's Test Results...................................................... 124

APPENDIX D - Mean Decrease in Accuracy for all Variables ............................. 129

APPENDIX E - Variable Correlation................................................................. 132 


\section{List of Tables}

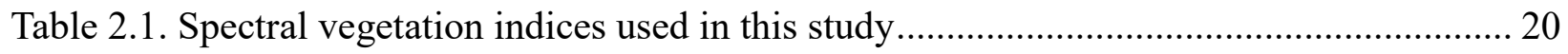

Table 2.2. TCT Coefficients for Landsat 8 at-satellite reflectance (Baig et al., 2014)................. 21

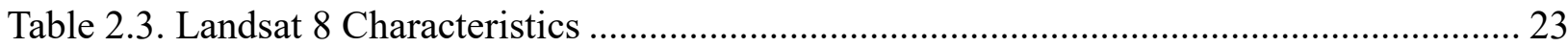

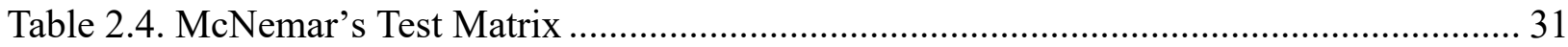

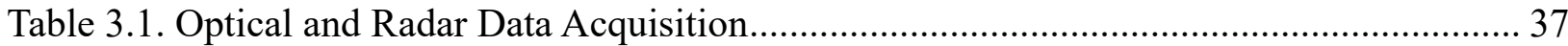

Table 3.2. Five aggregated land cover classes and 15 initial subclasses recorded in the field; final classes (1-3) and masked classes (4 and 5)............................................................................... 45

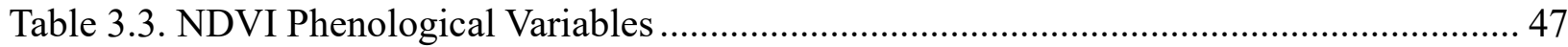

Table 3.4. Variable Combinations Used in RF Classifications ........................................................ 48

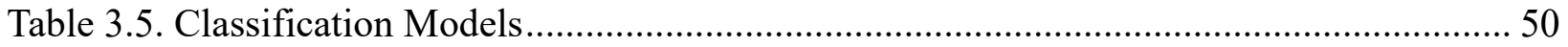

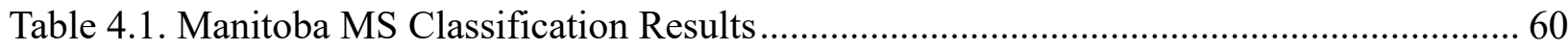

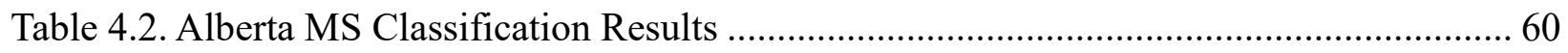

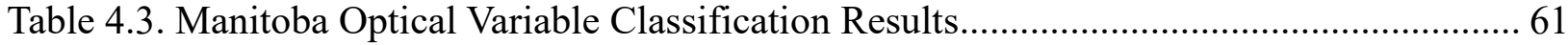

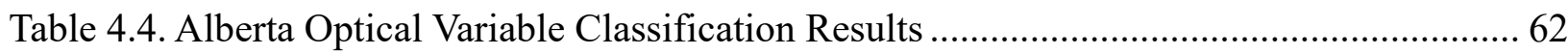

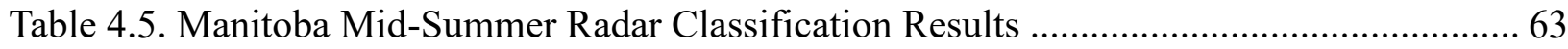

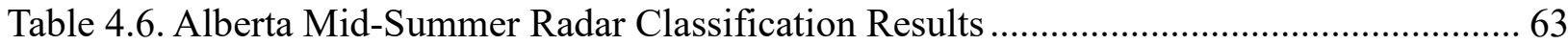

Table 4.7. Manitoba Optical \& Mid-Summer Radar Classification Results.................................... 65

Table 4.8. Alberta Optical \& Mid-Summer Radar Classification Results ....................................... 65

Table 4.9. Top 20 variables ranked by importance across $50 \mathrm{RF}$ iterations for Manitoba. An x in the correlation column signifies a higher ranking variable is significantly correlated $(r \geq 0.8) \ldots 72$

Table 4.10. Top 8 Manitoba variables by rank and strongly correlated variables $(r \geq 0.8)$.......... 72 Table 4.11. Chart depicting top 20 variables ranked by importance across 50 iterations of RF for Alberta. An x in the correlation column signifies a higher ranking variable is significantly

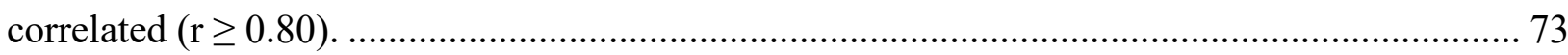

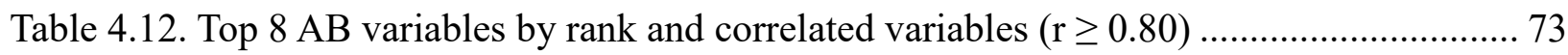

Table 4.13. Accuracy Statistics for Manitoba RF Variable Reduction Method .............................. 75 
Table 4.14. Accuracy Statistics for Alberta RF Variable Reduction Method. 75

Table A.1. Transformed Divergence of RS2 Speckle Filters 99

Table A.2. Classification Accuracy Statistics derived from the Error Matrices for the Manitoba

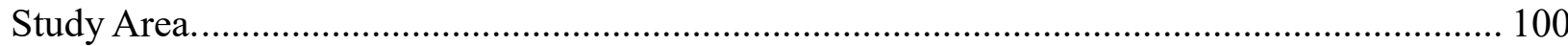

Table A.3. Manitoba single-date MS classification error matrices ............................................. 101

Table A.4. Manitoba single-date VI classification error matrices.............................................. 102

Table A.5. Manitoba single-date RS2 classification error matrix …………………................... 103

Table A.6. Manitoba single-date MS \& VI classification error matrices..................................... 104

Table A.7. Manitoba single-date MS \& RS2 classification error matrices ................................. 105

Table A.8. Manitoba single-date MS + VI + RS2 classification error matrices ......................... 106

Table A.9. Manitoba two-date MS classification error matrices ................................................ 107

Table A.10. Manitoba two-date MS \& VI classification error matrices ...................................... 108

Table A.11. Manitoba two-date MS \& VI + RS2 classification error matrices ........................... 109

Table A.12. Manitoba three-date classification error matrices (part 1) ........................................110

Table A.13. Manitoba three-date classification error matrices (part 2) .......................................111

Table A.14. Classification Accuracy Statistics derived from the Error Matrices for the Alberta

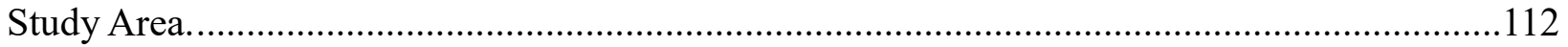

Table A.15. Alberta single-date MS classification error matrices...............................................113

Table A.16. Alberta single-date VI classification error matrices ................................................114

Table A.17. Alberta single-date RS2 classification error matrix................................................115

Table A.18. Alberta single-date MS \& VI classification error matrices ........................................116

Table A.19. Alberta single-date MS + RS2 classification error matrices ………........................117

Table A.20. Alberta single-date MS + VI \& RS2 classification error matrices ..........................118

Table A.21. Alberta two-date MS classification error matrices ...................................................119

Table A.22. Alberta two-date MS + VI classification error matrices........................................... 120

Table A.23. Alberta two-date MS + VI \& RS2 classification error matrices............................... 121

Table A.24. Alberta three-date classification error matrices (part 1) ............................................ 122

Table A.25. Alberta three-date classification error matrices (part 2) ........................................ 123 


\section{List of Figures}

Figure 1.1. Canada's rangeland and forage resources by Prairie Province in 2011 (Statistics Canada, 2011)

Figure 2.1. Prairie ecoregions. (Natural Resources Canada, 2011) 9

Figure 2.2. Seasonal growth distribution of cool- and warm-season grasses. (Volesky et al., 2003). 14

Figure 2.3. RADARSAT-2 SAR beam modes (MDA, 2014) 26

Figure 3.1. Location of Manitoba Study Area (Statistics Canada, 2011) .................................. 35

Figure 3.2. Location of Alberta Study Area (Statistics Canada, 2011) .................................... 36

Figure 3.3. Landsat 8 OLI Cloud and Cloud Shadow Masks .................................................. 39

Figure 3.4. Distribution of reference data for (a) Manitoba and (b) Alberta study areas. ........... 42

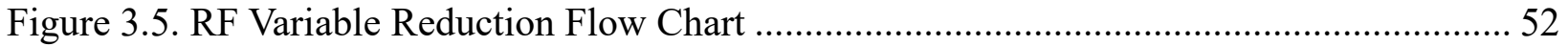

Figure 4.1. Spectral curves for three land cover classes over Manitoba study area derived from LS8 TOA data for A) spring (d147), B) late summer (d243), and C) fall (d291).................... 54

Figure 4.2. Spectral curves for three land cover classes over the Alberta study area derived from LS8 TOA data for A) spring (d139) B) mid-summer (d187), and C) late summer (d235)......... 55

Figure 4.3. Boxplots of Manitoba derived optical variables (spring (d147), late summer (d243) and fall (d291)) and Radar variables (VV and VH) rescaled to 0-1. The lines represent the minimum (bottom) and maximum (top) excluding outliers (dots), while the box represents the lower and upper quartile with the horizontal line representing the median. 57 Figure 4.4. Boxplots of Alberta derived optical variables; (spring (d139), mid-summer (d187) and late summer (d235)) and Radar variables (VV and VH) rescaled to $0-1$. The lines represent the minimum (bottom) and maximum (top) excluding outliers (dots), while the box represents the lower and upper quartile with the horizontal line representing the median.

Figure 4.5. Overall classification accuracy with the addition of mid-summer radar to multi-

spectral variables. 66

Figure 4.6. Rangeland classification accuracy (UA) with the addition of mid-summer radar to multi-spectral variables. 
Figure 4.7. Independent overall accuracy (OA) and RF OOB error for Manitoba classification models

Figure 4.8. Independent overall accuracy (OA) and RF OOB error for Alberta classification

models.

Figure 4.9. Maps of best and worst performing classification models for the Manitoba study area.

Figure 4.10. Maps of best and worst performing classification models for the Manitoba study area. 69

Figure 4.11. Classified map using top 8 important/uncorrelated variables for Manitoba. .......... 76

Figure 4.12. Classified map using top 8 important/uncorrelated variables for Alberta. 77

Figure A.1. McNemar's Chi-Square test comparing three-date MS classification to two-date MS classifications. 124

Figure A.2. McNemar's Chi-Square test comparing MS + VI classifications (1, 2, and 3-date) to MS classifications (1, 2 and 3-date). 125 Figure A.3. McNemar's Chi-Square test comparing single-date MS classifications to single-date VI classifications. 126

Figure A.4. McNemar's Chi-Square test comparing MS + RS2 classifications (1, 2, and 3-date) to MS classifications (1, 2 and 3-date). 127

Figure A.5. McNemar's Chi-Square test comparing three date classifications using all variables to the three-date MS classification and the three-date MS + RS2 classification ..... 128 Figure A.28. MDA for all Manitoba variables (Optical + Radar) for 1 iteration of the RF classification 130

Figure A.29. MDA for all Alberta variables (Optical + Radar) for 1 iteration of the RF classification 131

Figure A.8. Spearman correlation coefficients for all Manitoba variables 133

Figure A.9. Spearman correlation p-values for all Manitoba variables 134

Figure A.10. Spearman correlation coefficients for all Alberta variables 135

Figure A.11. Spearman correlation p-values for all Alberta variables 136 


\section{Chapter 1: Introduction}

With high rates of population increase in developing countries and increased urbanization, there is a demand for sustainable and productive agriculture systems worldwide. Climate change and increased biofuel production are the largest threats to long-term food security. In Canada, agricultural production is limited to $7.3 \%$ of the overall land-mass, where soil and climate conditions are favorable, and contributes over 100 billion dollars annually to the Canadian economy (Statistics Canada, 2006). The Prairie Provinces (Alberta, Saskatchewan and Manitoba) contain the most productive agricultural land in Canada, and are the largest producers of beef as well as oilseed and cereal crops. With an increased intensification of agricultural practices as well as the demand for biofuel production; there is an increased need for information on the condition, location, and extent of agricultural land cover in Canada in order to inform environment and land management policies.

Rangeland is defined by the Society for Range Management (SRM) as: “...land on which the indigenous vegetation (climax or natural potential) is predominantly grasses, grass-like plants, forbs, or shrubs and is managed as a natural ecosystem. If plants are introduced, they are managed similarly." The definition of rangeland includes natural grasslands. Seeded forage is managed differently than rangeland, and is defined as "a crop of cultivated plants other than separated grain, produced to be grazed or harvested for use as feed for animals" (SRM, 1998). Canada's Prairie rangeland and forage resources are two very complex and diverse land cover classes. The diversity is enhanced regionally due to geographic differences in management practices which are determined by climatic conditions and soil type. Rangeland and land providing forage are not only the basis of Canada's livestock industry; rangeland and seeded 
pasture are ecologically significant for the ecosystem services provided by natural and seminatural perennial land cover (Vaisey \& Strankman, 1999; Bailey et al., 2010a). The most valuable ecosystem services provided by rangeland and seeded forage at the regional scale are soil and water conservation, pollination, nitrogen fixation, carbon storage, forage production, and recreation (Chan et al., 2006). The biggest threat to native rangeland is the plowing of land and conversion to commodity cropping. The average annual rate of loss of North American native grasslands was 2\% between 2009 and 2015, with an estimated 148 million hectares remaining (World Wildlife Fund, 2016). As a result, resource managers and stakeholders depend on effective monitoring of native grasslands, including knowledge of land degradation and land cover change in order to conserve this rapidly disappearing biome.

\subsection{Research Context and Justification}

Having an accurate estimation of the location and extent of rangeland and forage resources has many benefits. Currently there is no accurate or reliable product or documentation which provides an estimate of these land cover classes in Canada for annual monitoring. The Census of Agriculture (2011) is the most recent estimate of the land area of forage resources. The remaining natural land for pasture and seeded pasture decreases on a gradient in the Prairie region from Alberta to Manitoba in the east. This is partly due to the earlier settlement of Manitoba, as well as the quality of the soil and abundant precipitation which makes the eastern part of the prairie region much better suited to intensive agriculture (Bailey et al., 2010b). An accurate estimation of Canada's rangeland and forage resources would provide support and monitoring for sustainable policy decisions in the agriculture industry. Sustainable agricultural practices such as the conversion of marginal cropland to native seeded pasture can preserve soil, 
build up organic matter, enhance biodiversity, and enhance the connectivity of wildlife corridors. On the other hand, an inventory of rangeland and seeded forage could also be used to monitor and protect remaining native rangeland from conversion to intensive agriculture. An inventory would provide much needed area estimates for future scenario modelling of land use change in response to climate, political, and socioeconomic change. This research fits within a larger initiative started in 2009 by the Earth Observation Team of the Science and Technology Branch (STB) at Agriculture and Agri-Food Canada (AAFC) to produce crop-type land cover mapping across the agricultural extent of Canada to support a national crop inventory (Fisette et al., 2014). While the methodologies used to create this product have been very successful for mapping annual crop types across Canada, the product contains problematic inaccuracies related to spectrally distinguishing native rangeland from seeded forage due to their regionally diverse dynamics.

The diversity of rangeland and forage resources makes regional-scale efforts of Land Use and Land Cover (LULC) mapping an onerous task. Fortunately, the advancement of technology due to the demand for Earth observation products for environmental monitoring has seen an exponential increase over the past decade in the availability of satellites and remote sensing imagery. This study uses random forest (RF), a robust machine learning classifier, to classify moderate resolution optical and radar data, as well as to determine the importance of key variables and acquisition dates for the differentiation of rangeland and seeded forage. Random forest is an efficient and accurate classifier of large and diverse datasets, and provides important internal estimates of variable importance and overall accuracy (Breiman, 2001). The overall context of this research was to investigate the use of multisource Earth observation (EO) data, including multitemporal optical and radar data, with a machine learning classifier (RF) for 
mapping rangeland and forage resources in Canada's Prairie ecozone. This research was carried out in two study areas in Manitoba and Alberta as described in 3.1.

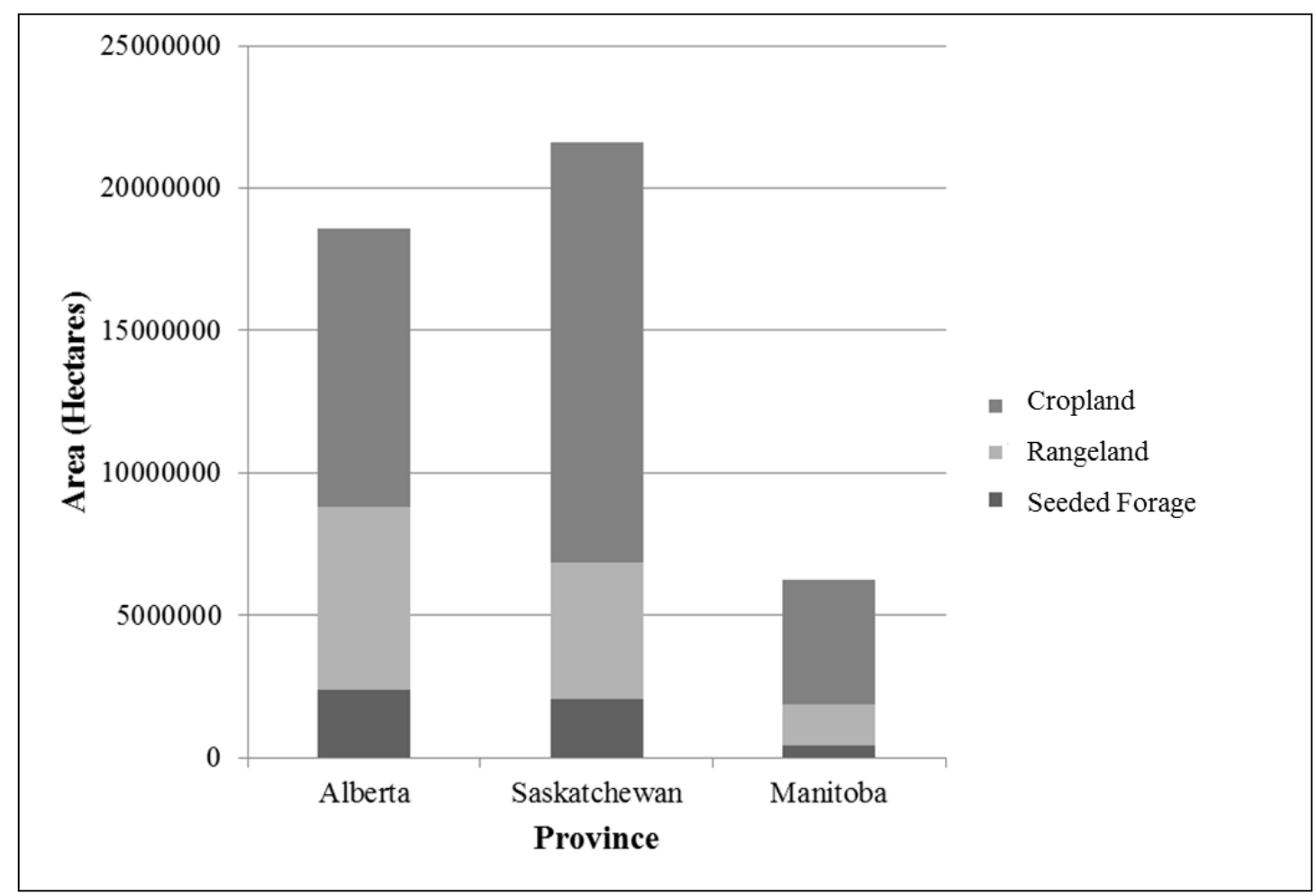

Figure 1.1. Canada's rangeland and forage resources by Prairie Province in 2011 (Statistics Canada, 2011)

\subsection{Research Objectives}

The two primary research objectives were:

1) Determine which type of medium-resolution remote sensing imagery (optical, radar, or both) can be useful for accurate mapping of Canada's rangeland and forage resources using a pixelbased random forest classifier.

a) Determine which available image acquisition date, or combination of image dates perform the best for each study area; for classifying rangeland and seeded forage. Determine if including all three dates of multispectral data has a significantly higher accuracy than the single and two-date classifications for each study area. 
b) Determine how the addition of radar and derived optical variables, on their own or included with the multispectral variables affect classification accuracy.

2) Determine the stability of error for random forest classifications using a reduced set of the most important and uncorrelated variables compared to classification performance using all optical and radar variables.

\subsection{Thesis Structure}

This thesis is organized into five chapters. The first chapter introduces the research topic of rangeland and forage resources in Canada, the need for accurate mapping of these resources, and the remote sensing based approach taken in this research to develop such capabilities. It also outlines the context and scope of the research as well as the research objectives. The second chapter provides a synthesis of relevant literature on the management practices and ecology of rangeland and forage resources, as well as a review of the proposed remote sensing methods and data used to in this research to classify rangeland and forage resources. Chapter three describes the study areas and field work, as well as the acquisition and processing of remotely sensed data, methods of variable extraction, classification, and accuracy assessment. Chapter four provides the results of each of the classifications for each area. The major findings and discussion, as well as the limitations of this research and implications for future research are outlined in Chapter five. 


\section{Chapter 2: Background}

The first section (2.1) of this chapter provides relevant background information and literature on the ecology and management of Canada's Prairie rangeland and forage resources. This background is necessary to understand the regional variability which is the main obstacle in accurate mapping of these land cover types using remote sensing. Section 2.2 provides a review of the literature on the remote sensing techniques implemented in this study.

\subsection{Canada's Rangeland and Forage Resources}

One of the problems associated with classifying seeded forage and rangeland using remote sensing data is the variation of ecology and management within each land cover type. With the settlement of western Canada, fertile soils were quickly converted to valuable cropland, leaving the drier and less productive fragments of land as native grassland (Bailey, 2010b). Vegetation dynamics on the remaining prairie grasslands in North America are a function of grazing, fire, climate, and soil (Gillen et al., 2000).

Relative to simplified cropping systems, perennial species offer many ecological benefits such as maintaining soil health, preserving habitats for species at risk and enhancing biodiversity, and carbon sequestration (Asbjonsen et al., 2013). Natural and semi-natural ecosystems such as rangeland and forage also provide societal benefits referred to as ecosystem services (Tilman et al., 2002). The following sections describe the ecology and management of forage and rangeland resources in the Prairie region of Canada. 


\subsubsection{Ecology}

Grasslands generally occur in areas with distinct climatic conditions comprised of low temperature and low water availability (Tieszen et al., 1997). These conditions make grasslands more susceptible than other temperate ecosystems to slight changes in climate including changes in temperature and precipitation. There is significant variation in ecology within the Great Plains grasslands of North America. The grassland biome in North America can be divided into ecoregions (Figure 2.1) or by dominant plant functional type (e.g., tall-grass, mixed-grass and short-grass). It is important to consider the variations of such ecological groups within the Prairie provinces as grasslands exhibit important phenological differences which must be understood when trying to classify them using remote sensing.

The Prairie ecozone in Canada is a northern extension of the Great Plains of North America. It is the most human-altered ecozone in Canada, and is characterized by a dry continental climate (Ecological Stratification Working Group, 1995). As the Canadian prairies were settled, there was pressure from the government to convert "unimproved" natural grassland to "improved land" by cultivation (Bailey et al., 2010a). The rapid conversion to cropland significantly reduced biodiversity and soil quality (Vaisey \& Strankman, 1999). The remaining natural grasslands are estimated to cover 11.4 million hectares, a mere $20 \%$ of the ancient natural grassland ecosystem (Bailey et al., 2010a). The remaining native prairie resources in Canada extend from the tall grass prairie in southeastern Manitoba (less than $1 \%$ remaining) to the aspen parkland and fescue grasslands in northwest Manitoba, Saskatchewan and Alberta (5\% remaining). Less than $20 \%$ of the southern mixed grass prairie remains in Alberta and Saskatchewan, where the climate is much less suited for crops without intensive irrigation (Morgan, 1995; Bailey et al., 2010a). The remaining native prairie is highly fragmented and is 
under threat by cultivation when irrigation is possible, as well as from further fragmentation due to expansion of roads and oil and gas development (Bailey et al., 2010a). Invasive plants are another growing threat to native prairie, which can upset the balance of native species (Vasquez et al., 2010). Properly managed rangeland and forage are valuable for ecosystem services including the provision of forage for livestock and wildlife, improvements to water and nutrient cycling, as well as the provision of habitat for native and commercial pollinators, and for species at risk (Wang et al., 2014; Nixon et al., 2015). Management practices that protect soil, water, and air tend to support carbon sequestration, and therefore contribute to offsetting greenhouse gas emissions (Wang et al., 2014).

Functional groupings of plants commonly found in North American grasslands are of three main morphologies: grasses, forbs, and shrubs. These plants are commonly categorized as warm season $\left(\mathrm{C}_{4}\right.$ photosynthetic pathway type $)$ and cool season plants $\left(\mathrm{C}_{3}\right.$ photosynthetic pathway type) corresponding to the timing of maximum plant growth (Lauenroth et al., 1997). Latitude and longitude, as well as climate, account for the variability in the distribution of plant functional types (Paruelo \& Lauenroth, 1996). $\mathrm{C}_{4}$ plants are known to have evolved from $\mathrm{C}_{3}$ ancestors and have a more complicated mechanism for $\mathrm{CO}_{2}$ fixation which can be distinguished using optical remote sensors through the differences in phenology (Davidson, 2002; Guo et al., 2003). Typically $\mathrm{C}_{3}$ species are "cool season" plants with lower light saturation and higher transpiration rates than $\mathrm{C}_{4}$ "warm season" plant species (Goodin \& Henebry, 1997). Grasses native to the northern limits of the Great Plains are typically $\mathrm{C}_{3}$, meaning they are adapted to the cooler climate, are frost tolerant, and are less photosynthetically active during the summer months (Wang et al., 2013). Non-native grasses such as Kentucky bluegrass (poa pratensis) and smooth bromegrass (bromus inermis) are $\mathrm{C}_{3}$ or cool-season grasses that are most 
photosynthetically active in the spring and fall months (Guo et al., 2003). A seeded forage stand such as hay or pasture includes a dominant proportion of $\mathrm{C}_{3}$ grasses, and therefore is much greener and productive in spring and fall. Native rangelands may have a more diverse mixture of $\mathrm{C}_{3}$ and $\mathrm{C}_{4}$ plants, depending on the region meaning there is a more complex vegetation dynamic (Rigge et al, 2013).

The common term "rangeland" is not exact or precise. Definitions may include native forest and grassland communities as well as communities that are invaded by non-native grasses, forbs, and shrubs. As native grasslands become overtaken by these species and other invasive plants, the vegetation phenology shifts and it becomes difficult to distinguish if the land was modified intentionally or if these vegetation types arrived by natural dispersion methods.

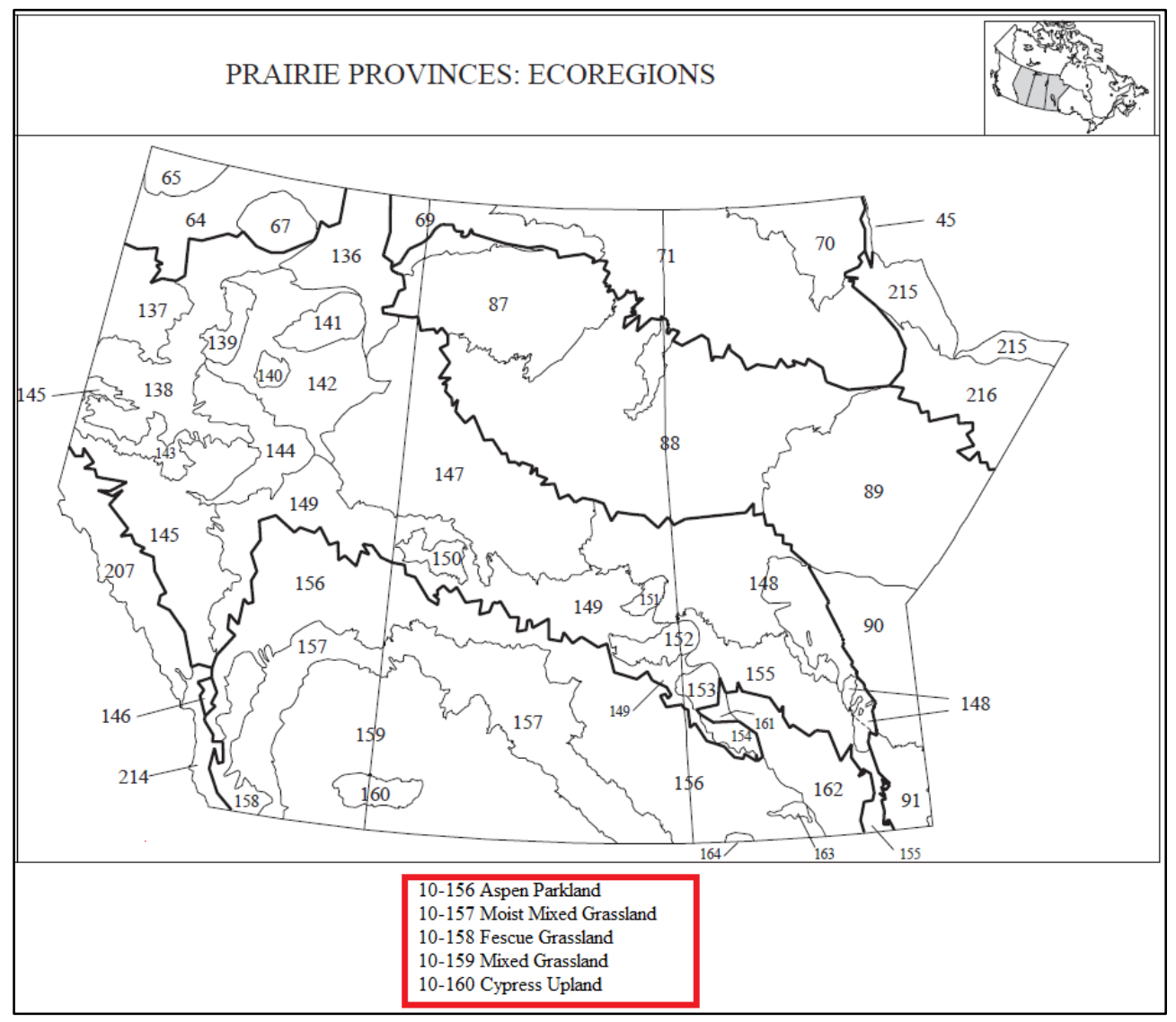

Figure 2.1. Prairie ecoregions. (Natural Resources Canada, 2011) 


\subsubsection{Management}

Canada's forage resources include native rangeland and seeded forage (such as pasture and hayland), as well as some annual cereal crops used for greenfeed (silage) (McCartney, 2011). Native rangeland and seeded forage are an important component of the beef cattle industry in western Canada and also provide critical habitat for wildlife and species at risk.

Different grazing systems are used to manage different types of grazing lands.

Continuous, seasonal, rotational, and switchback are all grazing systems implemented on Canadian prairie rangeland and pasture (Bailey et al., 2010a). Continuous grazing is the simplest as animals are turned out at the beginning of the season and remain there until the season ends. This system requires minimal management skill and if stocking rates are kept at a moderate level, it can be sustainable. A switchback grazing system requires two adjacent paddocks separated by fencing. Livestock graze one area for a determined length of time while the other paddock is rested for plant regrowth (Bruynooghe \& Macdonald, 2008). The objective of a rotational grazing system is to achieve a more uniform distribution of grazing across a landscape by using fencing to exclude cattle from grazing in certain areas (Fuhlendorf \& Engle, 2001). A rotational system limits damage from early grazing of forage species, and provides an effective rest period for forage (AAFRD, 2004). Grazing animals are attracted to areas closest to water with high quality forage and a low slope gradient, thus, without proper management, a patchy distribution of plant species and health may develop over time (Bailey et al., 2010a).

Seeded forage in the Canadian prairies mostly consists of reseeded non-native species, most commonly a mixture of non-native perennial grasses and legumes such as alfalfa (medicago sativa) or red clover (trifolium pretense) to improve pasture quality and extend the grazing 
season (Entz et al., 1995; Harker et al., 2000). In some ecoregions, such as the Aspen Parkland, it is a common practice to rotate annual crops with forage crops to control weed populations that reduce forage quality and can harm livestock (Harker et al., 2000). The average lifetime of a forage stand is 6.5 years; however the length can be longer in drier areas (Entz et al., 1995). In drier areas, pasture can be managed for the long term by properly managing grazing pressure (Bailey et al., 2010a).

Hayland is typically seeded with the same non-native plant species as pasture. During the growing season, hay is typically cut one to three times, while pasture can be grazed more often depending on management practices (Malhi et al., 2004). Harvesting of forage for hay removes all of the nutrients from the land, while grazing pastureland partially redistributes nutrients by cattle excrement. Harvesting as opposed to grazing also promotes an even stand growth, whereas selective grazing by livestock promotes patchy composition and coverage (Malhi et al., 2004).

\subsection{Remote Sensing of Rangeland and Forage}

The following consists of background and review of the pertinent remote sensing methods used in this study. Remote sensing has been used successfully as a tool for mapping vegetation over large areas. Optical remote sensors; which record reflectance in the visible, nearinfrared, and shortwave infrared bands are widely used for vegetation mapping due to the understanding of the links between plant biophysical variables and spectral reflectance (Jones \& Vaughan, 2010). Microwave remote sensing also has potential for mapping rangeland and forage, however, the linkages between radar backscatter and plant biophysical variables are less understood in these environments (Smith \& Buckley, 2011). 
The main problem associated with classifying rangeland and seeded forage is the variability of management and ecology within each land cover type. For instance, seeded forage mixtures tend to change depending on soil chemistry and livestock nutritional needs. Another issue is the complex link between land cover and land use. Land cover refers to the physical surface cover on the ground, while land use refers to the user's intention, or purpose for the land (Lillesand et al., 2015). Rangeland and forage land cover classes overlap in their use, which is to feed or graze livestock. Remote sensing is limited in regards to classifying land use, as spectral reflectance and patterns created by land use practices may vary for the same cover type and some cropping or managed land cover types may produce similar reflectance to unmanaged land cover types. For example, a heavily bio-invaded native rangeland may contain many of the same species as a nearby seeded pasture, and thus the native rangeland would be nearly indistinguishable from the tame pasture, even if the land is managed much differently (Jefferson et al., 2013). In the same regards, native grassland under conservation (not grazed) would be imperceptible from grazed grassland using most satellite data types. Similarly a pasture or cropland reverted to native grassland whether by abandonment or seeding would be undetectable by an optical sensor. With these considerations, remote-sensing based classification is limited by the radiance signal recorded at the sensor. Decisions on which classes or subclasses to include in a classification must be made in consideration of the temporal scale and spectral response characteristics of the sensor. Ongoing operational classification by Agriculture and Agri-Food Canada (AAFC) in mapping these resources demonstrates the complex nature of the problem, with much confusion occurring among these classes (Fisette et al., 2014).

A remote sensing-based land cover classification can be enhanced by including ancillary data sources such as soil information and climate data, and deriving or transforming additional 
variables from remotely sensed imagery. The following section presents the background to the remote sensing techniques used in this study to further enhance image information in an effort to optimize class distinction.

\subsubsection{Multi-temporal Remote Sensing and Vegetation Phenology}

Knowledge of the differences in vegetation phenology of relevant classes allows for the cognizant selection of imagery dates. Time series of vegetation indices (VIs) and VI-derived phenological variables have been successfully used to identify crop types (Peña-Berragán et al., 2011; Smith et al., 2015). Classification accuracy should be enhanced by using several multispectral images at key acquisition dates corresponding to the differences in growth cycles between cool- and warm-season grasses and forbs, and the distribution and dominance of these types within native rangeland and seeded forage. The following section describes the differences in plant phenology which are critical for understanding the importance of image acquisition timing.

Annual crops in the Prairie region are represented by winter cereals, which grow from mid-fall to late-spring and summer crops, which are seeded in spring and grow from mid-spring to late summer. Each annual crop type has an individual growth cycle that can be distinguished locally by temporal differences in the time of seed sowing, plant emergence, senescence, and harvest (Peña-Berragán et al., 2011).

Seeded forage such as hay and pasture permanently covers the soil and is influenced by cutting and grazing schedules throughout the growing season. Hay and tame pasture have moderate to high biomass and are usually comprised of a mixture of grass species and legumes. Because root structures are intact prior to snow melt, these plants have a much quicker spring 
emergence, or green-up. Non-native forage species such as alfalfa, orchard grass (Dactylis glomerata L.), crested wheatgrass (Agropyron cristatum), Kentucky bluegrass, and timothy (Phleum pretense), produce most of their biomass in spring and fall and become dormant in the driest months of summer (Jefferson et al., 2013). Native cool-season forage species tend to be more drought resistant when stressed under dry and hot conditions of the summer months and are generally inactive in spring (Volesky et al., 2003). Figure 2.2 is a graphic comparison of the growth distribution of cool and warm-season forage species. In the prairies, hay may be irrigated to increase biomass, and it undergoes dramatic decreases in biomass at one or more harvest events during the growing season.

Native forage species such as those found on rangeland also have intact root systems which allow a quick emergence in the spring. The pattern of emergence and senescence, as well as the peak level of biomass varies across the prairie ecosystem depending on the dominant grass species (Reed et al., 1994). Generally, rangeland or native pasture has sparse to moderate biomass with bare soil present in some areas.

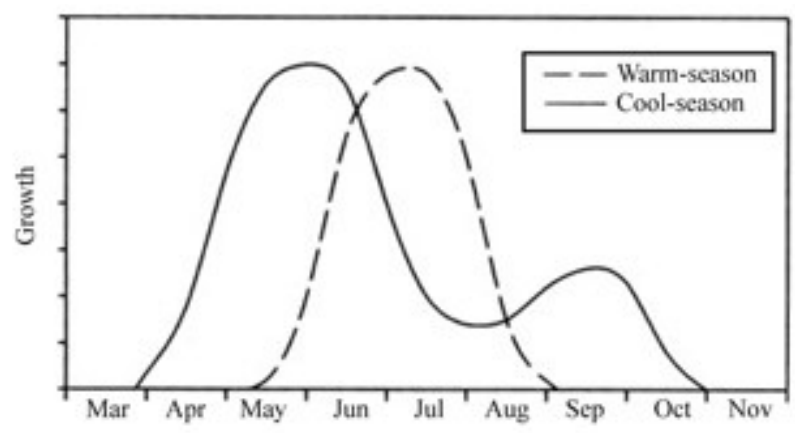

Figure 2.2. Seasonal growth distribution of cool-and warm-season grasses. (Volesky et al., 2003).

Since the launch of the first Landsat satellite in 1972, repeated, spectrally rich and synoptic imagery of the earth has been readily available for many research and application needs (Wulder et al., 2012). Optical remote sensing has the ability to predict important phenological 
stages such as the onset of growth, peak growth, and senescence. Current satellite sensors are not optimally configured for fine-resolution spatial and temporal phenological change analysis (Walker et al., 2014). Trade-offs between spatial and temporal resolution must be justified for the nature of a particular application. Satellite sensors with higher frequency coverage are more suited to studies of this nature. The most common sensor for studies relating to phenological change is the Moderate Resolution Imaging Spectroradiometer (MODIS) sensor, which has a coarse spatial resolution and a daily revisit period (Zhang et al., 2003; Penuelas et al., 2004; Walker et al., 2014). The MODIS sensor has two (of 36) spectral bands (red and near-infrared) with $250 \mathrm{~m}$ pixel size (the other bands being $500 \mathrm{~m}$ or $1000 \mathrm{~m}$ ) and is therefore useful for the evaluation of general phenology trends and large area studies. For regional to local scale studies, finer spatial resolution is generally preferable over high temporal resolution, however temporal resolution is an important consideration for capturing landscape-level processes. For this reason, studies monitoring agricultural land-use and land cover change (LULCC) typically require sensors providing 10 to $30 \mathrm{~m}$ spatial resolution with a temporal resolution allowing for the capture of spectral changes during key phenological stages (Jensen, 2015).

Guo et al. (2003) found that July Landsat imagery was the best single date of those tested, but that a three-date image dataset significantly improved classification accuracy of grassland types in Kansas. These results are, however, likely to be site specific. A similar study in eastern Europe, with the goal of accurately mapping agricultural land abandonment, found that the use of Landsat TM/ETM+ images from multiple dates is preferable for monitoring annual crops (Prishchepov et al., 2012). For studying seeded forage and rangeland, knowledge of the key differentiating phenological stages of $\mathrm{C}_{3}$ and $\mathrm{C}_{4}$ grasses (spring, mid-summer, late summer and fall) limits desirable acquisition dates to these periods. 


\subsubsection{Spectral Vegetation Indices}

Each pixel of rangeland in a Landsat image may include spectral radiance from green and senescent vegetation as well as soil and this varies over space and time (Mundava et al., 2014). Vegetation indices (VIs) in remote sensing use reflectance measurements from different wavelengths of the electromagnetic spectrum to provide information about vegetation composition, structure and health. VIs are generated by a combination of two or more original spectral bands and can be more clearly related to a biophysical parameter, such as water content or photosynthetic capacity (Jones \& Vaughan, 2010). Ideally, vegetation indices should be evaluated using biophysical data before they are used in a classification (Numata et al., 2007). Using multiple VIs derived from optical imagery has shown promise for monitoring rangeland condition (Hagen et al., 2012; Mundava et al, 2014; Tsalyuk et al., 2015; Smith et al., 2015) and in estimating ground cover in complex systems such as the mixed prairie grassland in Southern Alberta. Table 2.1 provides the spectral VIs used in this study along with the formulas used to derive them. These VIs were selected for this study over the many VIs published in the literature because they are most commonly cited for the key corresponding biophysical properties unique to agricultural landscapes. This study utilized four observable biophysical properties expected to be unique across rangeland, seeded forage, and annual cropland. These properties include vegetation greenness, soil-adjusted vegetation greenness, soil and canopy moisture, and vegetation senescence.

The Normalized Difference Vegetation Index (NDVI) (Table 2.1) is a common measure of live green vegetation (Lillesand et al., 2015) and is based on the knowledge that actively growing healthy vegetation absorbs most of the incoming visible light while leaf cells reflect or 
transmit a large amount of near-infrared light which is damaging to the plant cell structure (Rouse et al., 1973). The NDVI equation is calculated using the spectral reflectance measurements acquired in the red (visible) and near-infrared spectral region. An inter-annual time-series of NDVI values is expected to show dissimilar patterns for seeded forage, cropland, and rangeland as each cover type has different phenological traits, such as the rate and timing of spring green-up. NDVI values range between $(-1)$ and $(+1)$ and have a linear relationship with the density of green vegetation (LAI) and the photosynthetic capacity within a given pixel (Purevdorj et al., 2010). Using NDVI alone for estimating vegetation cover in low-cover environments has shown poorer performance than other VIs (Baugh \& Groeneveld, 2006) because NDVI is sensitive to the optical properties of the soil background, especially in areas where vegetation cover is sparse (Elvidge \& Lyon, 1985; Purevdorj et al., 2010).

The Normalized Difference Senescent Vegetation Index (NDSVI) is designed to detect and estimate crop residue or senescent vegetation cover (Qi et al., 2002; Marsett et al., 2006). It uses a SWIR band, which is sensitive to water absorption in place of the NIR band in the NDVI equation (Dean, 2005). As vegetation such as grass senesces and the water content in leaf tissue declines, reflectance in the SWIR region increases, while red reflectance increases due to reduced chlorophyll absorption (Qi et al., 2002). This VI was included in this study because indices that rely on the NIR band (such as NDVI) are poor predictors of biomass on rangeland sites due to the presence of senescent or dry vegetation and timing of senescence is significantly different for the three classes and also varies regionally (Todd et al., 1998; Mundava et al., 2014; Smith et al., 2015). Both green and senescent vegetation provide forage for grazing livestock, thus using indices that are sensitive to both was expected to better represent total canopy cover and contribute to more accurate classification-based inventory of rangeland and forage (Hagen et 
al., 2012). Because of the different species compositions and grazing/harvesting regimes of rangeland and forage, the amount of senescent vegetation as predicted by NDSVI would be lower for seeded forage than native rangeland. The timing and amount of senescent vegetation will also help to distinguish between forage and cropland. After the ripening stage of oilseeds, pulses, and cereals, the plant is allowed to reach senescence before harvest.

Soil properties and senescent vegetation can have a large impact on the reflectance measured at the satellite sensor, especially in rangelands when comparisons are being made across soil types (Hagen et al., 2012). As most rangelands within the study area are characterized by sparse vegetation cover, it was expected that a vegetation index that normalizes the effects of soil would more accurately represent green vegetation cover. The Soil Adjusted Vegetation Index (SAVI) was the first such VI designed for this purpose (Huete, 1988). Its equation (Eq. 2.1) is structured similar to NDVI, with the addition of a soil brightness correction factor $(L)$.

$$
S A V I=\frac{N I R-R}{(N I R+R+L)} \times(1+L)
$$

In addition rangelands include significant amounts of senescent vegetation following the peak of growth season. The Soil Adjusted Total Vegetation Index (SATVI) (Table 2.1) was designed to be sensitive to the amount of green and senescent vegetation (Marsett et al., 2006) while normalizing for soil effects by combining aspects of NDSVI (the SWIR band) and SAVI. SATVI was used instead of SAVI because of the additional senescent vegetation component. Therefore, SATVI was expected to be a more accurate measure of total vegetation than NDVI. SATVI was calculated for Landsat 8 using a default $L$-value of 0.5 , where $L$ is a constant related to the slope of the soil line in a feature-space plot (Marsett et al., 2006). The default $L$ value was used due the variability of soil types for both study areas, as well as the variability of moisture inputs for each optical acquisition date. 
The "Tasseled Cap" transformation (TCT) is a linear data transformation which transforms image data to a new set of orthogonal axes in a method similar to principal component analysis (Crist \& Kauth, 1986). TCT produces a set of three components useful for agricultural crop monitoring (Lillesand et al., 2015). TCW (wetness) is the $3^{\text {rd }}$ component, generally representing lower data variance than the components corresponding to brightness (TCB), and greenness (TCG), and often sensitive to soil and canopy moisture. The transformation coefficients (Table 2.1) are applied to the image in the form of a linear algebraic formula (Kauth \& Thomas, 1976). TCT has been used extensively for vegetation mapping and has shown promise for rangeland applications (Todd et al., 1998; Maynard et al., 2007; Karl \& Maurer, 2010). The TCW coefficients (Table 2.1) are also listed with the coefficients for the other TCT components in Table 2.2 (Biag et al., 2014). The TCT wetness coefficients for the SWIR bands are negative, corresponding to increases in TCW when soil and plant moisture decreases (Crist \& Cicone, 1984). A measure of soil/vegetation moisture was expected to be of importance for differentiating forage from rangeland, particularly in spring imagery. Wetness values were expected to increase as the percentage of green vegetation cover increases, and seeded forage generally has significantly greener biomass than rangeland in spring because of moisture and fertilizer inputs. 
Table 2.1. Spectral vegetation indices used in this study

\begin{tabular}{|c|c|c|}
\hline Spectral Index & Formula & Sources \\
\hline $\begin{array}{l}\text { Normalized Difference Vegetation } \\
\text { Index (NDVI) }\end{array}$ & $N D V I=\frac{\mathrm{NIR}-\mathrm{R}}{\mathrm{NIR}+\mathrm{R}}$ & Rouse et al. (1973) \\
\hline $\begin{array}{l}\text { Normalized Difference Senescent } \\
\text { Vegetation Index (NDSVI) }\end{array}$ & $N D S V I=\frac{\mathrm{SWIR}-\mathrm{R}}{\mathrm{SWIR}+\mathrm{R}}$ & Qi et al. (2002) \\
\hline Tasselled Cap Wetness (TCW) & $\begin{array}{l}T C W \\
=B(0.1511)+G(0.1973)+R(0.3283) \\
+N I R(0.3407)+S W I R 1(-0.7117) \\
+S W I R 2(-0.4559)\end{array}$ & $\begin{array}{l}\text { Kauth \& Thomas (1976), } \\
\text { Biag et al. (2014) }\end{array}$ \\
\hline $\begin{array}{l}\text { Soil Adjusted Total Vegetation Index } \\
\text { (SATVI) }\end{array}$ & $S A T V I=\frac{S W I R 1-R}{S W I R 1+R+L}(1+L)-\frac{S W I R 2}{2}$ & Marsett et al. (2006) \\
\hline
\end{tabular}

Note: $B, G, R, N I R, S W I R 1$ and SWIR2 signify the spectral band reflectance values for Landsat 8 OLI. The L value (SATVI) is a constant relating to the slope of the soil line (R-NIR) in a featurespace plot. 
Table 2.2. TCT Coefficients for Landsat 8 at-satellite reflectance (Baig et al., 2014).

\begin{tabular}{|ccccccc|}
\hline & (Blue) & (Green) & (Red) & (NIR) & (SWIR1) & (SWIR2) \\
TCT & Band 2 & Band 3 & Band 4 & Band 5 & Band 6 & Band 7 \\
\hline Brightness & 0.3029 & 0.2786 & 0.4733 & 0.5599 & 0.508 & 0.1872 \\
Greenness & -0.2941 & -0.243 & -0.5424 & 0.7276 & 0.0713 & -0.1608 \\
Wetness & 0.1511 & 0.1973 & 0.3283 & 0.3407 & -0.7117 & -0.4559 \\
TCT4 & -0.8239 & 0.0849 & 0.4396 & -0.058 & 0.2013 & -0.2773 \\
TCT5 & -0.3294 & 0.0557 & 0.1056 & 0.1855 & -0.4349 & 0.8085 \\
TCT6 & 0.1079 & -0.9023 & 0.4119 & 0.0575 & -0.0259 & 0.0252 \\
\hline
\end{tabular}

\subsubsection{Optical and Radar Imagery}

Multispectral remote sensing has proven to be an effective technology for mapping grassland and agricultural land cover. It can be used to estimate plant biophysical variables, as discussed above (Weiser et al., 1986). The use of polarimetric radar systems such as RADARSAT-2 and TerraSAR-X has also increased in popularity for grassland studies, often in conjunction with optical data as a way to increase accuracy when atmospheric interference is present (Buckley, 2004; Smith \& Buckley, 2011; Schuster et al., 2015). The principal advantage of synthetic aperture radar (SAR) systems is the ability to collect timely data without the impedance of cloud cover. SAR systems collect information on the height, structure and moisture of vegetation as a complement to optical systems, which collect information on chemical leaf composition (Schuster et al., 2015). The following sections discuss the advantages and technical specifications of the Landsat- 8 optical sensor and the RADARSAT-2 sensor, which were used in this study.

\subsubsection{Landsat 8 Operational Land Imager (OLI)}

The Landsat series of satellites are an ideal source of multispectral imagery for agricultural LULC mapping and monitoring applications due to their high quality and consistent 
spectral information content and freely-available archived imagery since 1972 (Wulder et al., 2012). Landsat imagery has been used extensively for agricultural land cover classifications and modelling (Fisette et al., 2006; Johnson \& Muller, 2010; Duro et al., 2014; Waldner et al., 2015; Ruffin et al., 2015). Onboard the sun-synchronous Landsat-8 satellite is the Operational Land Imager (OLI) which collects data over nine shortwave spectral bands across a $185 \mathrm{~km}$ swath, with a revisit period of 16 days as shown in Table 2.3 (Jensen, 2016).

To transform radiance recorded by the sensor to reflectance, atmospheric correction is needed (Hadjimitsis et al., 2010). This produces comparable units (surface reflectance) across all imagery dates (Song et al., 2001; Schroeder et al., 2006) and facilitates comparison of vegetation indices, which require reflectance data (Hadjimitsis et al., 2010). There are two types of atmospheric correction methods, absolute and relative. Absolute correction involves converting the digital number of each image pixel to surface reflectance, whereas relative atmospheric correction normalizes images to a single base image (Song et al., 2001; Lillesand et al., 2015). Algorithms such as those in the common software ATCOR-2 (applied in this study) often use a sensor-specific atmospheric database of look-up tables containing pre-calculated radiative transfer model results (Richter, 2008). Also, if clouds are present in the imagery, they and their shadows must be removed or masked. The Fmask algorithm (applied in this study) takes advantage of the Cirrus band (Band 9), which was incorporated into Landsat-8 and an objectbased approach to better detect cloud and cloud shadows (Zhu et al., 2015). 
Table 2.3. Landsat 8 Characteristics

\begin{tabular}{|l|c|c|}
\hline \multicolumn{2}{|c|}{ Landsat 8 Operational Land Imager (OLI) } \\
\multicolumn{1}{|c|}{ Band } & $\begin{array}{c}\text { Spectral Bandwidth } \\
(\mu \mathrm{m})\end{array}$ & $\begin{array}{c}\text { Image Pixel Size }(\mathrm{m}) \text { at } \\
\text { Nadir }\end{array}$ \\
\hline 1 Ultra-blue for coastal/aerosol & $0.433-0.453$ & $30 \times 30$ \\
\hline 2 Blue & $0.450-0.515$ & $30 \times 30$ \\
\hline 3 Green & $0.525-0.600$ & $30 \times 30$ \\
\hline 4 Red & $0.630-0.680$ & $30 \times 30$ \\
\hline 5 Near-infrared & $0.845-0.885$ & $30 \times 30$ \\
\hline 6 SWIR-1 & $1.56-1.66$ & $30 \times 30$ \\
\hline 7 SWIR-2 & $2.1-2.3$ & $30 \times 30$ \\
\hline 8 Panchromatic & $0.52-0.90$ & $15 \times 15$ \\
\hline 9 Cirrus & $1.36-1.39$ & $30 \times 30$ \\
\hline
\end{tabular}

Note: (Jensen, 2016).

\subsubsection{RADARSAT-2}

Radar imaging systems transmit pulses of microwave energy towards the ground or target where an interaction occurs. The return signal is then recorded by the receiver at the sensor. The intensity or fraction of returned energy, commonly referred to as backscattering, can then be interpreted to provide information on surface roughness, moisture, and topography (Lillesand et al., 2015). Synthetic Aperture Radar (SAR) utilizes the motion of the sensor (orbit) which simulates a much larger antenna and can generate high resolution remote sensing imagery. Radar systems transmit and read signals in a large range of microwave bands which are capable of penetrating clouds and are not reliant on sunlight. Spaceborne SAR systems are generally limited to a single wavelength band. The microwave region of the electromagnetic spectrum is quite large compared to the visible and infrared, and common bands include X-band $(2.4$ to $3.75 \mathrm{~cm})$, 
C-band $(3.75$ to $7.5 \mathrm{~cm})$ for terrain and agricultural mapping applications, and L-band (15 to 30 cm) (McNairn \& Brisco, 2004; Jensen, 2015). In addition to wavelength, radar signals can be transmitted and received in different modes of polarization. The polarization alignment of a transmitted or received microwave is most often either horizontal $(\mathrm{H})$ or vertical $(\mathrm{V})$. There are two typical like-polarized cases (HH and VV) and two cross-polarized cases (HV and VH); where the first letter signifies the transmitted polarization and the second letter indicates the received polarization (Lillesand et al., 2015). A greater amount of information can be acquired about the surface with an increasing number of polarization combinations. Quad-polarized systems collect all four modes of polarization, whereas dual- and single-polarized systems collect only two and one respectively. Additionally, the incident angle describes the angle between nadir (or locally, the normal to the surface) and the radar beam. Incidence angle is an important consideration for agricultural applications as the steepness of the angle affects the degree of backscatter (McNairn \& Brisco, 2004; Foody et al., 2007; Smith \& Buckley, 2011).

Radar backscatter from a vegetated surface is a function of vegetation structure and moisture (Lillesand et al., 2015). From an operational mapping perspective, radar can be both a substitute for optical data when non-ideal weather conditions limit acquisitions or it can be used to complement optical data as microwave energy interactions with vegetation and soil are different from those in optical spectral bands (Fisette et al., 2014). C-band radar has been used effectively for crop classification in annual crop inventory in combination with optical data (McNairn \& Brisco, 2004; Foody et al., 2007; McNairn et al., 2009; Fisette et al., 2014). Smith and Buckley (2011) evaluated RADARSAT-2 and found similar backscatter mechanisms between native rangeland and improved grassland; however, the classifier was able to distinguish native rangeland from annual crops using quad-pol fine resolution imagery. RADARSAT-2 has 
many possible beam modes and sensor modes for acquiring data, as shown in Figure 2.3. Due to data availability constraints (users are prioritized, with regular clients and the military having the highest priority), RADARSAT-2 data are difficult to acquire at a desired beam mode and timing for a prairie-wide scale. If they are to be used on their own for agricultural mapping, multiple acquisition dates and fine beam modes have been shown to increase classifier performance (Waske \& Braun, 2009; Skriver et al., 2011).

SAR data are commonly affected by random interference of the signal backscatter waves following their interactions with the ground surface. This results in constructive and destructive interference that varies in magnitude from pixel to pixel, producing a speckled appearance in the image. Speckle can be reduced by image processing techniques such as using the average of neighbouring pixel values (Lillesand et al., 2015). There are several studies that compare noise reduction techniques by comparing accuracy performance and the technical merits of each filtering technique (Shi \& Fung, 1994; Lee et al., 1994; Gagnon \& Jouan, 1997). Among the best known adaptive filters are the Lee adaptive filter, developed to remove speckle while preserving edges (Lee, 1980; 1981) and the enhanced Lee adaptive filter (Loupes et al., 1990), which divides the area to be filtered into three classes. This allows heterogeneous areas to be kernelfiltered, while homogeneous areas are filtered using an average filter, and small areas remain preserved (Lopes, 1990; Bolanos et al., 2016). 


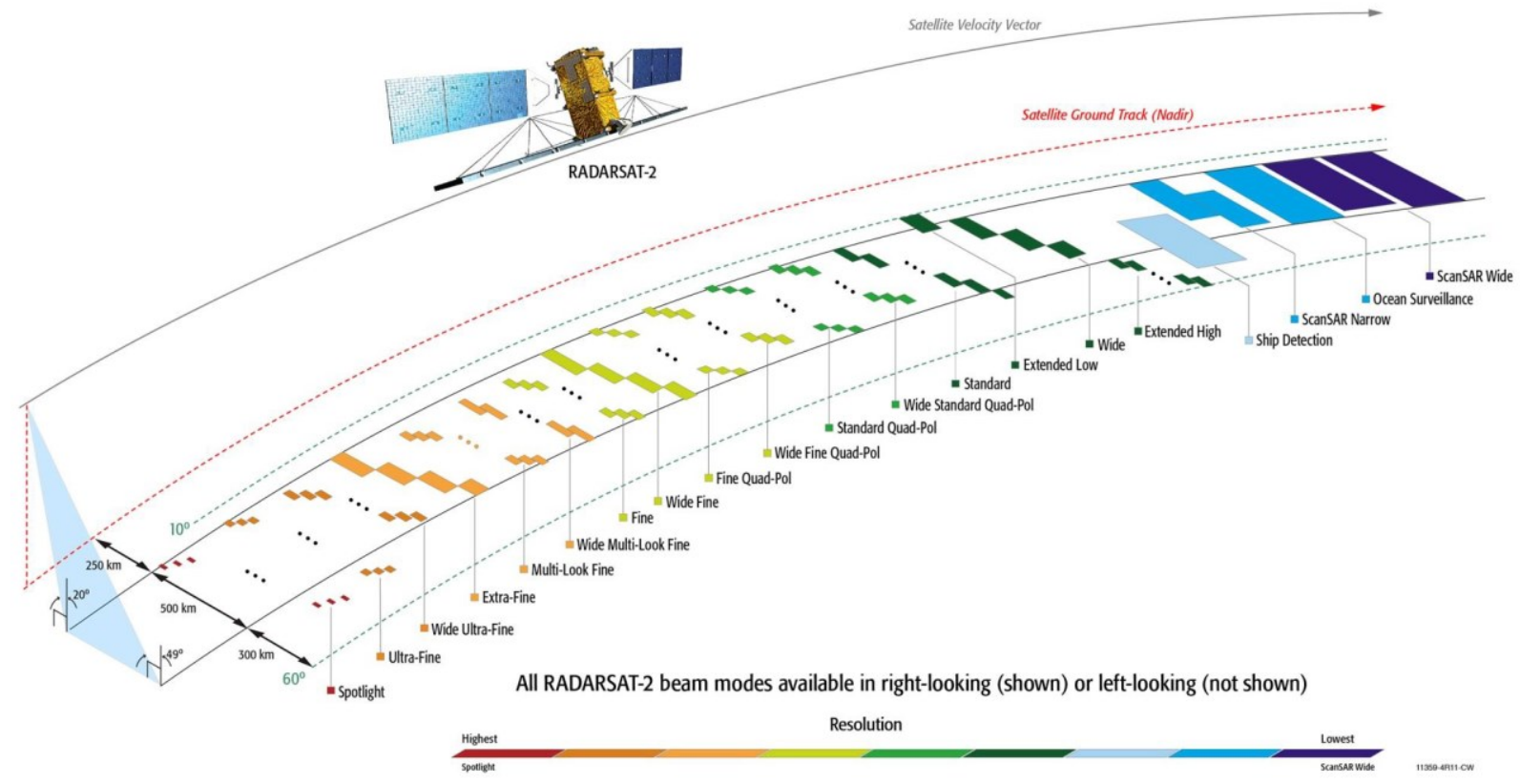

Figure 2.3. RADARSAT-2 SAR beam modes (MDA, 2014)

\subsubsection{Image Texture Analysis}

Seeded forage land cover types such as pasture and hay have a higher diversity of plant species and are influenced by grazing regimes; therefore, one would expect more spatially heterogeneous surface reflectance than for cropland classes such as cereals. Local spatial variation in image brightness or reflectance is generally considered as image texture. Image texture can be measured using a (usually square) window which defines the neighbourhood around a pixel. The Grey Level Co-occurance Matrix (GLCM) is a square matrix of the frequency of occurrence of all possible brightness levels in pairs of proximal pixels. It is used to reveal certain characteristics of the spatial distribution of the grey-levels or brightness values in an image (Haralick et al., 1973). First order texture measures such as mean, variance, and standard deviation are statistics calculated from the original image values and do not consider neighbour relationships (Hall-Beyer, 2008). The GLCM is used to derive second order texture 
calculations (ex. homogeneity, contrast, dissimilarity, entropy, angular second moment and correlation) and considers the relationship between neighbouring pixels in the original image (Haralick et al., 1973) by specifying the direction of sampling of pixel pairs and the lag (space) between sample pixel pairs. Homogeneity is an example GLCM texture metric that was selected for this research based on its use in pixel and object-based classifications as a discriminating variable for land cover classes (Dingle Robertson and King, 2011)

$$
\text { Homogeneity }=\sum_{i, j=0}^{N-1} \frac{P_{i, j}}{1+(i-j)^{2}}
$$

where, $i$ and $j$ are the row and column coordinates in the GLCM (Hall-Beyer, 2007).

Homogeneity increases as adjacent pixels within the neighbourhood or window have more similar brightness values (Hall-Beyer, 2007). GLCM texture metrics have been used to estimate above-ground biomass using high-resolution imagery (Ouma \& Tateishi, 2006). Texture has been found to be an important contributor for land cover mapping and biomass mapping when the spatial resolution of the image is sufficient to capture meaningful texture present in the imagery (Haralick et al., 1973; Gong et al., 1992; Lu et al., 2008; Li et al., 2011; Peña-Barragán et al., 2011). For example, Li et al. (2011) successfully used GLCM texture measures in combination with VIs and MS bands to improve vegetation classification accuracy of forest classes with large patch sizes. For specific study areas, care must be taken to determine the appropriate texture variables and associated window size (Chen et al., 2004).

\subsubsection{Random Forest Classifier}

The Random Forest (RF) algorithm is an ensemble classifier that uses a set of Classification and Regression Trees (CART) to make a classification (Breiman, 2001). The 
problem with using a single CART for classification is that decision trees are highly variable depending on the data, as subsequent splits further down the tree depend on previous splits. By using an ensemble approach to CART, RF has been shown to significantly outperform a single decision tree classifier for land cover classification using optical (Rodriguez-Galiano et al., 2012; Duro et al., 2012) and radar data (Waske \& Braun, 2009; Deschamps et al., 2012; Sonobe et al., 2014). The RF algorithm was chosen for this study because it is non-parametric and it provides indicators of predictor variable performance (Liaw \& Werner, 2002). Multisource data, meaning data from multiple sensors or geographic datasets, are difficult to classify using traditional parametric methods such as the Maximum Likelihood Classifier (MLC) (Gislason et al., 2006). Other non-parametric machine learning classifiers such as artificial neural networks (ANN) and support vector machines (SVM) are both well suited to high-dimensional datasets, however they are difficult to tune and parameterize; thus there has recently been relatively more focus on RF for remote sensing classification (Belgiu \& Drăgut, 2016). RF requires two parameters chosen by the user in order to produce a random forest: the number of decision trees to be generated (Ntree) and the number of variables to be selected and tested at each split when growing the trees (Mtry) (Liaw \& Werner, 2002). RF can be used for classification or regression, but for the purposes of this research, it was used as a classification algorithm. It is important to note that although Breiman (2001) states that RFs are immune to overfitting, recent literature has proved otherwise and shown that classifications can be improved by reducing the number of unimportant and correlated variables in the classification (Millard \& Richardson, 2015).

By using a bootstrap aggregating (bagging) approach (Breiman, 1996), RF is a unique classification algorithm as internal estimates monitor error and variable importance. RF provides an estimate of error calculated using the out-of-bag $(\mathrm{OOB})$ data set for each tree. Each tree in the 
forest is grown from a different bootstrap. This is done by bagging a random sample (typically $1 / 3$ ) of the original training set to create each unpruned decision tree. The remaining samples (OOB samples) are used to validate each tree (Breiman, 2001). However, this measure of error should not be used in place of independent accuracy assessment unless there is an insufficient validation dataset or presentation of accuracy statistics and an error matrix is unimportant. An independent accuracy assessment is important for comparing accuracy estimates between classifications, but it is not needed when determining the ranking of variable importance and tuning parameter values for the classifier. In order to provide realistic accuracy values in comparison of final map products, an independent accuracy assessment must be conducted using data that was left out of the classification.

The RF classifier produces two measures of variable importance. Gini importance is a measure that incorporates a weighted mean of the individual trees' improvement in the splitting criteria produced by each variable (Strobl et al., 2007). However, according to Strobl et al. (2007), a better measure is the mean decrease in accuracy (MDA), also known as "permutation accuracy", which determines the mean decrease in classification accuracy after permuting the predictor variable (Breiman, 2001). MDA is assessed by randomly permuting the importance of variables in each of the OOB samples (Breiman, 2001).

$\mathrm{RF}$ is able to handle high dimensional datasets with a large number of variables $(n)$ and a small number of prediction values $(p)$ (Gislason et al., 2006). Variable importance values have been found to be biased towards highly correlated variables; therefore an effort should be made to reduce the correlation in the dataset, for example, using principal component analysis (PCA), or a non-parametric correlation measure such as Spearman's rho (Strobl et al., 2008, Millard \& Richarson, 2013; Millard \& Richardson, 2015). 


\subsubsection{Accuracy Assessment}

It is critical for all land cover classifications produced using remotely sensed data to communicate the quality of the final product (Olofsson et al., 2014). Information on land cover can be used to detect change and inform policy decisions; therefore it is important to use a statistically robust sampling design and measures of accuracy (Stehman, 1996). The accuracy test set is often a subset removed from the reference data used to train the classifier in a supervised classification.

Ideally, a sampling design would be stratified by class and randomly distributed throughout the study area. Often this approach is impossible due to time and cost constraints for a particular study. The use of roadside or "windshield" surveys when the study area is large has been used in several agricultural studies as land units are especially large and uniform (South et al., 2004; Dingle Robertson \& King, 2011; Fisette et al., 2014; Hively et al., 2015). AAFC's annual space-based crop inventory uses spatially robust crop insurance data when available. Otherwise ground reference information is collected as point observations from field crews using predetermined routes (Fisette et al., 2014) that cover as large and spatially variable areas as possible.

Consideration must also be given to the number of required samples per given class. If the areas to be classified are greater than 400,000 ha, they require thorough sampling of at least 75-100 samples per category for inclusion in the accuracy assessment (Lillesand et al., 2015). Given 100 samples per class, and that this represents $1 / 3$ of the total reference sample locations ( $1 / 3$ being a common proportion of validation to training samples), a minimum of 300 samples per class would be needed to successfully run a supervised classification. 
A confusion or error matrix, hereafter referred to as an error matrix, is a cross tabulation of the classes assigned by the classifier against the validation classes from the reference data (Congalton, 1991; Foody, 2002; Olofsson et al., 2014). The error matrix summarizes key results and is used as a source for several statistical techniques (Congalton, 1991). Two summary measures derived from the error matrix are often reported: i) Overall accuracy, and ii) Cohen's Kappa coefficient (Cohen, 1960). Overall accuracy is calculated by dividing the total number of correctly classified pixels by the total number of reference pixels (Lillesand et al., 2015). It is a useful general measure but it is influenced by classes with a larger number of samples unless the error matrix is normalized to proportions. Measures of user's accuracy (error of commission), and producer's accuracy (error of omission) can also be calculated for each class using the error matrix (Lillesand et al., 2015).

To compare two classifications for significant differences in overall accuracy, a common approach is to use McNemar's test, a non-parametric test where a confusion matrix is collapsed into a matrix of 2 by 2 in dimension (McNemar, 1947; Foody, 2004). The 2 x 2 confusion matrix is a binary grid of correct vs. incorrectly classified pixels (Table 2.4).

Table 2.4. McNemar's Test Matrix

\begin{tabular}{cll}
\hline & \multicolumn{2}{c}{ Classification 2 } \\
\cline { 2 - 3 } Correct & Incorrect \\
\hline Classification 1 & & \\
Correct & $\mathrm{f}_{11}$ & $\mathrm{f}_{12}$ \\
Incorrect & $\mathrm{f}_{21}$ & $\mathrm{f}_{22}$ \\
\hline
\end{tabular}

$$
Z=\frac{f_{12}-f_{21}}{\sqrt{f_{12}-f_{21}}}
$$

McNemar's test is appropriate for comparison of thematic map accuracies when the same validation and training samples were used for each supervised classification (Diettrich, 1998). It 
has been used to determine the best classification method or input variables (Dingle Robertson \& King, 2011; Duro et al., 2012; Rodriguez-Galiano et al., 2012; Hao et al., 2015). 


\section{Chapter 3: Methodology}

This chapter describes the study areas, including the methodology used for the selection of the study sites and associated field work. It also describes the acquisition of optical and radar imagery data, and the methods of imagery pre-processing, atmospheric correction, variable extraction, classification techniques, post-classification processing, and map accuracy assessment. While Chapter 2 described the background to the remote sensing data types and image classification methods of this research, this chapter describes how these methods were implemented.

\subsection{Study Areas}

Two study areas were selected to represent the variability of soil and climate across the prairie ecoregion. Selecting more than one study area also accounts for some of the differences in range and forage management, as well as the diversity of dominant plant species and dynamics within the rangeland class. These areas were determined based on where field work was planned with collaborators at the Brandon and Lethbridge Agriculture and Agri-Food Canada research stations. Each area was covered by a single Landsat- 8 scene, one which overlaid Lethbridge, AB and another over Brandon, MB. Each Landsat scene was $170 \mathrm{~km}$ by $183 \mathrm{~km}$, or approximately $31,000 \mathrm{~km}^{2}$.

The first study area in Manitoba (Figure 3.1) covers a large region of the southwestern part of the province on the Manitoba-Saskatchewan border. The northern edge of the study area extends from the Saskatchewan border, near Roblin, MB to the shore of Lake Manitoba in the northeast. The southern border of the study area extends from Parkman, SK in the southwest to Pelican Lake, MB in the southeast. Comprised extensively of cultivated farmland, the dominant 
soil type is black and grey chernozem (Fuller, 2010). Where cultivation has not changed the landscape from its native state, open stands of trembling aspen (Populus tremula) and shrubs occur and encroach on fertile soils in absence of fire and grazing management (Bailey et al, 2010b). Numerous shallow kettle lakes or "potholes" are scattered across the region as remnants of the Wisconsinan glaciation which ended 10,000 years ago (Christiansen, 1979). What remains of native rangeland in this study site exists primarily in provincially funded community pastures and within areas under conservation. The largest and most notable community pastures include Ellice-Archie and Spy Hill-Ellice pastures on the Saskatchewan border. It should be noted that the study site also contains a large Canadian military training base. Canadian Forces Base Shilo is unique as it remains as $450 \mathrm{~km}^{2}$ of uncultivated and relatively intact native rangeland with minimal grazing pressure from livestock (Bailey et al., 2010a). Another stark contrast to the surrounding prairie farmland is the large tract of forested parkland within Riding Mountain National Park in the northern third of the study site. A unique feature of this study site is the land management practice of reverting cropland back to native pasture, whether by seeding native species or by letting the land revert back on its own due to farm abandonment. The growing season in 2015 for southwestern Manitoba was characterized by favourable growing conditions with an early but cool spring followed by normal temperatures and rainfall for the rest of the summer and fall (Manitoba Agriculture, 2015).

The second study area in Alberta (Figure 3.2) covers a large region in the southern part of the province. Climate conditions in southern Alberta are much drier than in the east, with an average precipitation of 200 to $250 \mathrm{~mm}$ from May to August in the western foothills to less than $200 \mathrm{~mm}$ towards the southeast. Along this west-east moisture gradient, the study site covers three 
major prairie ecoregions. Foothills fescue in the west transitions into mixed-grass prairie in the central part of the study site, which transitions into dry mixed-grass prairie in the east.

Contemporary challenges that threaten the integrity of Alberta's native prairie include: cropland intensification and land conversion, intensified oil and gas extraction, the invasion of introduced species along river corridors, and linear disturbances, such as buried oil and gas infrastructure (Prairie Conservation Forum, 2011). The 2015 growing season for the southern region of Alberta was characterized by a dry spring followed by a hot summer with limited precipitation. The limited moisture and cool nights caused slow growth for seeded hay and pasture, and grasses and legumes stopped growing and reached senescence in June. Production of hay was down $31.5 \%$ from 2014 (Shooshtarian, 2016).

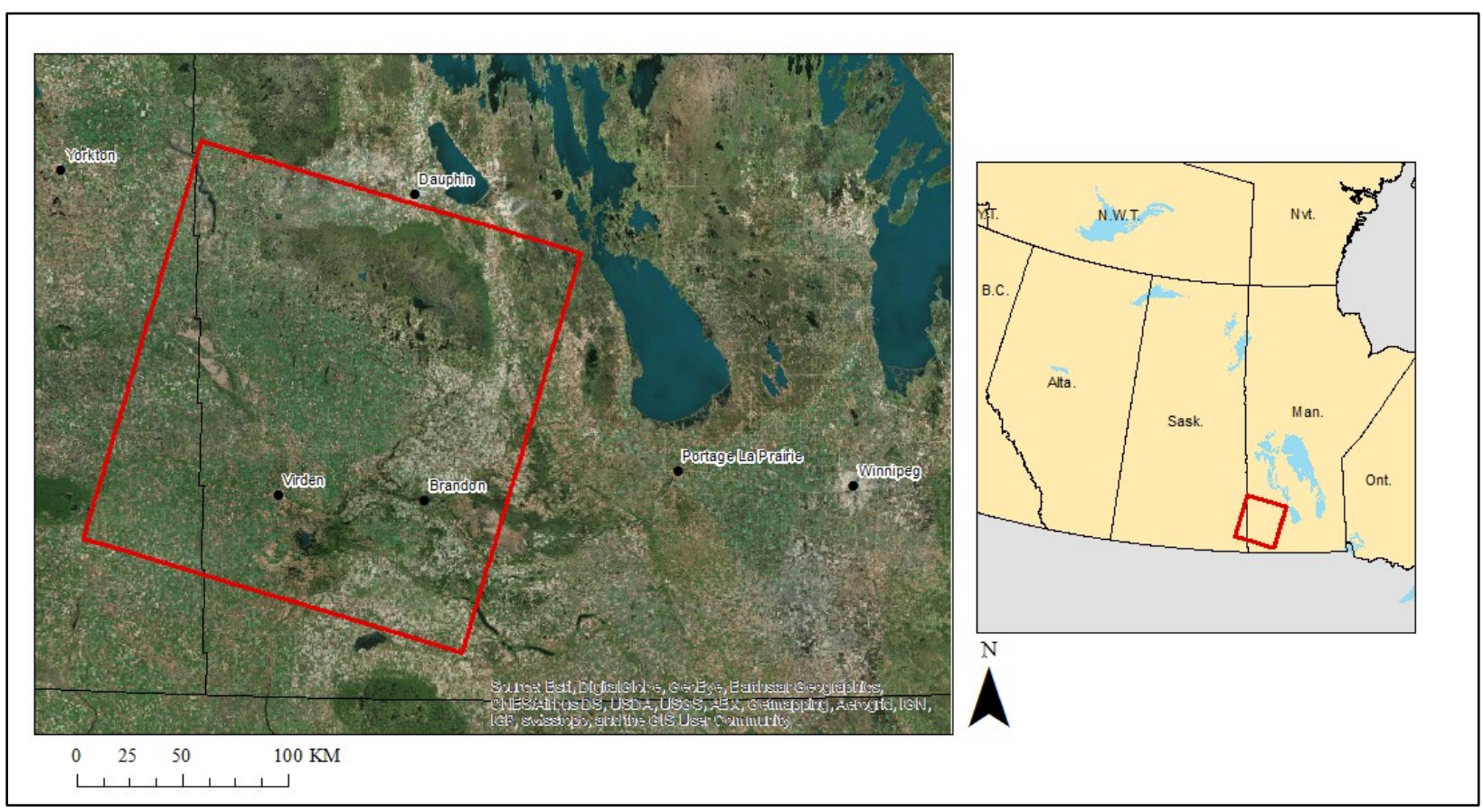

Figure 3.1. Location of Manitoba Study Area (Statistics Canada, 2011) 


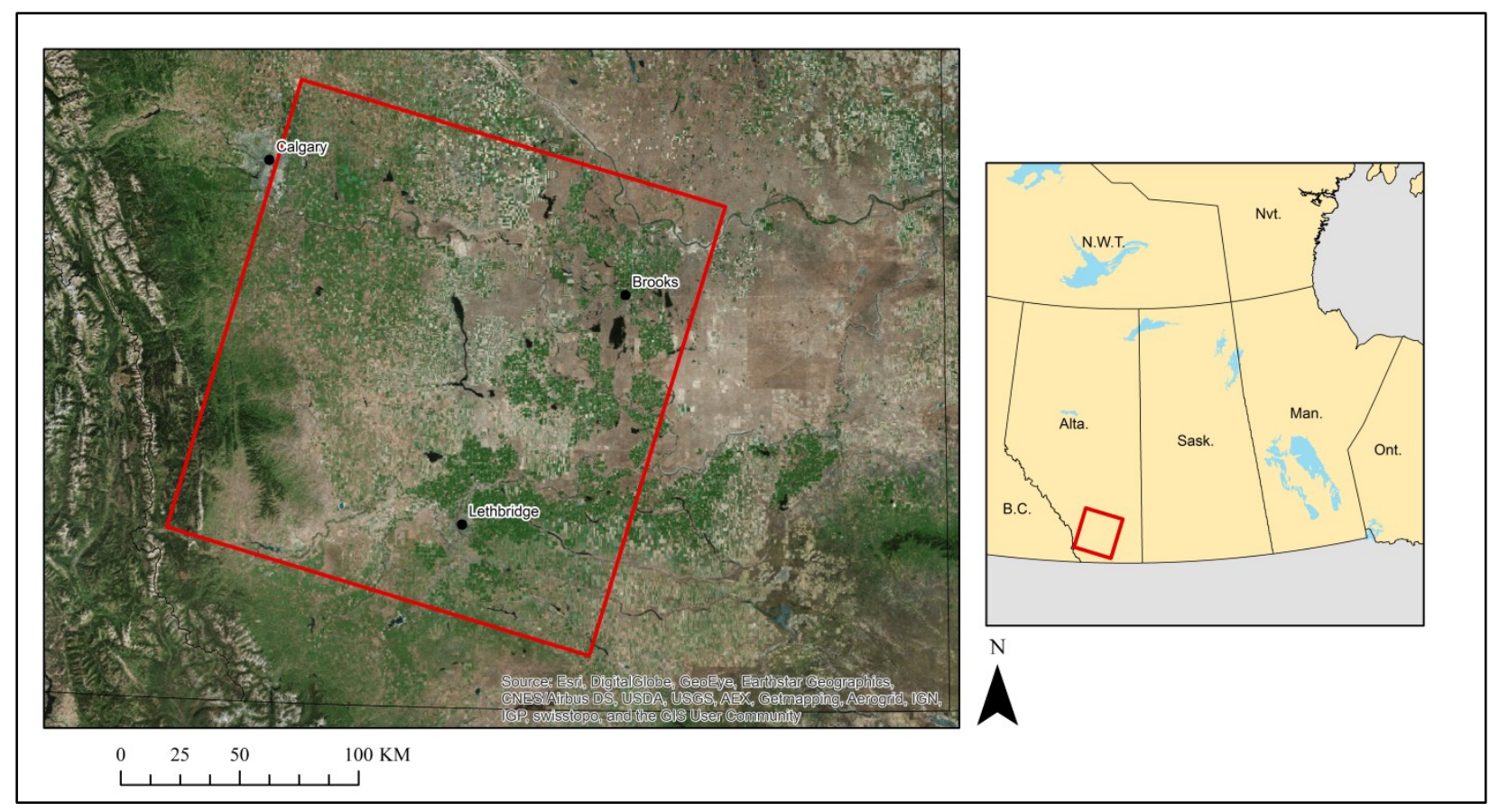

Figure 3.2. Location of Alberta Study Area (Statistics Canada, 2011)

\subsection{Imagery Acquisition}

Landsat 8 (LS8) OLI data were acquired from the USGS Landsat data archive (USGS, 2016). Level 1T (terrain corrected) scenes for WRS Path 041, Row 025 were acquired for the Alberta study area. Level 1T Landsat 8 OLI data were acquired for WRS Path 033, Row 025 for the Manitoba study area. The Level 1 ortho-rectified product (L1T) uses ground control points (GCPs) and a digital elevation model to correct distortions related to the sensor, satellite, and earth (USGS, 2015). The dates of acquisition for both optical and radar data can be found in Table 3.1. Imagery was acquired for the 2015 growing season for each study area. A total of 3 scenes for each study area were used that had sufficiently low $(<10 \%)$ cloud cover (Table 3.1). This included a late May (spring) and late August (late summer) image for both study areas. In addition to spring and late summer, a July image (mid-summer) was acquired for the Alberta area as well as an October image (fall) for the Manitoba area. 
Dual-polarization (VV and VH) wide-beam mode (W2) RADARSAT-2 (RS2) data were acquired over each study site for July 2015 . W2 is located in the middle of the three wide-swath beam modes (W1, W2, and W3) and has a near incidence angle of 30.6 degrees and a far incidence angle of 39.5 degrees. The image size $(150 \mathrm{~km} \times 150 \mathrm{~km})$ and resolution (pixel size $=$ $25 \mathrm{~m}$ ) of the W2 beam mode was the best available complement to the LS8 data and study area size. A total of 8 adjacent RS2 W2 images were acquired for the complete coverage of the Manitoba study area, and a total of 5 images were acquired for the coverage of the Alberta study area.

Table 3.1. Optical and Radar Data Acquisition

\begin{tabular}{|c|c|c|c|c|}
\hline Study Area & Sensor & $\begin{array}{c}\text { \% Cloud Cover } \\
\text { USGS Est. (Optical) } \\
\end{array}$ & \% Masked & Date of Acquisition (doy) \\
\hline \multirow[t]{5}{*}{ Manitoba } & \multirow[t]{3}{*}{ Landsat 8 OLI } & 0.56 & 6.78 & 27-May $(\mathrm{d} 147)$ \\
\hline & & 7.31 & 15.33 & 31-Aug (d243) \\
\hline & & 0.03 & 0.00 & 18-Oct (d291) \\
\hline & \multirow{2}{*}{$\begin{array}{l}\text { RADARSAT-2 } \\
\text { (W2) }\end{array}$} & NA & NA & 08-Jul (d189) \\
\hline & & NA & NA & 15-Jul (d196) \\
\hline \multirow[t]{5}{*}{ Alberta } & \multirow[t]{3}{*}{ Landsat 8 OLI } & 3.21 & 10.42 & 19-May (d139) \\
\hline & & 0.39 & 5.62 & 06-Jul (d187) \\
\hline & & 0.03 & 1.55 & 23-Aug (d235) \\
\hline & \multirow{2}{*}{$\begin{array}{l}\text { RADARSAT-2 } \\
\text { (W2) }\end{array}$} & NA & NA & 20-Jul (d201) \\
\hline & & NA & NA & 27-Jul (d208) \\
\hline
\end{tabular}

\subsection{Imagery Pre-Processing}

The following methods were applied to the originally acquired LS8 and RS2 data. These steps include geometric and terrain correction, atmospheric correction (LS8) and image filtering (RS2). Following geometric and radiometric correction, several LS8 optical variables were derived from the corrected imagery bands. 


\subsubsection{Landsat 8 Pre-Processing}

As the LS8 imagery had been ortho-rectified and given the topographic variations over the study areas were small, no additional geometric corrections were applied. Calibration of image data to radiance units is necessary prior to classification using multitemporal images in order to put images on the same radiometric scale (Song et al., 2001). The ATCOR-2 algorithm was implemented to correct for atmospheric distortions and convert image brightness values to top-of atmosphere reflectance values (Richter, 1996) as summarized in Section 2.2.3.1. The Environment Canada historical weather archive (http://climate.weather.gc.ca/) was used to determine visibility values $(\mathrm{km})$ for the date and location of each scene. Radiometric calibration coefficients, solar zenith, atmospheric information, and height, which are required for the ATCOR-2 algorithm, were acquired from the imagery metadata. Cloud and cloud shadow were removed from imagery by creating masks using the Fmask algorithm (Zhu et al., 2015). The cloud and cloud shadow masks were combined and used to mask problematic areas from the imagery that would have adversely affected land cover classifications. Following this, a much larger area was masked than initial cloud and shadow estimates from the Landsat Archive. The percentage of area masked using ATCOR-2 and Fmask for LS8 data can be seen in Table 3.1. Training and validation data were removed if they fell in areas with cloud or cloud shadow for any of the three LS8 images. Figure 3.3 presents a visual of the total area masked from the classification due to cloud and cloud shadow for each study area. 

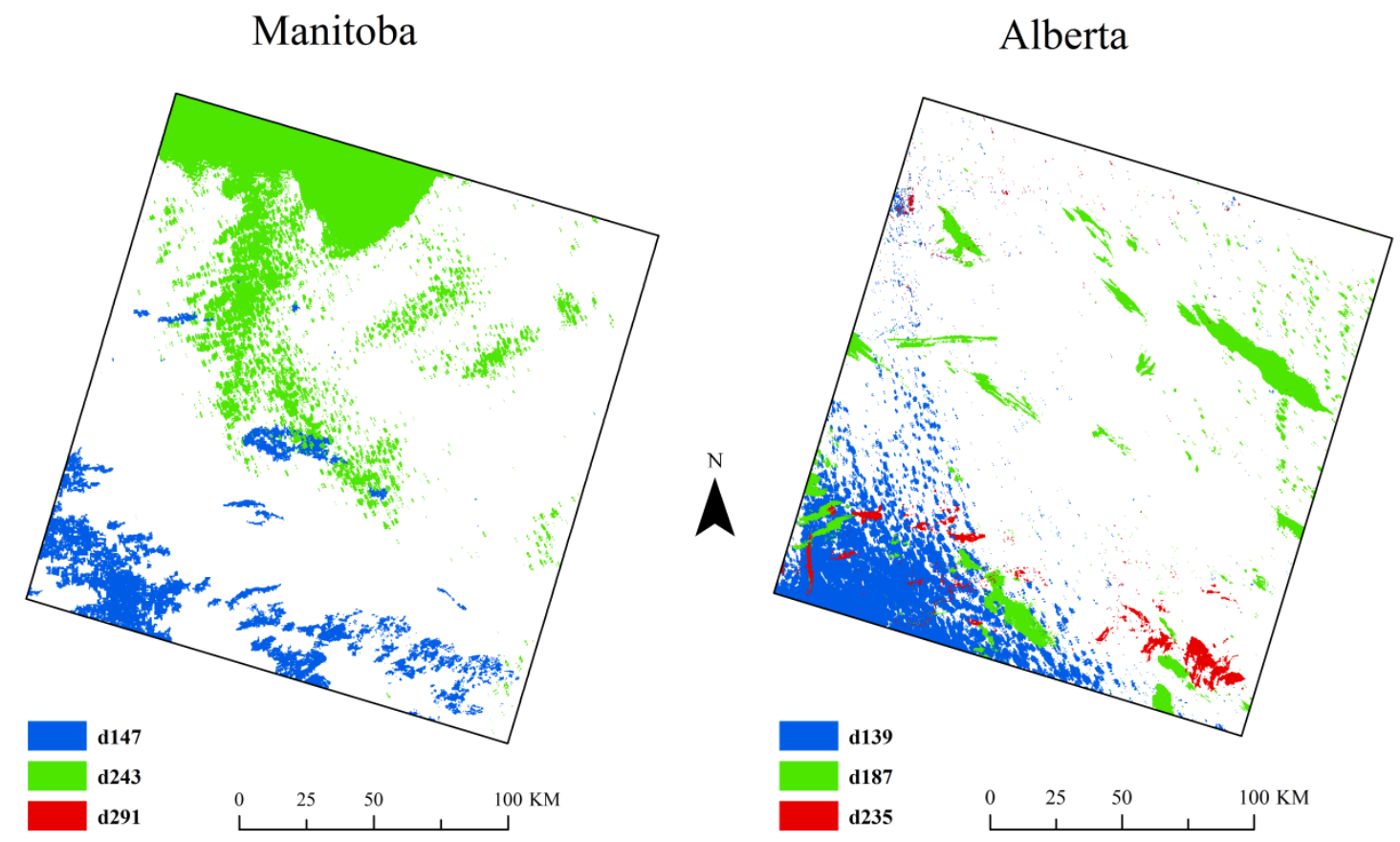

Figure 3.3. Landsat 8 OLI Cloud and Cloud Shadow Masks

\subsubsection{RADARSAT-2 Pre-Processing}

The dual polarization VV and VH images were orthorectified using ground control points (GCPs) and a digital elevation model (DEM). The orthorectified RS2 data were then re-projected to UTM coordinates to match the LS8 projection and resampled from $25 \mathrm{~m}$ to $30 \mathrm{~m}$ pixel size using nearest-neighbour resampling using PCI Geomatica OrthoEngine. Because the study areas covered a larger area than a single RS2 W2 image, multiple images had to be mosaicked to cover the broader area. After mosaicking, the visible seams due to varied incidence angle effects were 
removed using a histogram-matching colour balancing method derived from a histogram calculated from the mosaic dataset.

Two filters were compared for speckle noise reduction of the mosaicked radar imagery. The Lee adaptive filter (Lee, 1980) and the enhanced Lee adaptive filter (Loupes et al., 1990) were tested using a subset of the training data to test for spectral separability. The enhanced Lee filter is able to reduce high frequency noise while preserving edge features. Filter window size is an important factor; if it is too small the filter is ineffective and if it is too large the filter will reduce significant details. Moving window sizes of $3 \times 3$ and $5 \times 5$ pixels were tested on the VV and VH images for both study areas. The filter size with the largest statistical separability between classes using the transformed divergence (TD) measure (a covariance-weighted distance between class means) was selected as the appropriate speckle filter for the RS2 imagery (Lillesand et al., 2015). The TD measure was calculated using 10 known sample locations for each class from the reference data. It was found that the enhanced Lee adaptive filter outperformed the Lee adaptive filter with a 5 x 5 window size and was therefore applied to all images. Results of this test are presented in Appendix A. The results of the TD measure (Table A1) indicate that mid-summer radar, when filtered, only has the potential to discriminate rangeland from cropland for both study areas $(\mathrm{TD}>1.9)$.

\subsection{Reference Data Collection}

Reference data are necessary for conducting a supervised classification for both the training and validation stages. Field work was conducted in July of 2015 in the middle of the growing season when it was easiest to identify crop types and dominant forage species. An effort was made to sample a spatially representative portion of each field area. Given the size of each 
study area, information was recorded from inside a vehicle. The criterion for route selection was to sample as much of the landscape as possible in a given day within a given region of the study area. This restricted the data collection to fields visible from the roadside and with land cover homogeneity of at least $3 \times 3$ pixels $(90 \times 90 \mathrm{~m})$. Due to this constraint, subclasses such as native shrubland and meadow within the rangeland class were difficult to find and record accurately. At some locations permission was granted by the land owner or manager to drive across large tracts of land inaccessible by public roads. Permission was required to collect data for rangeland areas in Manitoba, as most areas of native rangeland were contained within community pasture areas not accessible to the public. At each location, the $\mathrm{X}$ and $\mathrm{Y}$ coordinates with class attribute information were recorded using a GPS-enabled ArcPad Tablet. Classes recorded were as described in Chapter 2 with additional comments on species composition and condition. Additional data were also acquired from provincial crop insurance datasets. Figure 3.4 a) and b) shows the locations of field-collected and crop insurance data for both study areas, which were used as reference in training and validation of RF classifications as described in Section 3.6. Ideally, training datasets used in random forest classifications should be created with class proportions equally representative of the actual class proportions on the ground (Millard and Richardson, 2015). As field data were collected from a vehicle and not randomly distributed, an effort was made to sample at equal intervals, with no more than one point per field, to limit spatial autocorrelation in the dataset. The rangeland class was unique from other classes as, in both study areas, it is typically contained within large tracts of land over many quarter-sections instead of smaller fields. Spatial autocorrelation was measured using Moran's I at several known rangeland sites using LS8 imagery (Moran, 1950). The Z score and p-value were used to determine the appropriate minimum distance along a line where pixel brightness is spatially 
independent. Using Moran's I, the appropriate distance between samples was determined to be $600 \mathrm{~m}$ in Manitoba and $1000 \mathrm{~m}$ in Alberta. The 400m difference between the two was attributed to the differences in species composition and management for the two study areas, with the Manitoba site being more spatially heterogeneous at the Landsat scale. This distance was maintained using a laser-rangefinder when the site had objects with vertical relief to focus on (fence posts or trees); otherwise the distance was quality checked using spatial buffers during post-processing.

In order to ensure placement accuracy of each data point, georeferenced high resolution imagery was loaded onto the tablet which gave a sense of field boundaries and irregular features within each field (ponds, trees, buildings etc.). Additionally, the final dataset was uploaded into Google Earth to quality check the placement of each data point.
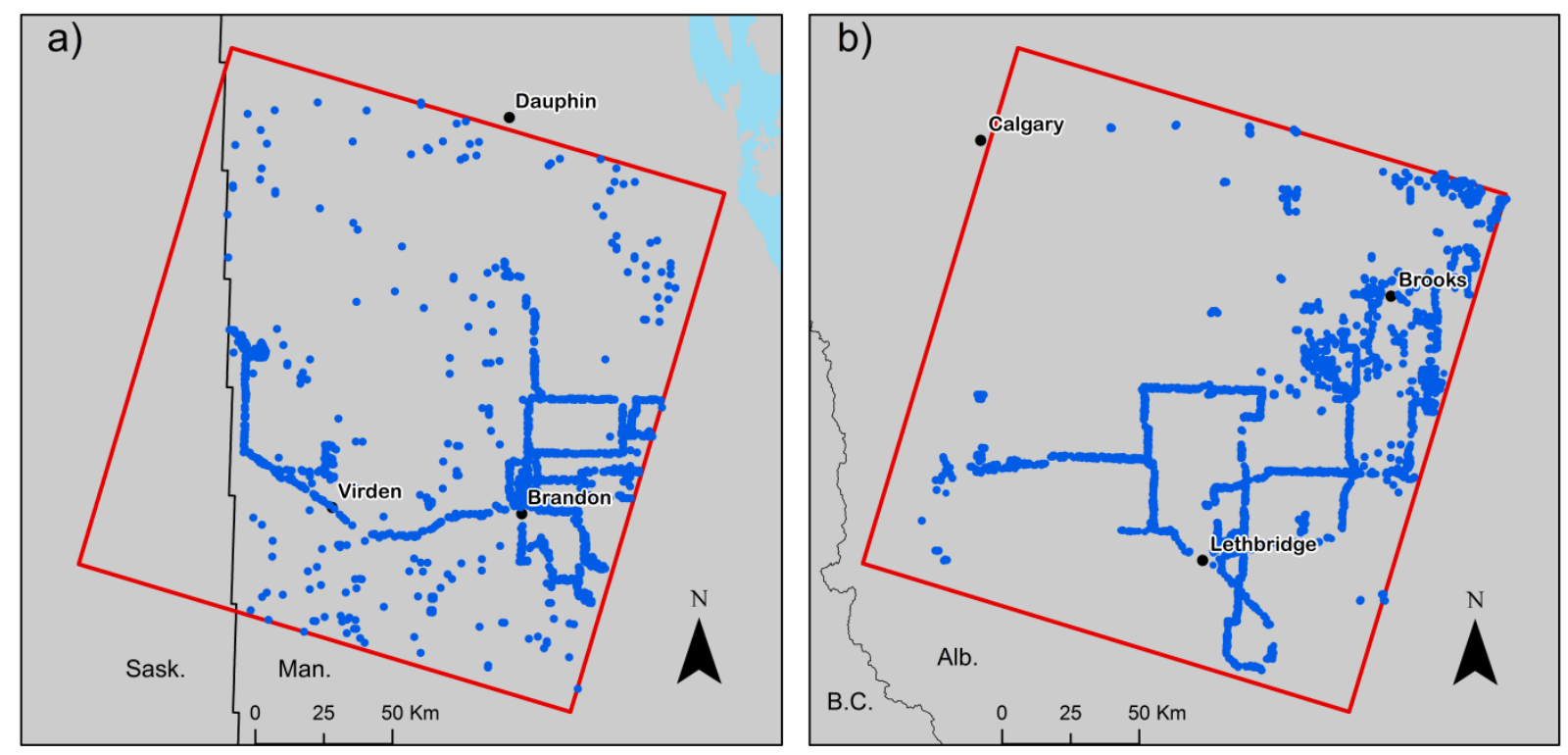

Figure 3.4. Distribution of reference data for (a) Manitoba and (b) Alberta study areas. 


\subsection{Land Cover Classes}

Once the field and image data sets had been finalized, initial random forest classifications revealed that given the spatial and temporal resolution of the satellite data, the subclasses within the original classification scheme (Table 3.2, Level 2 subclasses) were indistinguishable. Therefore, the subclasses were aggregated into broader classes (Level 1) as shown in Table 3.2. It was initially expected that seeded forage (Class 2) subclasses would be distinguishable using a multitemporal optical dataset however; the length of revisit frequency (16 days) of the LS8 sensor along with limiting cloud interference was insufficient to capture differences in harvest and grazing pressure. Additionally, multitemporal RS2 data were not available.

Initial classifications, as well as a t-test using the training dataset, proved that hay and pasture were indistinguishable using $30 \mathrm{~m}$ pixel data types. The cropland class encompasses both forage and non-forage annual crops as it was not possible to differentiate between cereals harvested for green-feed from cereals harvested for human consumption at this spectral and temporal resolution. Additionally, certain land cover types were masked out in order to focus the classification process on agricultural and rangeland classes (Classes 1-3). The Forest and woodland (Class 4), and "Other" class (Class 5) were masked out using an existing raster dataset “Land Use 2010" (AAFC, 2010). A surface water mask was created after some errors were found in the Land Use 2010 water layer. This involved using a k-means unsupervised classification of the spring LS8 images for each area when water is at its highest level and isolating the cluster with the spectral properties of water. Water was not included as a class in the classification as the spectral separability of water would artificially boost measures of overall accuracy. A mask of bare soil/fallow was needed for the Alberta study area due to the abundance of non-vegetated fields. It was created using a k-means unsupervised classification of the early July LS8 image, an 
image acquired before harvest. The class with the characteristic spectral signature of bare soil was isolated. The Manitoba study area did not have any observable areas of bare soil in the field dataset except where areas were too wet to be seeded due to spring rainfall. The common practice of planting summer fallow cover crops, as well as "no-till" farming in Manitoba to prevent soil erosion are possible factors for the lack of observable bare soil areas within the Manitoba study site. 
Table 3.2. Five aggregated land cover classes and 15 initial subclasses recorded in the field; final classes (1-3) and masked classes (4 and 5).

\begin{tabular}{|c|c|}
\hline Level 1: Class & Level 2: Subclass \\
\hline \multirow{4}{*}{ 1. Rangeland } & a. Upland Native Grassland \\
\hline & b. Upland Non-Native Grassland and Reverted Pasture \\
\hline & c. Meadow \\
\hline & d. Native Shrubland \\
\hline \multirow{4}{*}{ 2. Seeded Forage } & a. Perennial Pasture \\
\hline & b. Perennial Conservation \\
\hline & c. Hay - Moderate Production \\
\hline & d. Hay - High Production \\
\hline \multirow{2}{*}{ 3. Annual Cropland } & a. Annual Forage Crop \\
\hline & b. Annual Non-Forage Crop \\
\hline \multirow{2}{*}{ 4. Forest and Woodland } & a. Open Woodland \\
\hline & b. Forest \\
\hline \multirow{3}{*}{ 5. Other } & a. Surface Water \\
\hline & b. Bedrock and Bare Soil \\
\hline & c. Industrial and Urban \\
\hline
\end{tabular}

\subsection{Deriving Optical Variables}

In addition to the six corrected LS8 multispectral TOA reflectance variables $(\mathrm{B}, \mathrm{G}, \mathrm{R}$, NIR, SWIR1 \& SWIR2) per date, additional variables were derived to determine their potential 
in classification of these classes. The additional optical variables include 12 vegetation indices (VIs), and eight NDVI time-series variables (PhenNDVI) as discussed below.

\subsubsection{Vegetation Indices and Time-Series NDVI Variables}

The VIs were derived using the formulas presented in Table 2.1. Four VIs were calculated using the LS8 ATCOR-2 TOA reflectance for each of the three dates, including NDVI, NDSVI, TCW, and SATVI.

In addition to the VI variables, several variables were derived from NDVI images (PhenNDVI). As Table 3.3 presents, statistics such as the mean, standard deviation, minimum and maximum of the three NDVI images were calculated. The coefficient of variation $(\mathrm{CoV}=\sigma /$ $\mu$ ) of the three NDVI images is indicative of the stability of the NDVI values per pixel over the growing season, but it was limited to the three acquisition dates. Three difference variables were derived for each study site by calculating the difference between each pair of dates in the three date dataset for a total of eight PhenNDVI variables. Initial assessment of the optical variables included a comparison of the multispectral signatures for cropland, rangeland, and seeded forage for each image acquisition. Boxplots of the VIs were also created to understand the change in biophysical processes for each class across the growing season. 
Table 3.3. NDVI Phenological Variables

\begin{tabular}{|c|c|l|}
\hline PhenNDVI Name & Derived NDVI Variable & Description \\
\hline NDVI Min & Minimum & Minimum value of NDVI for three dates \\
\hline NDVI Max & Maximum & Maximum value of NDVI for three dates \\
\hline NDVI Mean & Mean & Mean $(\mu)$ value of NDVI for three dates \\
\hline NDVI SD & Standard Deviation & $\begin{array}{l}\text { Standard deviation }(\sigma) \text { of NDVI for three } \\
\text { dates }\end{array}$ \\
\hline NDVI CoV & Coefficient of Variation & \multicolumn{1}{c|}{ CoV $=\frac{\sigma}{\mu}$} \\
\hline NDVI Diff & Difference $(x 3)$ & $\begin{array}{l}\text { Difference between NDVI values } \\
\text { calculated between two dates }\end{array}$ \\
\hline
\end{tabular}

\subsection{Land Cover Classification}

The techniques utilized for each land cover classification, as well as the methods for accuracy assessment, and final classification comparisons (McNemar's test) are discussed below; background information for each given in Chapter 2. All supervised classifications in this study used a pixel-based RF algorithm. Thirty-four classifications were performed with different combinations of variables (MS, Radar, VIs, and PhenNDVI) and optical image dates (Table 3.4) for each study area. Following each classification, an independent accuracy assessment was conducted to provide an error matrix for a statistical comparison of accuracy. The effects of the inclusion/exclusion of certain groups of variables and image dates on overall and class accuracy were analyzed. 
Table 3.4. Variable Combinations Used in RF Classifications

\begin{tabular}{cccc}
\hline & \multicolumn{3}{c}{ Number of Classifications } \\
\cline { 2 - 4 } Variables & 1 Date & 2 Date & 3 Date \\
\hline MS & 3 & 2 & 1 \\
VI & 3 & NA & NA \\
Radar & 1 & NA & NA \\
MS + Radar & 3 & 2 & 1 \\
MS + VI & 3 & 2 & 1 \\
MS + VI + Radar & 3 & 2 & 1 \\
MS + VI + PhenNDVI + Radar & NA & NA & 1 \\
\hline
\end{tabular}

\subsubsection{Random Forest Classification}

The RF algorithm was used for all classifications. It was run in R Statistics using a script adapted from Millard and Richardson (2015). The RF script utilized the randomForest (Liaw \& Wiener, 2002) and raster (Hijmans, 2014) R packages. Ntree was selected initially at 1501 trees, but was reduced to 1001 trees after assessing error convergence for several classifications which increased the efficiency of the classification and reduced the probability of overfitting. For all classifications the Mtry parameter was set to the default value of $\sqrt{p}$ where $p$ denotes the number of variables used in the classification (Liaw \& Wiener, 2002). RF OOB error, as well as measures of variable importance were recorded for each classification to aid in the analysis of results.

\subsubsection{Classification Accuracy Assessment}

Classification accuracy assessments for each study area used an independent validation set of $1 / 3$ of the total reference data set. The independent validation set was removed from the reference set prior to classification using a stratified random sampling technique and therefore maintained the proportion of each class as in the whole reference set. The validation set was then used to extract the class values from each final classified map, in order to create a confusion 
matrix to calculate values of overall accuracy and Cohen's Kappa for comparison to the RFgenerated OOB error as described in Chapter 2. The error matrix was also used to provide a measure of errors of omission, or Producer's Accuracy (PA), as well as errors of commission, or User's Accuracy (UA) for each class.

\subsection{Assessing Variable Importance}

The variable importance measures created by the RF classification are one way of determining the optimal set of predictor variables, however this approach is limited as it does not consider the operational efficiency of variables. This section presents the two methods used to determine the optimal set of predictor variables for RF classification: 1) the relative efficiency of variable groups was evaluated by comparing the classification performance when variable groups were included vs. excluded; and 2) variable importance measures were calculated for an initial classification that included all of the variables for each area and compared with subsequent classifications implemented with reduced variable sets that excluded unimportant and correlated variables.

\subsubsection{Predictor Variable Performance}

The impact that strategic groups of variables (MS, VI, PhenNDVI, and Radar) and acquisition dates have on classification accuracy was assessed by running a number of individual classifications on radar, optical, and optical + radar variables as seen in Table 3.5. McNemar's test (see Section 2.2.6) was conducted to assess the statistical significance of the difference in accuracy between each classification (Foody, 2004). As each model was run, the OOB error and variable importance measures were recorded before independent accuracy was assessed. Maps of 
the prediction performance for each class were created to assess uncertainty for each pixel within the classifier for the model that used all optical (3 dates) and radar variables.

Table 3.5. Classification Models

\begin{tabular}{|c|c|c|}
\hline & Alberta & Manitoba \\
\hline Optical (LS8) & $\begin{array}{l}\text { MS (1) - Spring } \\
\text { MS (1) - Mid Summer } \\
\text { MS (1) - Late Summer } \\
\text { VI (1) - Spring } \\
\text { VI (1) - Mid Summer } \\
\text { VI (1) - Late Summer } \\
\text { MS (2) - Spring \& Mid Summer } \\
\text { MS (2) - Spring \& Late Summer } \\
\text { MS (2) - Mid \& Late Summer } \\
\text { MS (3) } \\
\text { MS (1)+VI (1) - Spring } \\
\text { MS (1) + VI (1) - Mid Summer } \\
\text { MS (1) + VI (1) - Late Summer } \\
\text { MS (2) + VI (2) - Spring \& Mid Summer } \\
\text { MS (2) + VI (2) - Spring \& Late Summer } \\
\text { MS (2) + VI (2) - Mid \& Late Summer } \\
\text { MS (3) + VI (3) } \\
\text { MS (3) + VI (3) + PhenNDVI }\end{array}$ & $\begin{array}{l}\text { MS (1) - Spring } \\
\text { MS (1) - Late Summer } \\
\text { MS (1) - Fall } \\
\text { VI (1) - Spring } \\
\text { VI (1) - Late Summer } \\
\text { VI (1) - Fall } \\
\text { MS (2) - Spring \& Late Summer } \\
\text { MS (2) - Spring \& Fall } \\
\text { MS (2) - Late Summer \& Fall } \\
\text { MS (3) } \\
\text { MS (1) + VI (1) - Spring } \\
\text { MS (1) + VI (1) - Late Summer } \\
\text { MS (1) + VI (1) - Fall } \\
\text { MS (2) + VI (2) - Spring \& Late Summer } \\
\text { MS (2) + VI (2) - Spring \& Fall } \\
\text { MS (2) + VI (2) - Late Summer \& Fall } \\
\text { MS (3) + VI (3) } \\
\text { MS (3) + VI (3) + PhenNDVI }\end{array}$ \\
\hline Radar (RS2) & Radar & Radar \\
\hline Optical + Radar & $\begin{array}{l}\text { MS (1) + Radar - Spring } \\
\text { MS (1) + Radar - Mid Summer } \\
\text { MS (1) + Radar - Late Summer } \\
\text { MS (2) + Radar - Spring \& Mid Summer } \\
\text { MS (2) + Radar - Spring \& Late Summer } \\
\text { MS (2) + Radar - Mid \& Late Summer } \\
\text { MS (3) + Radar } \\
\text { MS (1) + VI (1) + Radar - Spring } \\
\text { MS (1) + VI (1) + Radar - Mid Summer } \\
\text { MS (1) + VI (1) + Radar - Late Summer } \\
\text { MS (2) + VI (2) + Radar - Spring \& Mid Summer } \\
\text { MS (2) + VI (2) + Radar - Spring \& Late Summer } \\
\text { MS (2) + VI (2) + Radar - Mid \& Late Summer } \\
\text { MS (3) + VI (3) + Radar } \\
\text { MS (3) + VI (3) + PhenNDVI + Radar }\end{array}$ & $\begin{array}{l}\text { MS (1) + Radar - Spring } \\
\text { MS (1) + Radar - Late Summer } \\
\text { MS (1) + Radar - Fall } \\
\text { MS (2) + Radar - Spring and Late Summer } \\
\text { MS (2) + Radar - Spring and Fall } \\
\text { MS (2) + Radar - Late Summer and Fall } \\
\text { MS (3) + Radar } \\
\text { MS (1) + VI (1) + Radar - Spring } \\
\text { MS (1) + VI (1) + Radar - Late Summer } \\
\text { MS (1) + VI (1) + Radar - Fall } \\
\text { MS (2) + VI (2) + Radar - Spring \& Late Summer } \\
\text { MS (2) + VI (2) + Radar - Spring \& Fall } \\
\text { MS (2) + VI (2) + Radar - Late Summer \& Fall } \\
\text { MS (3) + VI (3) + Radar } \\
\text { MS (3) + VI (3) + PhenNDVI + Radar }\end{array}$ \\
\hline
\end{tabular}

\subsubsection{RF Variable Reduction}

A final classification for each area was conducted to determine if reducing the variables in a strategic way can, in this instance, reduce model over-fitting while increasing independent map accuracy. Overfitting influences accuracy if unimportant and correlated variables remain in 
the classification. The final model would also determine which variables had the highest predictive power for each study site. The random forest classifier provides two built in measures of variable importance for each classification. For the ranking of variables by importance, the mean decrease in accuracy measure was used (Breiman, 2001).

The flowchart in Figure 3.5 outlines the main process for creating an efficient model containing a reduced number of variables. In order to reduce the variables, a RF classification was run a total of 50 times for each study area using all variables and all of the training/validation data to get a stable representation of variable importance. Variable importance was ranked using the mean decrease in accuracy values for all three classes for all iterations, and variables of high importance (top 20 of 40) were retained. Using pixel values extracted from each training site, a Spearman rank correlation matrix was tabulated using all variables. It has been shown that the removal of highly correlated variables from random forest models reduces the possibility of over-fitting (Millard and Richardson, 2015). Variables with a high correlation (greater than 0.8) which ranked lower in importance were removed from the initial model of 20 important variables. The remaining uncorrelated variables were reduced by importance (stepwise) to determine the effect on error. The final (most efficient) model was selected for each study area based on the stability of error and the fewest number of final variables. The error matrix from the final variable-reduced model was then compared to the model using all optical and radar variables using McNemar's test. The final important variables were compared for each study area. 


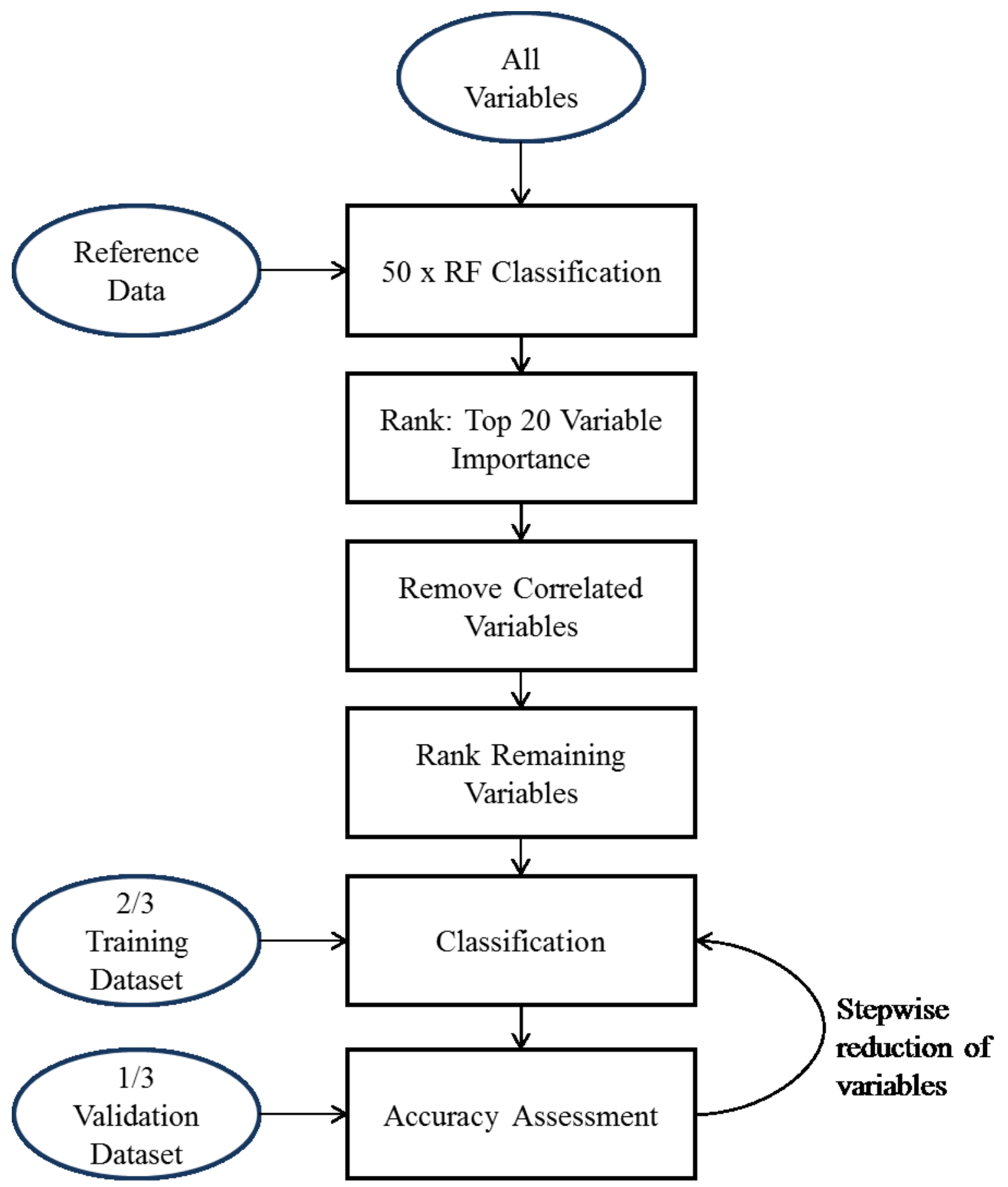

Figure 3.5. RF Variable Reduction Flow Chart 


\section{Chapter 4: Results}

This chapter presents an analysis of the separability of optical and radar variables, followed by the results of the RF classification models.

\subsection{Variable Analysis}

Assessment of variable separability is often a first step in a supervised classification, however due to the non-parametric nature of the RF classification and robustness against noise this step is often overlooked (Breiman, 2001). The following section presents the preliminary analysis of the separability of the LS8 multispectral bands, derived optical variables, as well as radar variables for each of the three classes (annual cropland, rangeland, and seeded forage).

\subsubsection{Multitemporal Multispectral Analysis}

The three classes were first analyzed to determine the importance of optical image date acquisition. Each area had only three cloud-free (less than 10\%) images for 2015, the year when field data were collected. Figures 4.1 and 4.2 display the spectral curves for the three classes, using pixels representing a random subset of the field dataset. The differences between rangeland and seeded forage are much more pronounced in Alberta than Manitoba when comparing the two spring images (Figure 4.1 - A and Figure 4.2 - A). The rangeland class in the Alberta study area had a similar NIR reflectance as annual cropland in the same area which is lower than seeded forage, indicating that only sparse photosynthetically active vegetation is present in spring in both these classes, compared to more full green vegetation in seeded forage. The SWIR reflectance in spring shows, for both provinces, that cropland is driest, followed by rangeland and seeded forage. This confirms that crops are planted on lands which are drier in spring. The nearly identical reflectance of rangeland and seeded forage in the Manitoba study area indicates that the dominant grass and legume species of these classes have similar timing of 
spring green-up and are thus harder to differentiate at this stage in the growing season (Figure $4.1-$ A). Towards the end of the growing season (late summer and fall) there is more divergence in the spectral differences between these two classes (Figure 4.1 - B and C). For both study areas, the spectral curve for the rangeland class remains stable relative to the other classes over the three dates, meaning less phenological change occurs. This may be due to the absence of rapid harvesting events on rangeland. The NIR surface reflectance for the rangeland class is close to $25 \%$ for all three image dates, whereas NIR for the seeded forage class fluctuates and is higher than $25 \%$ for the three dates.

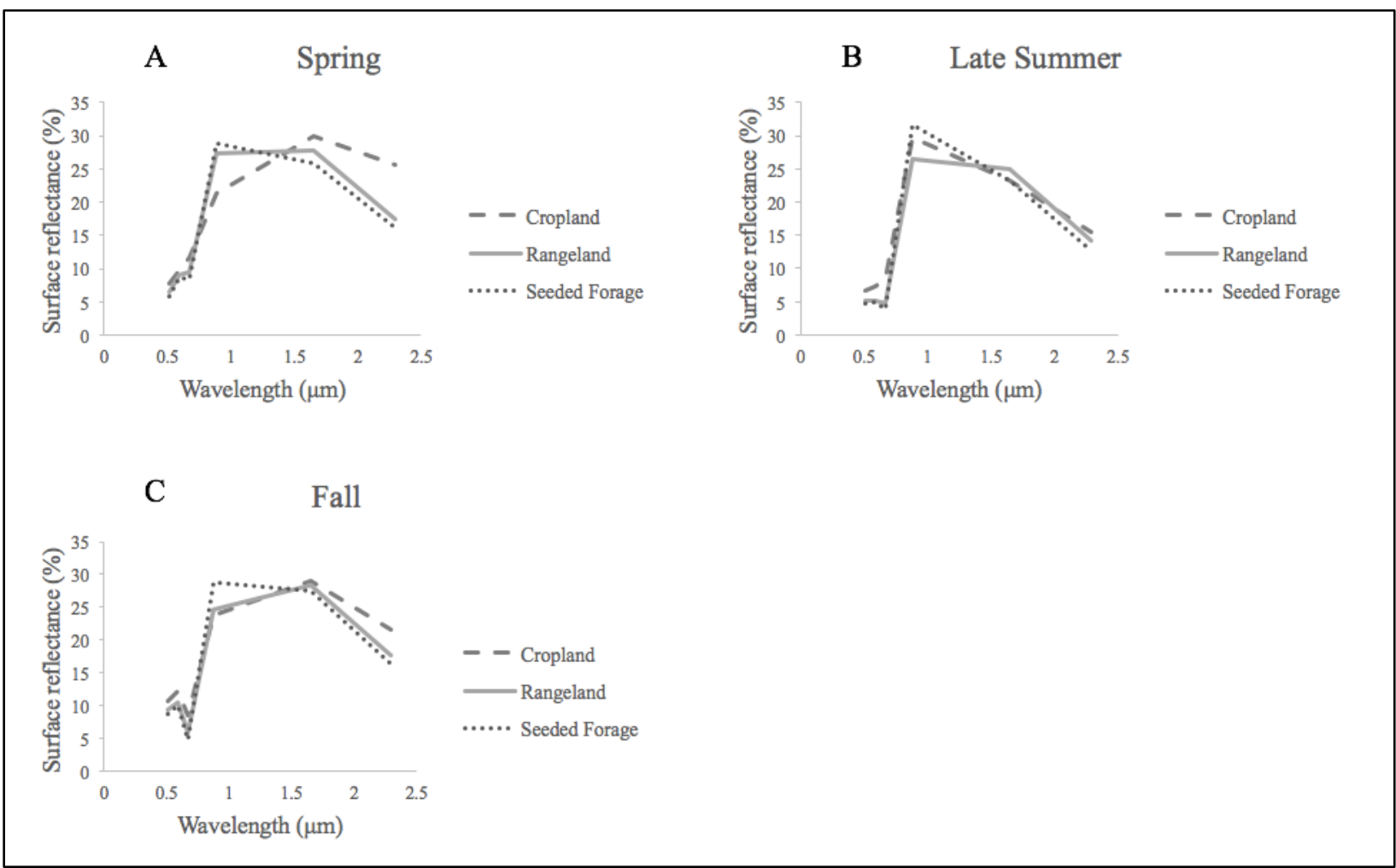

Figure 4.1. Spectral curves for three land cover classes over Manitoba study area derived from LS8 TOA data for A) spring (d147), B) late summer (d243), and C) fall (d291). 


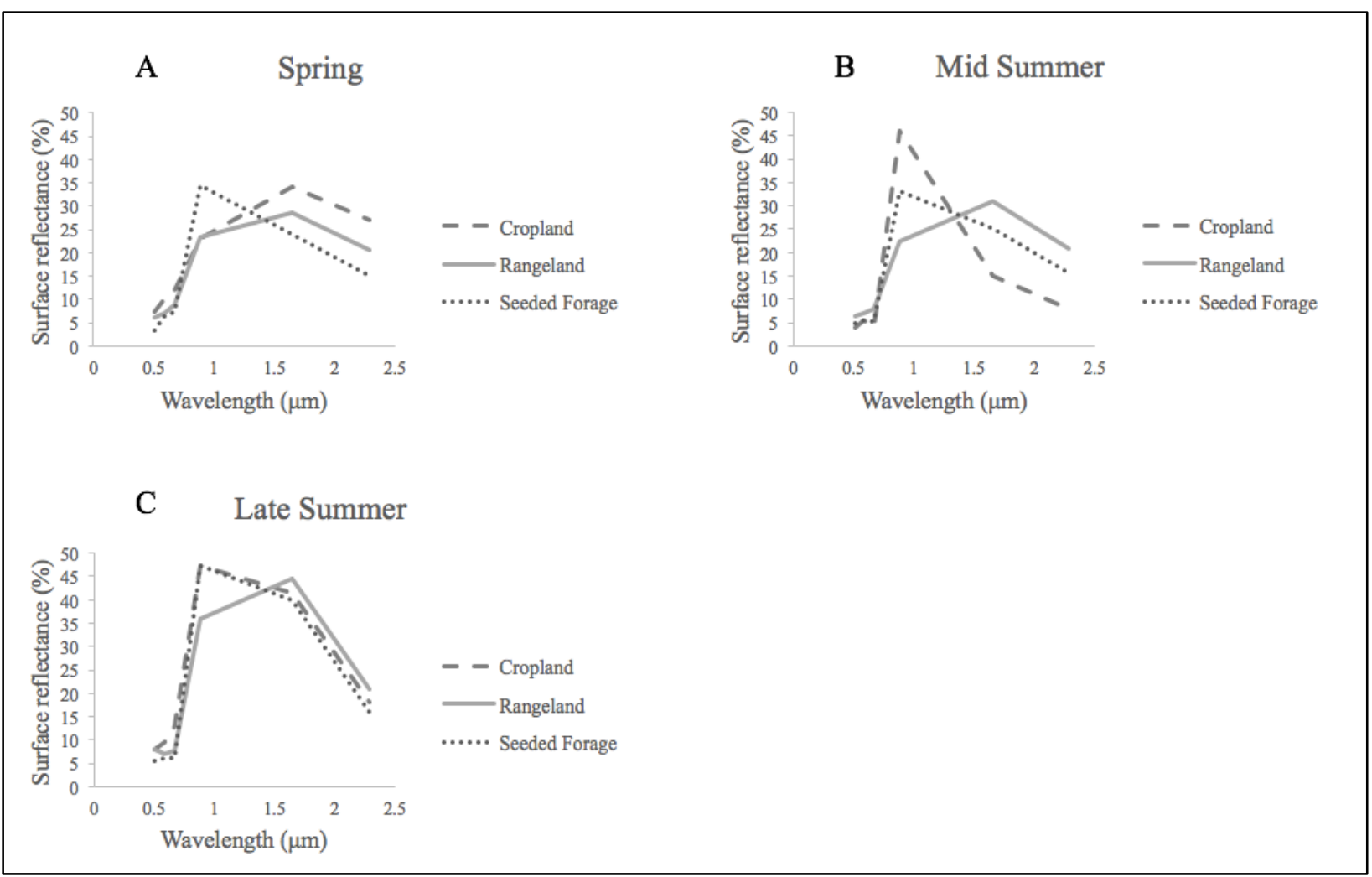

Figure 4.2. Spectral curves for three land cover classes over the Alberta study area derived from LS8 TOA data for A) spring (d139) B) mid-summer (d187), and C) late summer (d235).

\subsubsection{Variable Separability}

Figures 4.3 and 4.4 compare the distributions of the optical (excluding the MS bands) and radar variables for the three classes across each study area. The data were rescaled from 0 to 1 for visual comparison and no data transformations were applied. The lines on either side of each box represent the minimum (bottom) and maximum (top) excluding outliers, while the lower and upper bounds of the box represent the lower and upper quartile, respectively, with the horizontal line representing the median. Concurrent with the physiological differences observed in the field, the separability between the rangeland and seeded forage classes is much greater in the Alberta study area (Figure 4.4) than the Manitoba study area (Figure 4.3). The spring VI variables such as NDVI have some separation between classes. The cropland class has a consistently lower 
spring NDSVI, NDVI, SATVI, and TCW than the seeded forage and rangeland classes, while the seeded forage class is consistently highest. A similar relationship can be observed with the fall VI variables for Manitoba.

Among the RS2 variables, the class with the lowest median value (backscatter) is the rangeland class for both provinces. Cropland RS2 (VV and VH) backscatter has the highest median with the widest quartiles of the three classes indicating the most variability in surface roughness. The similarity between medians for the seeded forage and rangeland classes for Manitoba indicate that the RS2 variables will not be effective at separating these two classes; whereas the rangeland and forage classes have a higher separability in the Alberta study area. The best discriminating variables for the rangeland and seeded forage appear to be the variables which are related to greenness, or amount of photosynthetically active vegetation at the beginning and end of the growing season. 


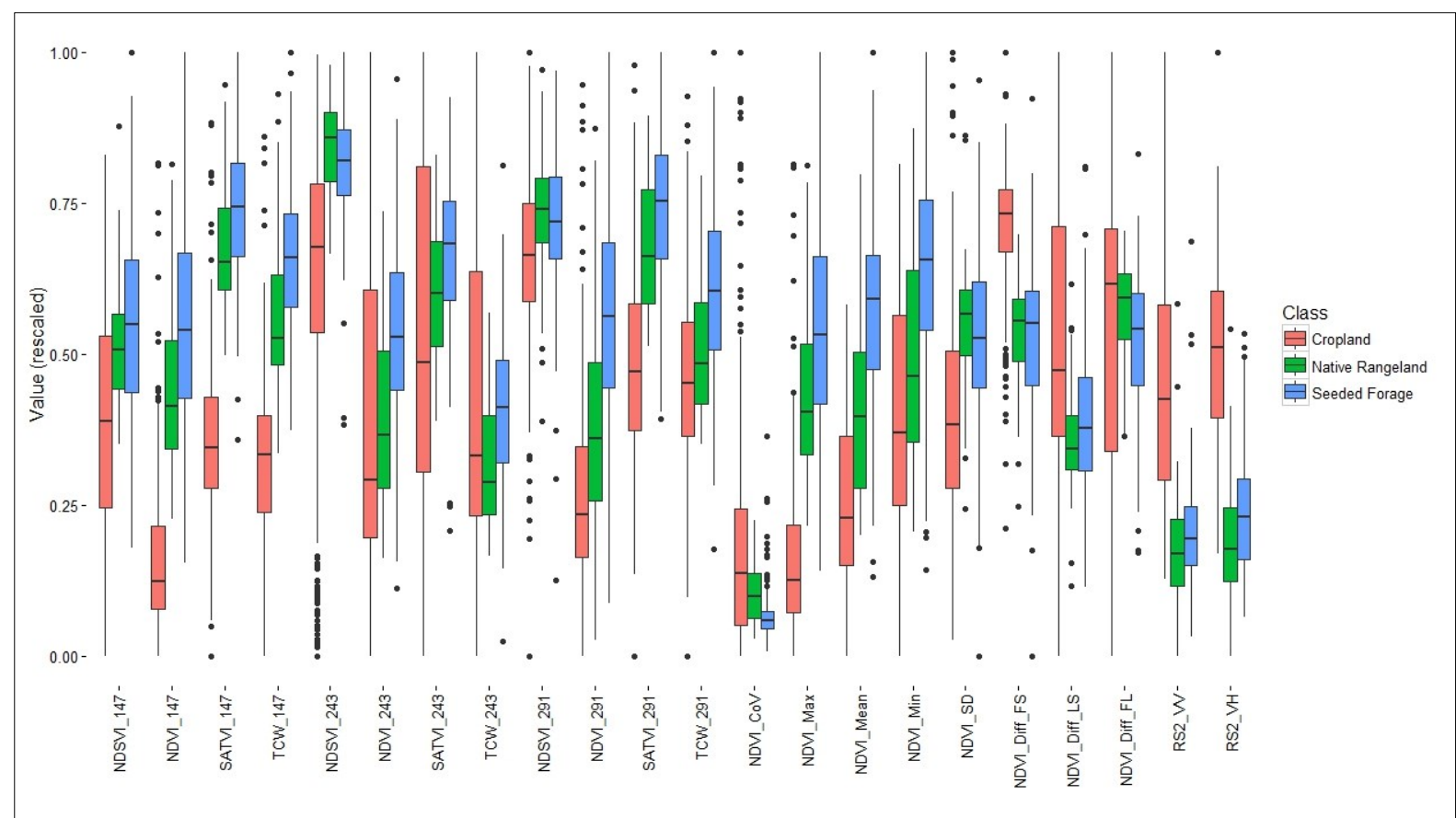

Figure 4.3. Boxplots of Manitoba derived optical variables (spring (d147), late summer (d243) and fall (d291)) and Radar variables (VV and VH) rescaled to $0-1$. The lines represent the minimum (bottom) and maximum (top) excluding outliers (dots), while the box represents the lower and upper quartile with the horizontal line representing the median.

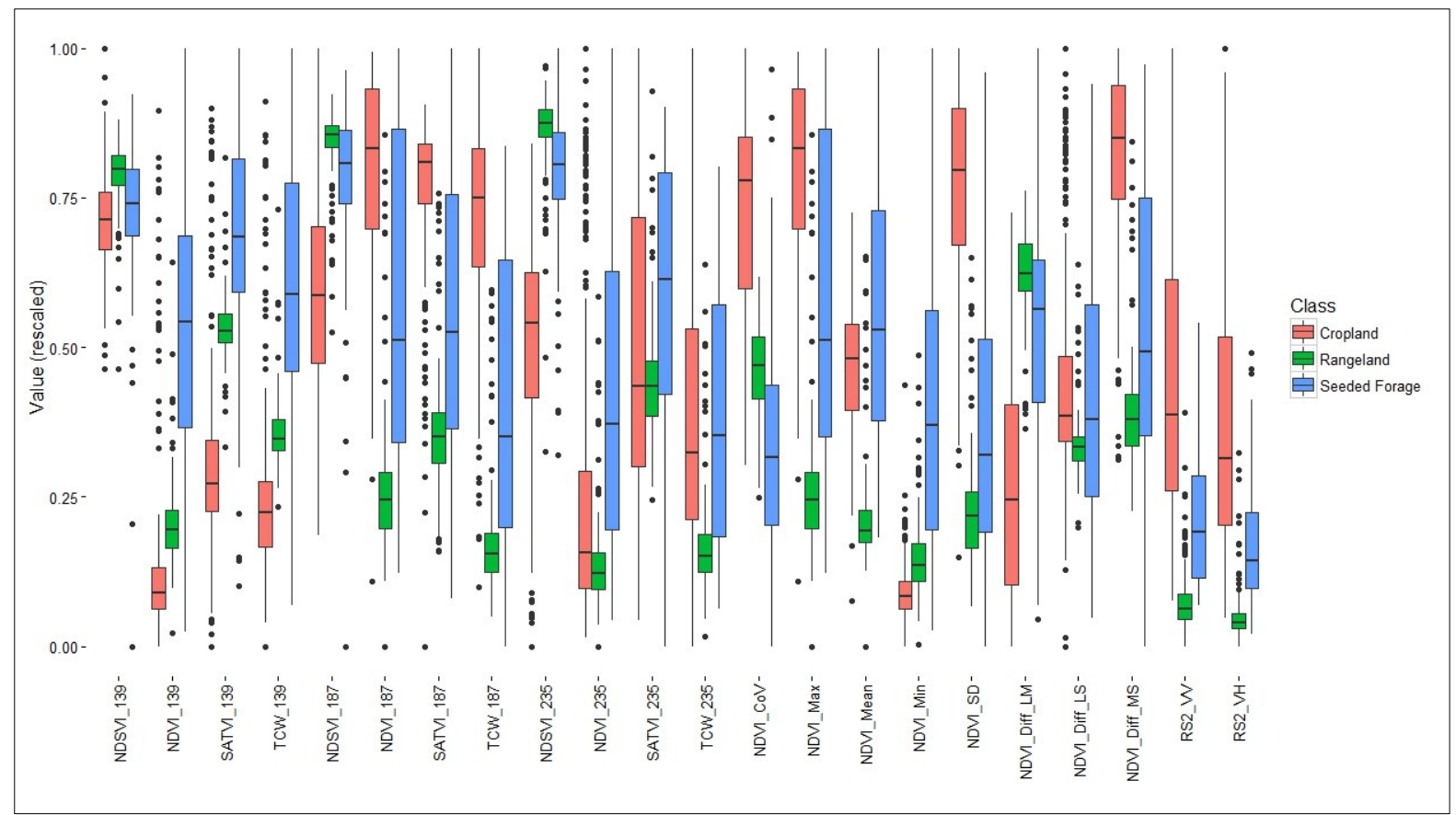

Figure 4.4. Boxplots of Alberta derived optical variables; (spring (d139), mid-summer (d187) and late summer (d235)) and Radar variables (VV and VH) rescaled to 0 -1. The lines represent the minimum (bottom) and maximum (top) excluding outliers (dots), while the box represents the lower and upper quartile with the horizontal line representing the median. 


\subsection{Evaluation of RF Models}

The following sections describe the classification performance of the 31 combinations of data classified using the RF algorithm for each study area. Classification performance and accuracy statistics, as well as RF OOB error are presented in Appendix B along with the classification error matrices used to derive the independent error statistics. The statistical comparisons of the error matrices using McNemar's test are located in Appendix C. A final map of the highest performing RF model adjacent to the poorest performing model is shown in Figures 4.9 (Manitoba) and 4.10 (Alberta). It is important to note that the proportions within the reference data are unequal between classes, so measures of overall accuracy should only be used for comparison of classifications and not as literal measure of overall classification performance. The higher proportion of cropland reference samples skew the measure of overall accuracy as the cropland class had the highest class accuracy. Validation samples could not be randomly collected due to the requirement to follow roads and because the observations were made during field travel directed by other AAFC researchers for their own research needs.

\subsubsection{Evaluation of MS Acquisition Dates}

A total of seven classifications were performed on the multispectral (MS) variables for comparison of accuracy statistics (Tables 4.1 and 4.2). The MS variables include the 6 atmospherically corrected reflectance data for the multispectral bands from the three LS8 images acquired for each study area.

Of the three single-date MS classifications of the Manitoba study area, the highest overall accuracy was late summer followed closely by spring; the poorest was the fall image. 
Classification accuracy (independent accuracy and OOB) for each date improved with the addition of a second image date. For the single-date classifications, spring class-based user's accuracy (UA: 100\% - errors of commission) was higher for cropland and rangeland than for the other two dates. Seeded forage UA was highest using the late summer MS variables.

Using all three dates of LS8 imagery in the classifier outperformed all three combinations of two date classification using MS variables. However, according to the McNemar's test (Appendix C), the three date MS classification did not significantly outperform the highest performing two date classification, which used spring and fall images. In other words, the addition of late summer MS variables did not significantly $(\mathrm{p} \leq 0.05)$ increase classification accuracy when added to the spring and fall MS imagery. Classification accuracy increased significantly with the addition of spring MS variables to the late summer and fall MS variables, as well as when fall MS imagery was added to spring and late summer MS variables.

Of the three single-date MS classifications performed for the Alberta study area, the highest overall accuracy was achieved with spring data, followed closely by late summer. Classification accuracy (independent and OOB) was modestly improved with the addition of a second image date. Class based UA was highest for cropland using spring or late summer data, while UA for rangeland was highest using the mid-summer MS variables (94.12\%), closely followed by spring $(93.57 \%)$. The seeded forage class UA was similar for all three single-date MS classifications.

Using all three dates of LS8 imagery significantly outperformed all three combinations of two-date MS classifications as evident from the overall accuracy, OOB error and Kappa in Table 4.2 and the McNemar's test results comparing the classification error matrices in Appendix B. In Tables 4.1 and 4.2 below, "Overall Accuracy" is the independent error derived from the 
associated error matrices in Appendix B, while OOB Error is the internal estimate of overall classification error derived from the RF classifier.

Table 4.1. Manitoba MS Classification Results

\begin{tabular}{|c|c|c|c|c|c|c|c|c|c|c|c|}
\hline Classification Variables & $\begin{array}{c}\text { Overall } \\
\text { Accuracy }\end{array}$ & $\begin{array}{c}\text { Cropland } \\
\text { PA }\end{array}$ & $\begin{array}{c}\text { Cropland } \\
\text { UA }\end{array}$ & $\begin{array}{c}\text { Rangeland } \\
\text { PA }\end{array}$ & $\begin{array}{c}\text { Rangeland } \\
\text { UA }\end{array}$ & $\begin{array}{c}\text { Seeded } \\
\text { Forage } \\
\text { PA }\end{array}$ & $\begin{array}{c}\text { Seeded } \\
\text { Forage } \\
\text { UA }\end{array}$ & $\begin{array}{l}\mathrm{OOB} \\
\text { Error }\end{array}$ & $\begin{array}{c}\text { Difference } \\
\text { in Error } \\
(\mathrm{OA}- \\
\mathrm{OOB})\end{array}$ & $\begin{array}{c}\# \text { of } \\
\text { Variables }\end{array}$ & $\begin{array}{c}\text { Cohen's } \\
\text { Kappa }\end{array}$ \\
\hline MS (1) - Spring & 84.85 & 95.82 & 96.18 & 54.65 & 74.60 & 82.88 & 71.18 & 83.40 & 1.45 & 6 & 0.75 \\
\hline MS (1) - Late Summer & 85.86 & 97.72 & 95.90 & 59.30 & 70.83 & 80.14 & 75.48 & 85.48 & 0.38 & 6 & 0.76 \\
\hline MS (1) - Fall & 80.61 & 94.68 & 88.93 & 48.84 & 68.85 & 73.97 & 70.13 & 82.68 & -2.07 & 6 & 0.67 \\
\hline MS (2) - Spring \& Late Summer & 87.88 & 98.48 & 96.64 & 58.14 & 79.37 & 86.30 & 76.83 & 89.42 & -1.54 & 12 & 0.80 \\
\hline MS (2) - Spring \& Fall & 88.89 & 97.34 & 96.97 & 67.44 & 82.86 & 86.30 & 78.26 & 88.69 & 0.20 & 12 & 0.81 \\
\hline MS (2) - Late Summer \& Fall & 86.26 & 98.10 & 95.20 & 59.30 & 72.86 & 80.82 & 76.62 & 88.69 & -2.43 & 12 & 0.77 \\
\hline MS (3) & 89.49 & 98.86 & 98.86 & 62.79 & 78.26 & 88.36 & 79.14 & 90.77 & -1.28 & 18 & 0.82 \\
\hline
\end{tabular}

Table 4.2. Alberta MS Classification Results

\begin{tabular}{|c|c|c|c|c|c|c|c|c|c|c|c|}
\hline Classification Variables & $\begin{array}{c}\text { Overall } \\
\text { Accuracy }\end{array}$ & $\begin{array}{c}\text { Cropland } \\
\text { PA }\end{array}$ & $\begin{array}{c}\text { Cropland } \\
\text { UA }\end{array}$ & $\begin{array}{c}\text { Rangeland } \\
\text { PA }\end{array}$ & $\begin{array}{c}\text { Rangeland } \\
\text { UA }\end{array}$ & $\begin{array}{c}\text { Seeded } \\
\text { Forage } \\
\text { PA }\end{array}$ & $\begin{array}{c}\text { Seeded } \\
\text { Forage } \\
\text { UA }\end{array}$ & $\begin{array}{l}\text { OOB } \\
\text { Error }\end{array}$ & $\begin{array}{l}\text { Difference } \\
\text { in Error } \\
(\mathrm{OA}- \\
\mathrm{OOB})\end{array}$ & $\begin{array}{c}\# \text { of } \\
\text { Variables }\end{array}$ & $\begin{array}{c}\text { Cohen's } \\
\text { Kappa }\end{array}$ \\
\hline MS (1) - Spring & 88.80 & 90.65 & 92.53 & 90.97 & 93.57 & 81.82 & 75.63 & 89.12 & -0.32 & 6 & 0.82 \\
\hline MS (1) - Mid Summer & 86.40 & 93.50 & 86.47 & 88.89 & 94.12 & 67.27 & 75.51 & 83.97 & 2.43 & 6 & 0.78 \\
\hline MS (1) - Late Summer & 88.00 & 96.34 & 92.58 & 83.33 & 89.55 & 75.45 & 75.45 & 87.89 & 0.11 & 6 & 0.81 \\
\hline MS (2) - Spring \& Mid Summer & 90.60 & 95.12 & 93.98 & 89.58 & 94.16 & 81.82 & 78.95 & 91.00 & -0.40 & 12 & 0.85 \\
\hline MS (2) - Spring \& Late Summer & 91.20 & 97.56 & 94.12 & 88.19 & 91.37 & 80.91 & 83.96 & 91.89 & -0.69 & 12 & 0.86 \\
\hline MS (2) - Mid \& Late Summer & 89.80 & 95.53 & 92.16 & 88.19 & 94.07 & 79.09 & 79.09 & 87.68 & 2.12 & 12 & 0.84 \\
\hline MS (3) & 92.80 & 96.75 & 95.58 & 90.97 & 95.62 & 86.36 & 83.33 & 92.53 & 0.27 & 18 & 0.88 \\
\hline
\end{tabular}

\subsubsection{Evaluation of Optical Models}

The classification accuracy was not significantly improved (McNemar's test, Appendix C) with the addition of VI variables to the three date MS classification or the single date MS classifications for both study areas (Tables 4.3 and 4.4). Similarly, the Manitoba study area did not see an improvement in accuracy when the VI variables were included in the two date MS classification; however the Alberta site had a significant increase in accuracy when the 4 VI variables were classified with the MS variables for the mid- and late-summer images $(p=0.003$, Appendix C). The addition of the VI and PhenNDVI variables did not significantly improve the accuracy of the three date MS classification for either study area. This may be due to the correlation between some MS variables and VI variables (Appendix E). 
Classification results also showed that the VI variables were not suitable for replacement of the MS variables. When the single date MS variables were replaced with the corresponding single-date VI variables (Table 4.3), the MS variables performed significantly better for the Manitoba study area $(\mathrm{p} \leq 0.05$, Appendix $\mathrm{C})$. For the Alberta study area, the VI single date classification was outperformed by the corresponding single date MS variables (Table 4.4) but not to a significant degree $(\mathrm{p}>0.05)$.

The Manitoba study area had a significantly lower PA than UA for the rangeland class for all classifications. These higher errors of omissions indicate some reference sample pixels in the rangeland class should have been included in the seeded forage class. This is an indication of a larger problem with using the same definition of rangeland for two very different areas. The Manitoba study area differed from the Alberta study area in that the dominant species of the rangeland and seeded forage classes were spectrally and phenologically more similar.

Table 4.3. Manitoba Optical Variable Classification Results

\begin{tabular}{|c|c|c|c|c|c|c|c|c|c|c|c|}
\hline Classification Variables & $\begin{array}{c}\text { Overall } \\
\text { Accuracy }\end{array}$ & $\begin{array}{c}\text { Cropland } \\
\text { PA }\end{array}$ & $\begin{array}{c}\text { Cropland } \\
\text { UA }\end{array}$ & $\begin{array}{c}\text { Rangeland } \\
\text { PA }\end{array}$ & $\begin{array}{c}\text { Rangeland } \\
\text { UA }\end{array}$ & $\begin{array}{c}\text { Seeded } \\
\text { Forage } \\
\text { PA } \\
\end{array}$ & $\begin{array}{c}\text { Seeded } \\
\text { Forage } \\
\text { UA } \\
\end{array}$ & $\begin{array}{l}\mathrm{OOB} \\
\text { Error }\end{array}$ & $\begin{array}{c}\text { Difference } \\
\text { in Error } \\
(\mathrm{OA}- \\
\mathrm{OOB})\end{array}$ & $\begin{array}{c}\text { \# of } \\
\text { Variables } \\
\end{array}$ & $\begin{array}{c}\text { Cohen's } \\
\text { Kappa }\end{array}$ \\
\hline MS (1) - Spring & 84.85 & 95.82 & 96.18 & 54.65 & 74.60 & 82.88 & 71.18 & 83.40 & 1.45 & 6 & 0.75 \\
\hline MS (1) - Late Summer & 85.86 & 97.72 & 95.90 & 59.30 & 70.83 & 80.14 & 75.48 & 85.48 & 0.38 & 6 & 0.76 \\
\hline MS (1) - Fall & 80.61 & 94.68 & 88.93 & 48.84 & 68.85 & 73.97 & 70.13 & 82.68 & -2.07 & 6 & 0.67 \\
\hline VI (1) - Spring & 82.22 & 93.54 & 93.89 & 58.14 & 62.50 & 76.03 & 72.55 & 81.43 & 0.79 & 4 & 0.70 \\
\hline VI (1) - Late Summer & 82.42 & 98.48 & 93.17 & 47.67 & 62.12 & 73.97 & 71.52 & 83.09 & -0.67 & 4 & 0.70 \\
\hline VI (1) - Fall & 78.59 & 91.63 & 87.96 & 47.67 & 60.29 & 73.29 & 69.93 & 82.78 & -4.19 & 4 & 0.64 \\
\hline MS (2) - Spring \& Late Summer & 87.88 & 98.48 & 96.64 & 58.14 & 79.37 & 86.30 & 76.83 & 89.42 & -1.54 & 12 & 0.80 \\
\hline MS (2) - Spring \& Fall & 88.89 & 97.34 & 96.97 & 67.44 & 82.86 & 86.30 & 78.26 & 88.69 & 0.20 & 12 & 0.81 \\
\hline MS (2) - Late Summer \& Fall & 86.26 & 98.10 & 95.20 & 59.30 & 72.86 & 80.82 & 76.62 & 88.69 & -2.43 & 12 & 0.77 \\
\hline MS (3) & 89.49 & 98.86 & 98.86 & 62.79 & 78.26 & 88.36 & 79.14 & 90.77 & -1.28 & 18 & 0.82 \\
\hline MS (1) + VI (1) - Spring & 85.05 & 95.44 & 96.54 & 55.81 & 75.00 & 83.56 & 71.35 & 84.34 & 0.71 & 10 & 0.75 \\
\hline MS (1) + VI (1) - Late Summer & 85.45 & 98.10 & 96.63 & 58.14 & 66.67 & 78.77 & 75.16 & 85.27 & 0.18 & 10 & 0.76 \\
\hline MS (1) + VI (1) - Fall & 80.00 & 92.02 & 90.30 & 52.33 & 64.29 & 74.66 & 69.43 & 84.34 & -4.34 & 10 & 0.66 \\
\hline MS (2) + VI (2) - Spring \& Late Summer & 88.08 & 98.10 & 97.73 & 58.14 & 78.13 & 87.67 & 76.65 & 89.83 & -1.75 & 20 & 0.80 \\
\hline MS (2) + VI (2) - Spring \& Fall & 88.69 & 96.58 & 97.32 & 66.28 & 83.82 & 87.67 & 77.11 & 89.42 & -0.73 & 20 & 0.81 \\
\hline MS (2) + VI (2) - Late Summer \& Fall & 86.67 & 98.48 & 95.22 & 59.30 & 75.00 & 81.51 & 76.77 & 89.32 & -2.65 & 20 & 0.77 \\
\hline $\operatorname{MS}(3)+\mathrm{VI}(3)$ & 89.29 & 98.86 & 98.86 & 62.79 & 77.14 & 87.67 & 79.01 & 90.98 & -1.69 & 30 & 0.82 \\
\hline MS (3) + VI (3) + PhenNDVI & 88.69 & 98.86 & 98.11 & 60.47 & 78.79 & 86.99 & 77.44 & 89.94 & -1.25 & 38 & 0.81 \\
\hline
\end{tabular}


Table 4.4. Alberta Optical Variable Classification Results

\begin{tabular}{|c|c|c|c|c|c|c|c|c|c|c|c|}
\hline Classification Variables & $\begin{array}{c}\text { Overall } \\
\text { Accuracy }\end{array}$ & $\begin{array}{c}\text { Cropland } \\
\text { PA }\end{array}$ & $\begin{array}{c}\text { Cropland } \\
\text { UA }\end{array}$ & $\begin{array}{c}\text { Rangeland } \\
\text { PA }\end{array}$ & $\begin{array}{c}\text { Rangeland } \\
\text { UA }\end{array}$ & $\begin{array}{c}\text { Seeded } \\
\text { Forage PA }\end{array}$ & $\begin{array}{c}\text { Seeded } \\
\text { Forage } \\
\text { UA } \\
\end{array}$ & $\begin{array}{l}\mathrm{OOB} \\
\text { Error }\end{array}$ & $\begin{array}{c}\text { Difference } \\
\text { in Error } \\
(\mathrm{OA}- \\
\mathrm{OOB})\end{array}$ & $\begin{array}{c}\text { \# of } \\
\text { Variables }\end{array}$ & $\begin{array}{c}\text { Cohen's } \\
\text { Kappa }\end{array}$ \\
\hline MS (1) - Spring & 88.80 & 90.65 & 92.53 & 90.97 & 93.57 & 81.82 & 75.63 & 89.12 & -0.32 & 6 & 0.82 \\
\hline MS (1) - Mid Summer & 86.40 & 93.50 & 86.47 & 88.89 & 94.12 & 67.27 & 75.51 & 83.97 & 2.43 & 6 & 0.78 \\
\hline MS (1) - Late Summer & 88.00 & 96.34 & 92.58 & 83.33 & 89.55 & 75.45 & 75.45 & 87.89 & 0.11 & 6 & 0.81 \\
\hline VI (1) - Spring & 88.00 & 91.87 & 91.13 & 88.19 & 94.78 & 79.09 & 73.73 & 84.68 & 3.32 & 4 & 0.81 \\
\hline VI (1) - Mid Summer & 84.60 & 95.93 & 84.59 & 88.89 & 88.28 & 53.64 & 77.63 & 81.80 & 2.80 & 4 & 0.75 \\
\hline VI (1) - Late Summer & 86.80 & 94.72 & 94.33 & 84.03 & 83.45 & 72.73 & 74.07 & 88.43 & -1.63 & 4 & 0.79 \\
\hline MS (2) - Spring \& Mid Summer & 90.60 & 95.12 & 93.98 & 89.58 & 94.16 & 81.82 & 78.95 & 91.00 & -0.40 & 12 & 0.85 \\
\hline MS (2) - Spring \& Late Summer & 91.20 & 97.56 & 94.12 & 88.19 & 91.37 & 80.91 & 83.96 & 91.89 & -0.69 & 12 & 0.86 \\
\hline MS (2) - Mid \& Late Summer & 89.80 & 95.53 & 92.16 & 88.19 & 94.07 & 79.09 & 79.09 & 87.68 & 2.12 & 12 & 0.84 \\
\hline MS (3) & 92.80 & 96.75 & 95.58 & 90.97 & 95.62 & 86.36 & 83.33 & 92.53 & 0.27 & 18 & 0.88 \\
\hline MS (1) + VI (1) - Spring & 88.40 & 91.06 & 91.80 & 89.58 & 94.85 & 80.91 & 74.17 & 90.56 & -2.16 & 10 & 0.82 \\
\hline MS (1) + VI (1) - Mid Summer & 87.60 & 95.12 & 85.71 & 90.97 & 94.24 & 66.36 & 82.95 & 84.82 & 2.78 & 10 & 0.80 \\
\hline MS (1) + VI (1) - Late Summer & 87.80 & 95.53 & 94.00 & 81.94 & 88.72 & 78.18 & 73.50 & 88.85 & -1.05 & 10 & 0.81 \\
\hline MS (2) + VI (2) - Spring \& Mid Summer & 92.40 & 98.37 & 93.44 & 92.36 & 93.01 & 79.09 & 88.78 & 91.15 & 1.25 & 20 & 0.88 \\
\hline MS (2) + VI (2) - Spring \& Late Summer & 91.40 & 96.75 & 94.82 & 87.50 & 94.74 & 84.55 & 80.17 & 91.84 & -0.44 & 20 & 0.86 \\
\hline MS (2) + VI (2) - Mid \& Late Summer & 92.00 & 96.75 & 94.44 & 88.89 & 94.81 & 85.45 & 83.19 & 89.94 & 2.06 & 20 & 0.87 \\
\hline MS (3) + VI (3) & 92.60 & 97.97 & 95.26 & 89.58 & 95.56 & 84.55 & 83.04 & 93.17 & -0.57 & 30 & 0.88 \\
\hline MS (3) + VI (3) + PhenNDVI & 93.60 & 97.97 & 96.40 & 90.97 & 95.62 & 87.27 & 84.96 & 92.47 & 1.13 & 38 & 0.90 \\
\hline
\end{tabular}

\subsubsection{Evaluation of the Radar Model}

The model using only C-band VV and VH radar backscatter intensity did not perform well overall for the Manitoba study area (overall accuracy $=68.48 \%$; Table 4.5 ). Class-based UA and PA were very poor for the seeded forage and rangeland classes. Better results were achieved for the Alberta study area (overall accuracy $=75.80 \%$; Table 4.6). Radar performed poorly for differentiating the seeded forage class from cropland and rangeland for both study areas. The radar-only classification was the poorest performing model overall for both study areas. The classified maps are shown in Figures 4.9 and 4.10. When compared to the best performing classifier, the radar-only map exhibits a high amount of noise, as well as an underrepresentation of the seeded forage class, which is misclassified as cropland in many areas. 
Table 4.5. Manitoba Mid-Summer Radar Classification Results

\begin{tabular}{|c|c|c|c|c|c|c|c|c|c|c|c|}
\hline Classification Variables & $\begin{array}{c}\text { Overall } \\
\text { Accuracy }\end{array}$ & $\begin{array}{c}\text { Cropland } \\
\text { PA }\end{array}$ & $\begin{array}{c}\text { Cropland } \\
\text { UA }\end{array}$ & $\begin{array}{c}\text { Rangeland } \\
\text { PA }\end{array}$ & $\begin{array}{c}\text { Rangeland } \\
\text { UA }\end{array}$ & $\begin{array}{c}\text { Seeded } \\
\text { Forage } \\
\text { PA }\end{array}$ & $\begin{array}{c}\text { Seeded } \\
\text { Forage } \\
\text { UA }\end{array}$ & $\begin{array}{l}\text { OOB } \\
\text { Error }\end{array}$ & $\begin{array}{c}\text { Difference } \\
\text { in Error } \\
(\mathrm{OA}- \\
\mathrm{OOB})\end{array}$ & $\begin{array}{c}\text { \# of } \\
\text { Variables }\end{array}$ & $\begin{array}{c}\text { Cohen's } \\
\text { Kappa }\end{array}$ \\
\hline Radar & 68.48 & 88.21 & 85.61 & 38.37 & 39.76 & 50.68 & 52.48 & 67.84 & 0.64 & 2 & 0.47 \\
\hline
\end{tabular}

Table 4.6. Alberta Mid-Summer Radar Classification Results

\begin{tabular}{|c|c|c|c|c|c|c|c|c|c|c|c|}
\hline Classification Variables & $\begin{array}{c}\text { Overall } \\
\text { Accuracy }\end{array}$ & $\begin{array}{c}\text { Cropland } \\
\text { PA }\end{array}$ & $\begin{array}{c}\text { Cropland } \\
\text { UA }\end{array}$ & $\begin{array}{c}\text { Rangeland } \\
\text { PA }\end{array}$ & $\begin{array}{c}\text { Rangeland } \\
\text { UA }\end{array}$ & $\begin{array}{l}\text { Seeded } \\
\text { Forage } \\
\text { PA }\end{array}$ & $\begin{array}{c}\text { Seeded } \\
\text { Forage } \\
\text { UA }\end{array}$ & $\begin{array}{l}\text { OOB } \\
\text { Error }\end{array}$ & $\begin{array}{l}\text { Difference } \\
\text { in Error } \\
(\mathrm{OA}- \\
\text { OOB) }\end{array}$ & $\begin{array}{c}\text { \# of } \\
\text { Variables }\end{array}$ & $\begin{array}{c}\text { Cohen's } \\
\text { Kappa }\end{array}$ \\
\hline Radar & 75.80 & 87.80 & 76.60 & 84.72 & 87.77 & 37.27 & 51.90 & 74.62 & 1.18 & 2 & 0.60 \\
\hline
\end{tabular}

\subsubsection{Evaluation of Optical and Radar Models}

Tables 4.7 and 4.8 describe the RF classification results achieved with the combination of optical (MS, VI, and PhenNDVI) and radar variables for Manitoba and Alberta, respectively. The accuracy statistics were derived from classification error matrices in Appendix B. Addition of radar to MS variables did not always significantly improve classification accuracy (McNemar's test; Appendix C). For the Manitoba study area, classification accuracy was significantly improved with the addition of Radar to spring and fall single-date MS classifications, as well as when radar was added to the two-date MS classification using late summer and fall LS8 imagery. For the Alberta study area, MS classification accuracy was not significantly improved with the addition of radar to single, two and three-date classifications for the Alberta study area. Neither study area saw significant improvements in classification when radar was added to the three-date MS variables. Figure 4.5 compares the difference in overall classification accuracy for Manitoba and Alberta when radar variables were added to single, two and three-date MS classifications.

Figure 4.6 compares the difference in rangeland classification accuracy (UA) with the addition of radar to single, two and three-date MS classifications. These were the largest improvements achieved with the addition of radar to MS variables. 
Overall accuracy and RF OOB error were very closely related for both study areas across all iterations of classification variables (Figures 4.7 and 4.8). OOB error trended towards overestimation when compared to OA in Manitoba (Figure 4.7). A map of a subset of the highest performing model for each study area contrasted with the worst-performing model (radar only) for Manitoba is shown in Figure 4.9, and Alberta in Figure 4.10. The best performing model for Manitoba based on overall accuracy was the classification of the three-date MS variables with radar. The model excluding radar MS (3) had the same overall accuracy (89.49\%) and was not significantly different ( $p \geq 0.05$; Appendix $C$ ), however, the classification with radar had slightly elevated accuracy for the rangeland class, and OOB error was higher. These simpler models outperformed the model using all variables in the Manitoba study area $(\mathrm{p}=0.074)$, by conventional criteria these models are not significantly different. The highest-performing model for the Alberta study area was the model with all variables (MS (3) + VI (3) + PhenNDVI + Radar), which significantly outperformed the three-date MS with radar classification (MS (3) + Radar) ( $\leq$ 0.05; Appendix C). 
Table 4.7. Manitoba Optical \& Mid-Summer Radar Classification Results

\begin{tabular}{|c|c|c|c|c|c|c|c|c|c|c|c|}
\hline Classification Variables & $\begin{array}{c}\text { Overall } \\
\text { Accuracy }\end{array}$ & $\begin{array}{c}\text { Cropland } \\
\text { PA }\end{array}$ & $\begin{array}{c}\text { Cropland } \\
\text { UA }\end{array}$ & $\begin{array}{c}\text { Rangeland } \\
\text { PA }\end{array}$ & $\begin{array}{l}\text { Rangeland } \\
\text { UA }\end{array}$ & $\begin{array}{c}\text { Seeded } \\
\text { Forage } \\
\text { PA } \\
\end{array}$ & $\begin{array}{c}\text { Seeded } \\
\text { Forage } \\
\text { UA } \\
\end{array}$ & $\begin{array}{l}\text { OOB } \\
\text { Error }\end{array}$ & $\begin{array}{c}\text { Difference } \\
\text { in Error } \\
(\mathrm{OA}- \\
\mathrm{OOB})\end{array}$ & $\begin{array}{c}\# \text { of } \\
\text { Variables }\end{array}$ & $\begin{array}{c}\text { Cohen's } \\
\text { Kappa } \\
\end{array}$ \\
\hline MS (1) + Radar - Spring & 86.67 & 95.82 & 96.55 & 60.47 & 80.00 & 85.62 & 73.96 & 86.94 & -0.27 & 8 & 0.78 \\
\hline MS (1) + Radar - Late Summer & 87.07 & 97.72 & 95.90 & 55.81 & 76.19 & 86.30 & 76.83 & 87.97 & -0.90 & 8 & 0.78 \\
\hline MS (1) + Radar - Fall & 84.65 & 95.82 & 94.03 & 60.47 & 74.29 & 78.77 & 73.25 & 85.06 & -0.41 & 8 & 0.74 \\
\hline MS (2) + Radar - Spring and Late Summer & 88.69 & 97.72 & 98.09 & 61.63 & 80.30 & 88.36 & 77.25 & 90.26 & -1.57 & 14 & 0.81 \\
\hline MS (2) + Radar - Spring and Fall & 88.69 & 97.34 & 97.34 & 62.79 & 83.08 & 88.36 & 77.25 & 90.25 & -1.56 & 14 & 0.81 \\
\hline MS (2) + Radar - Late Summer and Fall & 89.09 & 99.24 & 96.31 & 63.95 & 80.88 & 85.62 & 80.13 & 90.87 & -1.78 & 14 & 0.82 \\
\hline MS (3) + Radar & 89.49 & 98.86 & 98.48 & 63.95 & 78.57 & 87.67 & 79.50 & 91.70 & -2.21 & 20 & 0.82 \\
\hline MS (1) + VI (1) + Radar - Spring & 86.87 & 96.20 & 96.20 & 62.79 & 79.41 & 84.25 & 75.00 & 87.66 & -0.79 & 12 & 0.83 \\
\hline MS (1) + VI (1) + Radar - Late Summer & 86.67 & 98.10 & 95.91 & 56.98 & 75.38 & 83.56 & 75.78 & 88.90 & -2.23 & 12 & 0.79 \\
\hline MS (1) + VI (1) + Radar - Fall & 84.85 & 96.20 & 94.40 & 59.30 & 73.91 & 79.45 & 73.42 & 84.96 & -0.11 & 12 & 0.84 \\
\hline MS (2) + VI (2) + Radar - Spring \& Late Summer & 88.89 & 98.10 & 98.10 & 60.47 & 81.25 & 89.04 & 77.38 & 90.46 & -1.57 & 22 & 0.81 \\
\hline MS (2) + VI (2) + Radar - Spring \& Fall & 89.09 & 97.72 & 97.35 & 65.12 & 82.35 & 87.67 & 78.53 & 89.94 & -0.85 & 22 & 0.82 \\
\hline MS (2) + VI (2) + Radar - Late Summer \& Fall & 89.29 & 98.86 & 97.01 & 66.28 & 80.28 & 85.62 & 80.13 & 90.87 & -1.58 & 22 & 0.82 \\
\hline MS (3) + VI (3) + Radar & 88.28 & 98.10 & 98.10 & 60.47 & 77.61 & 86.99 & 76.97 & 91.08 & -2.80 & 32 & 0.80 \\
\hline MS (3) + VI (3) + PhenNDVI + Radar & 88.48 & 98.48 & 97.37 & 60.47 & 80.00 & 86.99 & 77.44 & 90.66 & -2.18 & 40 & 0.81 \\
\hline
\end{tabular}

Table 4.8. Alberta Optical \& Mid-Summer Radar Classification Results

\begin{tabular}{|c|c|c|c|c|c|c|c|c|c|c|c|}
\hline Classification Variables & $\begin{array}{c}\text { Overall } \\
\text { Accuracy }\end{array}$ & $\begin{array}{c}\text { Cropland } \\
\text { PA }\end{array}$ & $\begin{array}{c}\text { Cropland } \\
\text { UA }\end{array}$ & $\begin{array}{c}\text { Rangeland } \\
\text { PA }\end{array}$ & $\begin{array}{l}\text { Rangeland } \\
\text { UA }\end{array}$ & $\begin{array}{c}\text { Seeded } \\
\text { Forage } \\
\text { PA } \\
\end{array}$ & $\begin{array}{c}\text { Seeded } \\
\text { Forage } \\
\text { UA }\end{array}$ & $\begin{array}{l}\text { OOB } \\
\text { Error }\end{array}$ & $\begin{array}{c}\text { Difference } \\
\text { in Error } \\
(\mathrm{OA}- \\
\mathrm{OOB})\end{array}$ & $\begin{array}{c}\text { \# of } \\
\text { Variables }\end{array}$ & $\begin{array}{r}\text { Cohen's } \\
\text { Kappa } \\
\end{array}$ \\
\hline MS (1) + Radar - Spring & 88.60 & 91.46 & 93.36 & 90.28 & 93.53 & 80.00 & 73.33 & 91.19 & -2.59 & 8 & 0.82 \\
\hline MS (1) + Radar - Mid Summer & 88.00 & 92.28 & 88.33 & 90.97 & 95.62 & 74.55 & 77.36 & 85.47 & 2.53 & 8 & 0.81 \\
\hline MS (1) + Radar - Late Summer & 88.20 & 95.12 & 92.86 & 85.42 & 92.48 & 76.36 & 73.04 & 88.19 & 0.01 & 8 & 0.81 \\
\hline MS (2) + Radar - Spring \& Mid Summer & 91.40 & 96.34 & 92.58 & 90.97 & 96.32 & 80.91 & 82.41 & 91.93 & -0.53 & 14 & 0.86 \\
\hline MS (2) + Radar - Spring \& Late Summer & 91.80 & 97.15 & 94.84 & 89.58 & 94.16 & 82.73 & 81.98 & 93.10 & -1.30 & 14 & 0.87 \\
\hline MS (2) + Radar - Mid \& Late Summer & 90.00 & 95.93 & 92.91 & 87.50 & 94.03 & 80.00 & 78.57 & 89.54 & 0.46 & 14 & 0.84 \\
\hline MS (3) + Radar & 92.20 & 96.75 & 94.82 & 90.97 & 95.62 & 83.64 & 82.14 & 92.87 & -0.67 & 20 & 0.88 \\
\hline MS (1) + VI (1) + Radar - Spring & 89.00 & 91.46 & 93.36 & 89.58 & 94.85 & 82.73 & 73.98 & 90.47 & -1.47 & 12 & 0.83 \\
\hline MS (1) + VI (1) + Radar - Mid Summer & 86.80 & 92.68 & 88.03 & 88.19 & 94.07 & 71.82 & 74.53 & 85.88 & 0.92 & 12 & 0.79 \\
\hline MS (1) + VI (1) + Radar - Late Summer & 89.80 & 95.93 & 93.65 & 85.42 & 92.48 & 81.82 & 78.26 & 90.24 & -0.44 & 12 & 0.84 \\
\hline MS (2) + VI (2) + Radar - Spring \& Mid Summer & 92.60 & 98.37 & 93.80 & 91.67 & 94.96 & 80.91 & 86.41 & 92.68 & -0.08 & 22 & 0.88 \\
\hline MS (2) + VI (2) + Radar - Spring \& Late Summer & 92.60 & 97.56 & 96.00 & 89.58 & 94.16 & 85.45 & 83.19 & 92.10 & 0.50 & 22 & 0.88 \\
\hline MS (2) + VI (2) + Radar - Mid \& Late Summer & 91.80 & 96.75 & 95.58 & 88.19 & 94.07 & 85.45 & 81.03 & 91.57 & 0.23 & 22 & 0.87 \\
\hline MS (3) + VI (3) + Radar & 93.40 & 98.78 & 95.67 & 89.58 & 95.56 & 86.36 & 85.59 & 92.52 & 0.88 & 32 & 0.89 \\
\hline MS (3) + VI (3) + PhenNDVI + Radar & 94.00 & 97.97 & 96.02 & 91.67 & 96.35 & 88.18 & 86.61 & 93.73 & 0.27 & 40 & 0.90 \\
\hline
\end{tabular}




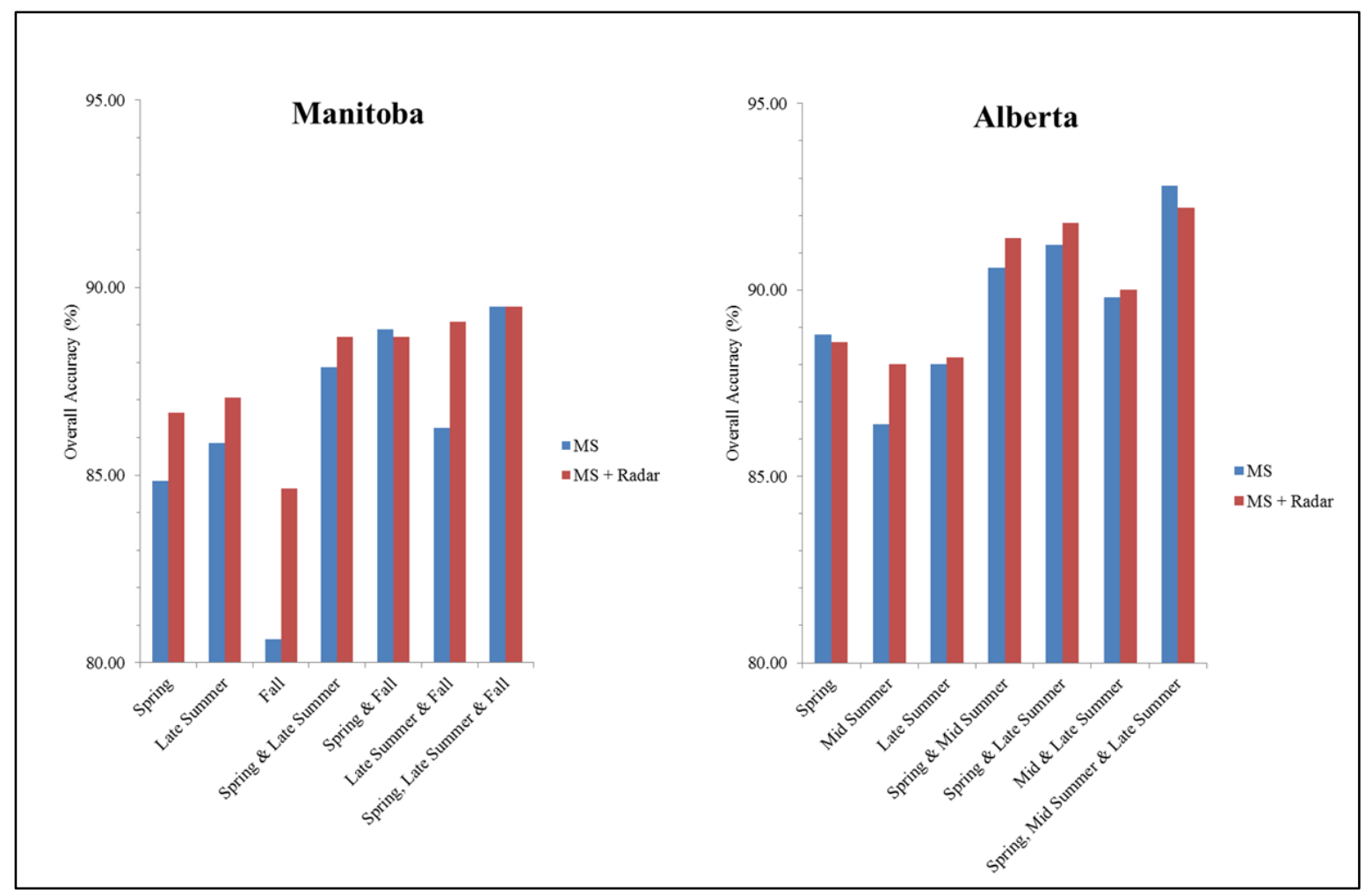

Figure 4.5. Overall classification accuracy with the addition of mid-summer radar to multispectral variables.

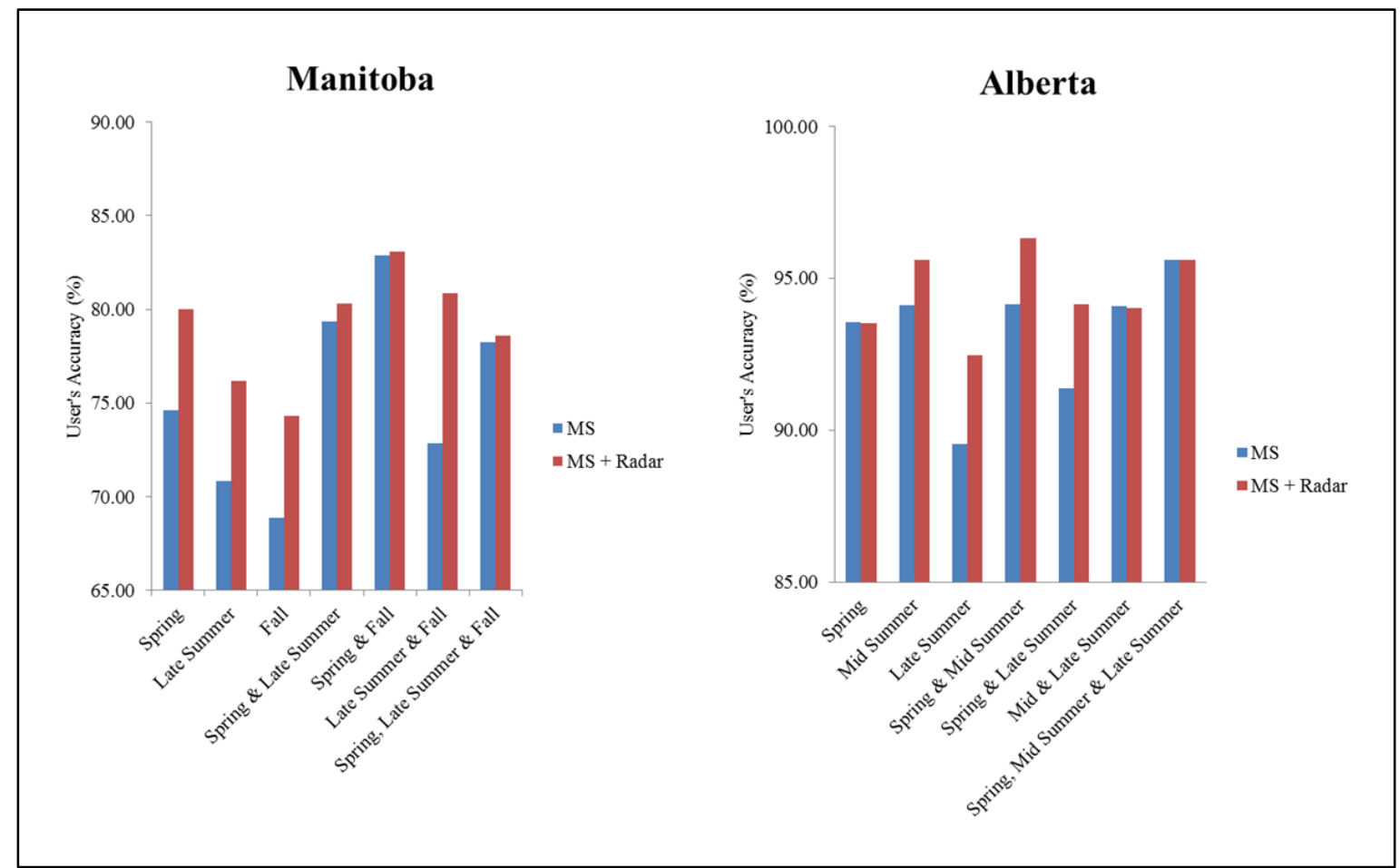

Figure 4.6. Rangeland classification accuracy (UA) with the addition of mid-summer radar to multi-spectral variables. 


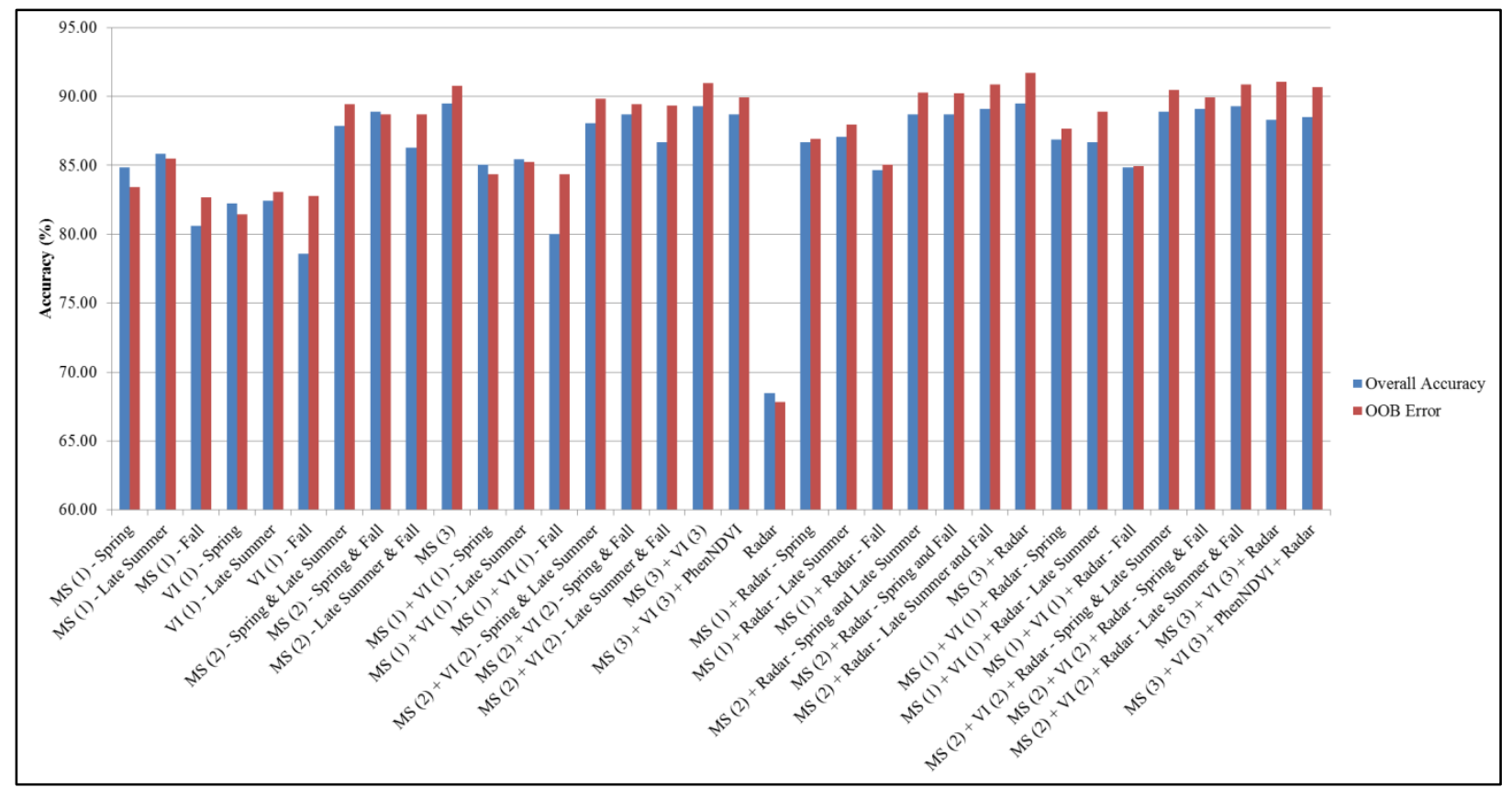

Figure 4.7. Independent overall accuracy (OA) and RF OOB error for Manitoba classification models.

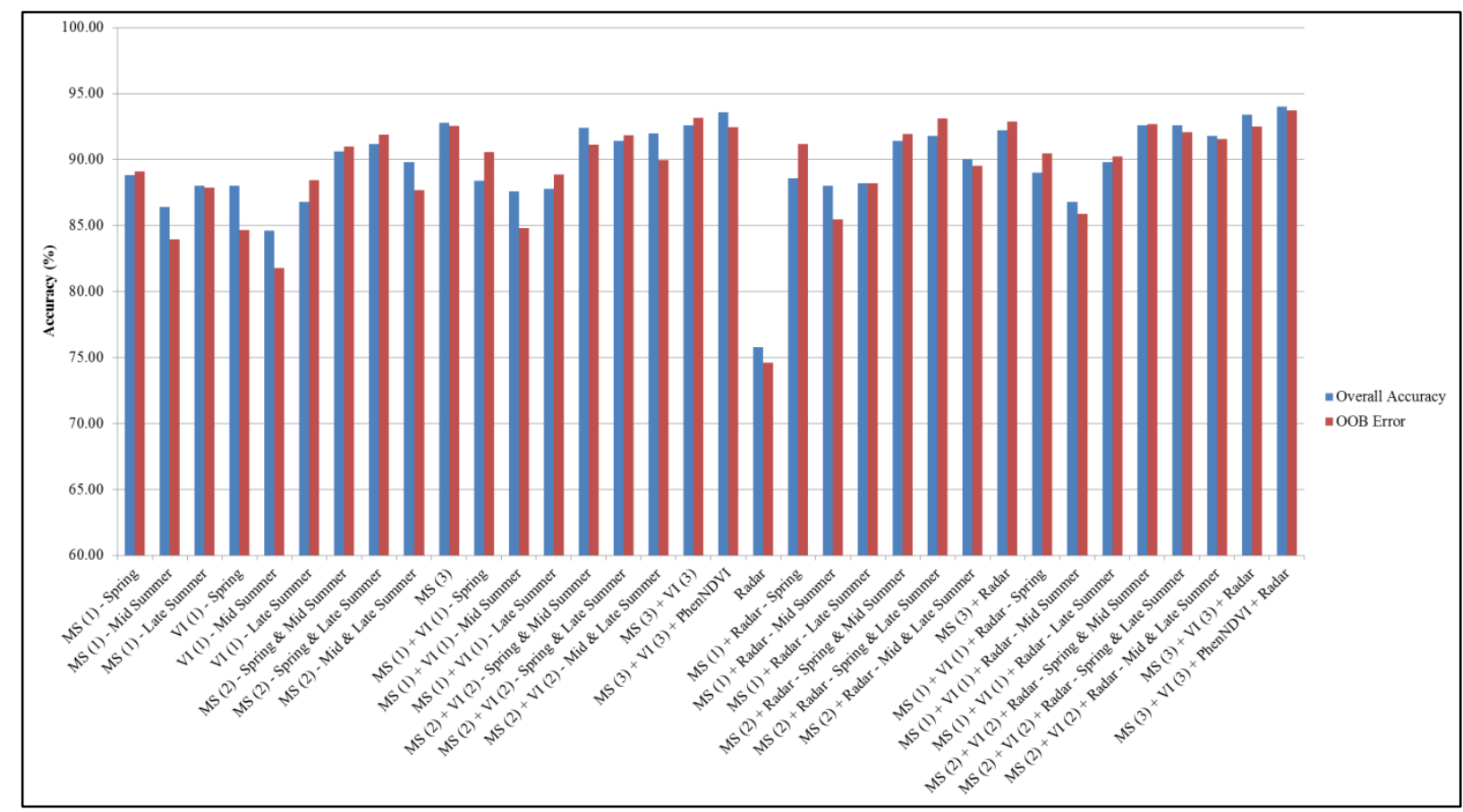

Figure 4.8. Independent overall accuracy $(O A)$ and $R F$ OOB error for Alberta classification models. 

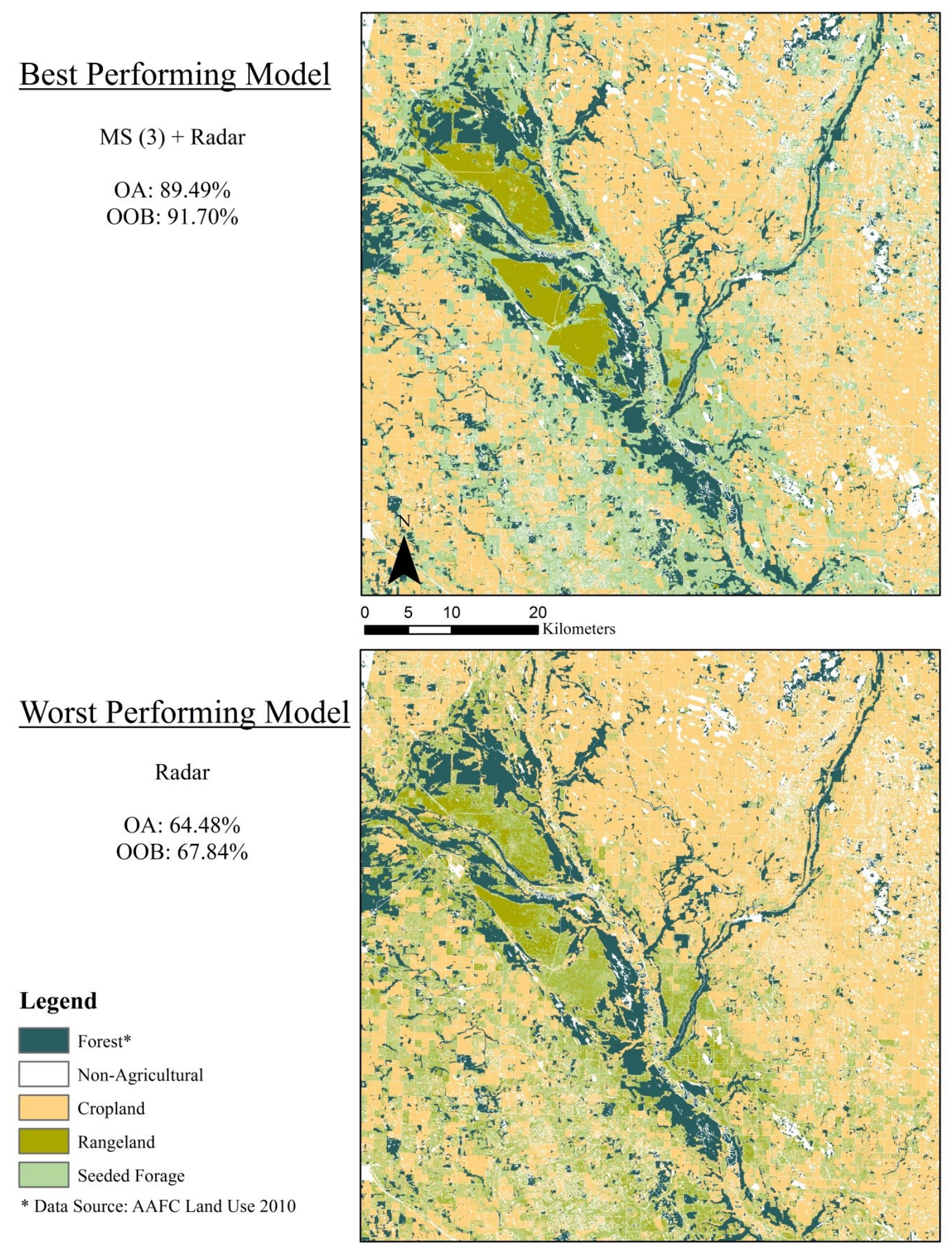

Figure 4.9. Maps of best and worst performing classification models for the Manitoba study area. 


\section{Best Performing Model}

MS (3) + VI (3) + PhenNDVI + Radar

OA: $94.00 \%$

OOB: $93.73 \%$

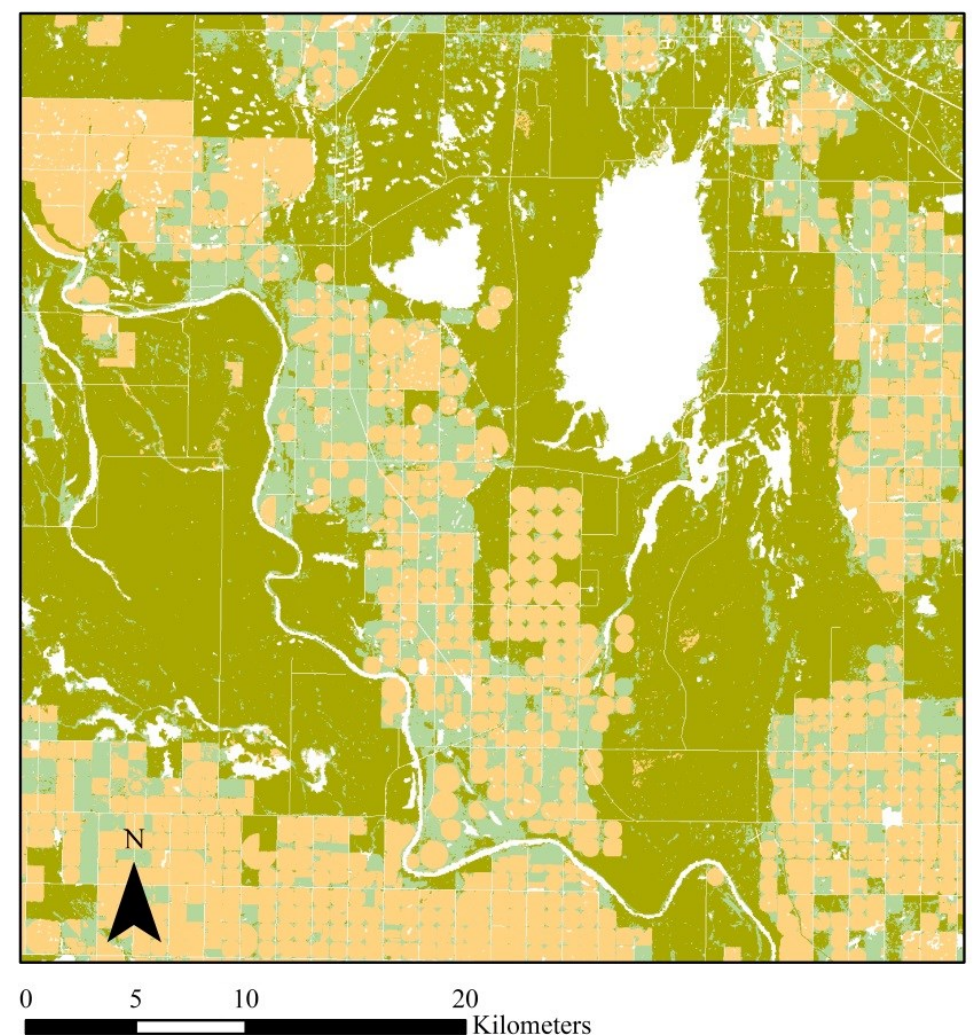

\section{Worst Performing Model}

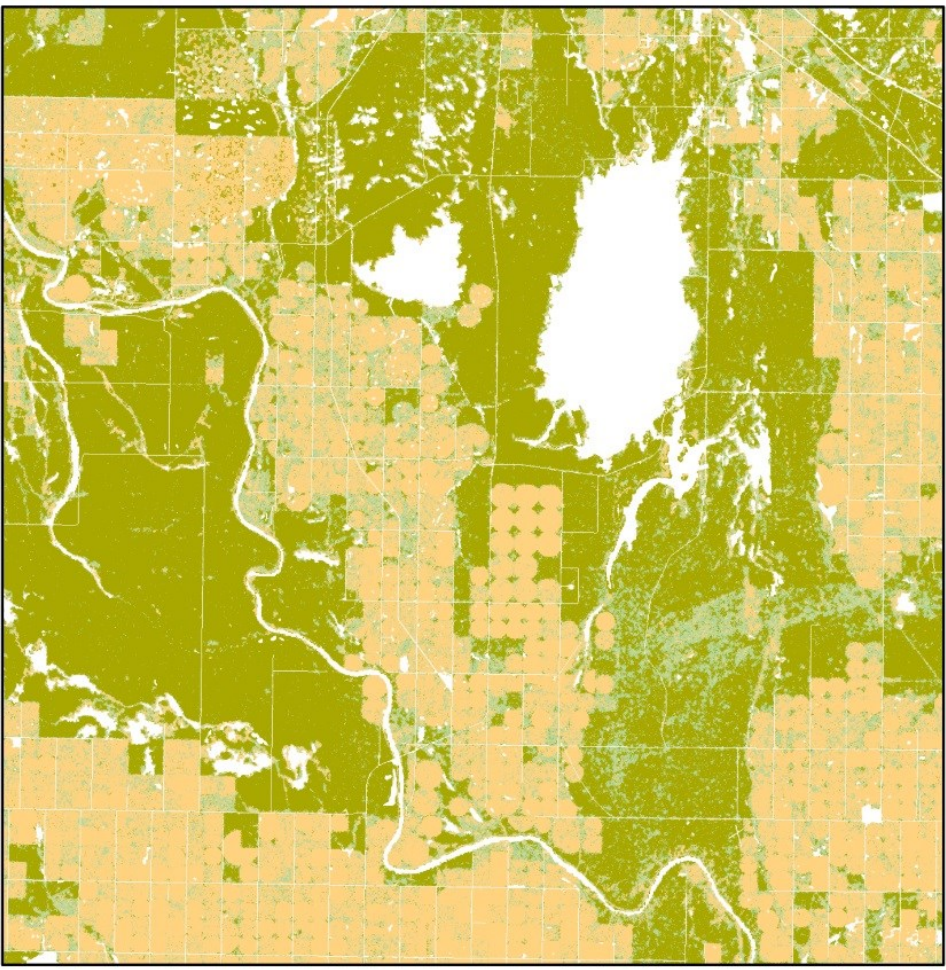

\section{Legend}

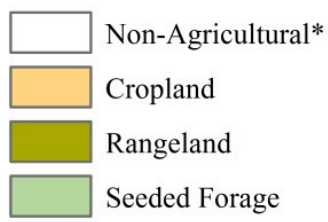

* Data Source: AAFC Land Use 2010

OA: $75.80 \%$

OOB: $74.62 \%$

Figure 4.10. Maps of best and worst performing classification models for the Manitoba study area. 


\subsection{Evaluation of RF Variable Importance}

The mean decrease in accuracy (MDA) statistic was used to rank the variables by importance for both study areas. Variable importance was fairly stable across the 50 iterations of RF for both study areas. Variables with lesser importance were less stable than variables with a high importance. From the 40 variables (MS, VI, PhenNDVI, and Radar) the top 20 were organized by ranking as shown in Table 4.9 (Manitoba) and Figure 4.11 (Alberta). An example of the variable importance (MDA) ranking for the 40 variables (a single iteration of RF) is shown in Appendix D. After the variables were ranked by importance, lower ranked variables in a variable pair that was significantly correlated $(\mathrm{r} \geq 0.80)$ were removed. The correlation tables, along with the associated significance levels are shown in Appendix E. Table 4.10 shows the top eight variables for the Manitoba study area, as well as the variables correlated with each of these. Table 4.12 shows the top eight variables for the Alberta study area as well as their associated correlated variables. The Radar variables ranked at the top for Manitoba, while the spring optical variables (MS and VI) were ranked as the most important of the Alberta variables. Overlapping among the top 8 variables for each study area were the NDVI CoV, spring shortwave infrared (SWIR2) and near-infrared (NIR), and mid-summer Radar backscatter. A classified map of the rangeland and seeded forage resources for each study area using the top eight important and uncorrelated variables is shown in Figure 4.11 (Manitoba) and Figure 4.12 (Alberta). The main errors found in Figure 12 were small areas within areas classified as rangeland which were misclassified as seeded forage. It is unlikely that small irregular-shaped features are seeded forage stands within an existing stand of rangeland. These areas are edges of riparian zones, 
where vegetation is greener and would be easily removed by placing a buffer around water bodies, as riparian vegetation is often protected from grazing and is non-agricultural land. 
Table 4.9. Top 20 variables ranked by importance across 50 RF iterations for Manitoba. An $x$ in the correlation column signifies a higher ranking variable is significantly correlated $(r \geq 0.8)$.

\begin{tabular}{|c|c|c|c|c|c|c|c|c|c|c|c|c|c|c|c|c|c|c|c|c|c|c|c|}
\hline \multirow{2}{*}{$\begin{array}{c}\text { Variable } \\
\text { Importance } \\
\text { Ranking }\end{array}$} & \multirow{2}{*}{$\begin{array}{c}\text { Variable } \\
\text { Group }\end{array}$} & \multirow[b]{2}{*}{ Variable Name } & \multirow{2}{*}{$\begin{array}{l}\text { Correlation } \\
\text { (Spearman) }\end{array}$} & \multicolumn{20}{|c|}{ Variable Importance Ranking (50 iterations) } \\
\hline & & & & 1 & 2 & 3 & 4 & 5 & 6 & 7 & 8 & 9 & 10 & 11 & 12 & 13 & 14 & 15 & 16 & 17 & 18 & & 20 \\
\hline 1 & Radar & RS2 VH & & 50 & 0 & 0 & 0 & 0 & 0 & 0 & 0 & 0 & 0 & 0 & 0 & 0 & 0 & 0 & 0 & 0 & 0 & 0 & \\
\hline 2 & Radar & RS2 VV & $\mathrm{X}$ & & 50 & 0 & 0 & 0 & 0 & 0 & 0 & 0 & 0 & 0 & 0 & 0 & 0 & 0 & 0 & 0 & 0 & 0 & \\
\hline 3 & MS & SWIR2 - d147 & & 0 & 0 & 28 & 18 & 4 & 0 & 0 & 0 & 0 & 0 & 0 & 0 & 0 & 0 & 0 & 0 & 0 & 0 & 0 & \\
\hline 4 & VI & SATVI - d147 & $\mathrm{X}$ & 0 & 0 & 19 & 23 & 8 & 0 & 0 & 0 & 0 & 0 & 0 & 0 & 0 & 0 & 0 & 0 & 0 & 0 & 0 & \\
\hline 5 & VI & NDVI - d291 & & 0 & 0 & 3 & 9 & 38 & 0 & 0 & 0 & 0 & 0 & 0 & 0 & 0 & 0 & 0 & 0 & 0 & 0 & 0 & \\
\hline 6 & VI & TCW - d147 & $\mathrm{X}$ & 0 & 0 & 0 & 0 & 0 & 44 & 6 & 0 & 0 & 0 & 0 & 0 & 0 & 0 & 0 & 0 & 0 & 0 & 0 & \\
\hline 7 & MS & NIR - d147 & & 0 & 0 & 0 & 0 & 0 & 6 & 29 & 10 & 3 & 2 & 0 & 0 & 0 & 0 & 0 & 0 & 0 & 0 & 0 & \\
\hline 8 & MS & Red - d243 & & 0 & 0 & 0 & 0 & 0 & 0 & 9 & 20 & 11 & 5 & 4 & 0 & 1 & 0 & 0 & 0 & 0 & 0 & 0 & \\
\hline 9 & MS & Red - d291 & & 0 & 0 & 0 & 0 & 0 & 0 & 5 & 6 & 14 & 13 & 10 & 2 & 0 & 0 & 0 & 0 & 0 & 0 & 0 & \\
\hline 10 & PhenNDVI & NDVI CoV & & 0 & 0 & 0 & 0 & 0 & 0 & 1 & 7 & 10 & 14 & 10 & 6 & 2 & 0 & 0 & 0 & 0 & 0 & 0 & \\
\hline 11 & MS & Blue - d291 & $\mathrm{X}$ & 0 & 0 & 0 & 0 & 0 & 0 & 0 & 5 & 10 & 9 & 14 & 5 & 6 & 1 & 0 & 0 & 0 & 0 & 0 & \\
\hline 12 & VI & NDVI - d147 & $\mathrm{X}$ & 0 & 0 & 0 & 0 & 0 & 0 & 0 & 1 & 1 & 4 & 7 & 18 & 13 & 6 & 0 & 0 & 0 & 0 & 0 & \\
\hline 13 & PhenNDVI & NDVI Min & $\mathrm{X}$ & 0 & 0 & 0 & 0 & 0 & 0 & 0 & 1 & 1 & 3 & 5 & 15 & 16 & 5 & 2 & 1 & 0 & 1 & 0 & \\
\hline 14 & MS & NIR - d291 & $\mathrm{X}$ & 0 & 0 & 0 & 0 & 0 & 0 & 0 & 0 & 0 & 0 & 0 & 3 & 4 & 13 & 13 & 9 & 5 & 0 & 1 & \\
\hline 15 & & Blue & $\mathrm{X}$ & 0 & 0 & 0 & 0 & 0 & 0 & 0 & 0 & 0 & 0 & 0 & 0 & 3 & 9 & 10 & 3 & 8 & 9 & 4 & \\
\hline 16 & VI & NDVI - d243 & $\mathrm{X}$ & 0 & 0 & 0 & 0 & 0 & 0 & 0 & 0 & 0 & 0 & 0 & 0 & 0 & 3 & 7 & 14 & 11 & 6 & 3 & \\
\hline 17 & VI & SATVI - d291 & & 0 & 0 & 0 & 0 & 0 & 0 & 0 & 0 & 0 & 0 & 0 & 1 & 1 & 4 & 6 & 11 & 11 & 5 & 4 & \\
\hline 18 & MS & IR2 - d291 & $\mathrm{X}$ & 0 & 0 & 0 & 0 & 0 & 0 & 0 & 0 & 0 & 0 & 0 & 0 & 4 & 9 & 9 & 6 & 5 & 14 & 0 & \\
\hline 19 & henNDVI & NDVI Mean & $\mathrm{X}$ & 0 & 0 & 0 & 0 & 0 & 0 & 0 & 0 & 0 & 0 & 0 & 0 & 0 & 0 & 0 & 4 & 3 & 3 & 9 & 10 \\
\hline 20 & PhenNDVI & NDVI Max & $X$ & 0 & 0 & 0 & 0 & 0 & 0 & 0 & 0 & 0 & 0 & 0 & 0 & 0 & 0 & 1 & 0 & 7 & 6 & 7 & \\
\hline
\end{tabular}

Table 4.10. Top 8 Manitoba variables by rank and strongly correlated variables $(r \geq 0.8)$

\begin{tabular}{|c|c|c|l|}
\hline Rank & $\begin{array}{c}\text { Variable } \\
\text { Group }\end{array}$ & Variable Name & \multicolumn{1}{|c|}{ Correlated Variables } \\
\hline 1 & Radar & RS2 VH & RS2 VV \\
2 & MS & SWIR2 - d147 & NDVI - d147; SATVI - d147; TCW - d147; NDVI Max \\
3 & VI & NDVI - d291 & NIR - d291 \\
4 & MS & NIR - d147 & \\
5 & MS & R - d243 & B - d243; G - d243; SWIR2 - d243; SATVI - d243 \\
6 & MS & R - d291 & B - d291; G - d291 \\
7 & PhenNDVI & NDVI CoV & NIR - d243; NDVI - d243; NDVI Mean; NDVI Min \\
8 & VI & SATVI - d291 & SWIR - d291; TCW - d291 \\
\hline
\end{tabular}


Table 4.11. Chart depicting top 20 variables ranked by importance across 50 iterations of RF for Alberta. An $x$ in the correlation column signifies a higher ranking variable is significantly correlated $(r \geq 0.80)$.

\begin{tabular}{|c|c|c|c|c|c|c|c|c|c|c|c|c|c|c|c|c|c|c|c|c|c|c|}
\hline \multirow{2}{*}{$\begin{array}{c}\text { Variable } \\
\text { Importance } \\
\text { Ranking } \\
\end{array}$} & \multirow{2}{*}{$\begin{array}{l}\text { Variable } \\
\text { Group }\end{array}$} & \multirow[b]{2}{*}{ Variable Name } & \multirow{2}{*}{$\begin{array}{l}\text { Correlation } \\
\text { (Spearman) }\end{array}$} & \multicolumn{19}{|c|}{ Variable Importance Ranking (50 iterations) } \\
\hline & & & & 1 & 2 & 3 & 4 & 5 & 6 & 7 & 8 & 9 & 10 & 111 & 12 & 13 & 14 & 15 & 161 & 17 & 181 & 1920 \\
\hline 1 & PhenNDVI & NDVI Min & & 32 & 18 & 0 & 0 & 0 & 0 & 0 & 0 & 0 & 0 & 0 & 0 & 0 & 0 & 0 & 0 & 0 & 0 & $\begin{array}{ll}0 & 0\end{array}$ \\
\hline 2 & VI & NDVI - d139 & $\mathrm{X}$ & 18 & 31 & 1 & 0 & 0 & 0 & 0 & 0 & 0 & 0 & 0 & 0 & 0 & 0 & 0 & 0 & 0 & 0 & 0 \\
\hline 3 & PhenNDVI & NDVI CoV & & 0 & 1 & 49 & 0 & 0 & 0 & 0 & 0 & 0 & 0 & 0 & 0 & 0 & 0 & 0 & 0 & 0 & 0 & 0 \\
\hline 4 & $\mathrm{~N}$ & NIR - d139 & & 0 & 0 & & 28 & 11 & 4 & 4 & 2 & 1 & 0 & 0 & 0 & 0 & 0 & 0 & 0 & 0 & 0 & 0 \\
\hline 5 & $\mathrm{~N}$ & SWIR & & 0 & 0 & 0 & 7 & 16 & 14 & 7 & 4 & 2 & 0 & 0 & 0 & 0 & 0 & 0 & 0 & 0 & 0 & 0 \\
\hline 6 & VI & SATVI & $\mathrm{X}$ & 0 & 0 & 0 & 6 & 11 & 10 & 9 & 10 & 4 & 0 & 0 & 0 & 0 & 0 & 0 & 0 & 0 & 0 & 0 \\
\hline 7 & VI & TCW - d139 & & 0 & 0 & 0 & 5 & 5 & 8 & 15 & 7 & 6 & 3 & 1 & 0 & 0 & 0 & 0 & 0 & 0 & 0 & 0 \\
\hline 8 & VI & NDSVI - d235 & & 0 & 0 & 0 & 1 & 6 & 9 & 8 & 19 & 7 & 0 & 0 & 0 & 0 & 0 & 0 & 0 & 0 & 0 & 0 \\
\hline 9 & MS & Blue - & $\mathrm{X}$ & 0 & 0 & 0 & 3 & 1 & 4 & 7 & & 20 & 6 & 1 & 1 & 0 & 0 & 0 & 0 & 0 & 0 & 0 \\
\hline 10 & Radar & RS2 VV & & 0 & 0 & 0 & 0 & 0 & 1 & 0 & 1 & & 23 & 10 & 7 & 4 & 0 & 0 & 0 & 0 & 0 & 0 \\
\hline 11 & MS & Red - d235 & & 0 & 0 & 0 & 0 & 0 & 0 & 0 & 0 & 4 & 11 & 26 & 9 & 0 & 0 & 0 & 0 & 0 & 0 & 0 \\
\hline 12 & Radar & RS2 VH & $\mathrm{X}$ & 0 & 0 & 0 & 0 & 0 & 0 & 0 & 0 & 2 & 7 & 112 & 23 & 6 & 0 & 0 & 1 & 0 & 0 & 0 \\
\hline 13 & PhenNDVI & & & 0 & 0 & 0 & 0 & 0 & 0 & 0 & 0 & 0 & 0 & 1 & & 22 & 17 & 3 & 2 & 0 & 0 & 0 \\
\hline 14 & MS & Green - d235 & $\mathrm{X}$ & 0 & 0 & 0 & 0 & 0 & 0 & 0 & 0 & 0 & 0 & 0 & & 10 & 14 & 16 & 7 & 0 & 0 & 0 \\
\hline 15 & VI & NDVI - d235 & & 0 & 0 & 0 & 0 & 0 & 0 & 0 & 0 & 0 & 0 & 0 & 0 & 4 & 5 & 15 & 14 & 6 & 3 & 0 \\
\hline 16 & PhenNDVI & NDVI & & 0 & 0 & 0 & 0 & 0 & 0 & 0 & 0 & 0 & 0 & 0 & 1 & 4 & 8 & 7 & 11 & 17 & 1 & \\
\hline 17 & MS & NIR - d235 & $\mathrm{X}$ & 0 & 0 & 0 & 0 & 0 & 0 & 0 & 0 & 0 & 0 & 0 & 0 & 0 & 0 & 0 & 3 & & 11 & 911 \\
\hline 18 & MS & Red - d139 & $\mathrm{X}$ & 0 & 0 & 0 & 0 & 0 & 0 & 0 & 0 & 0 & 0 & 0 & 0 & 0 & 2 & 1 & 3 & & & 116 \\
\hline 19 & MS & Blue - d235 & $\mathrm{X}$ & 0 & 0 & 0 & 0 & 0 & 0 & 0 & 0 & 0 & 0 & 0 & 0 & 0 & 0 & 0 & 2 & & 12 & 911 \\
\hline 20 & MS & SWIR1 - d235 & & 0 & 0 & 0 & 0 & 0 & 0 & 0 & 0 & 0 & 0 & 0 & 0 & 0 & 0 & 0 & 0 & & 0 & $\begin{array}{ll}18 \\
\end{array}$ \\
\hline
\end{tabular}

Table 4.12. Top 8 AB variables by rank and correlated variables $(r \geq 0.80)$

\begin{tabular}{|c|c|c|ll|}
\hline Rank & $\begin{array}{c}\text { Variable } \\
\text { Group }\end{array}$ & Variable Name & \multicolumn{1}{|c|}{ Correlated Variables } \\
\hline 1 & PhenNDVI & NDVI Min & NDVI - d139 \\
2 & PhenNDVI & NDVI CoV & NDVI SD; NDVI Diff L-M \\
3 & MS & NIR - d139 & \\
4 & MS & SWIR2 - d139 & B - d139; G - d139; R - d139; SWIR1 - d139; SATVI - d139; TCW - d139 \\
5 & VI & TCW - d139 & G - d139; R - d139; SWIR1 - d139; SWIR2 - d139; NDVI - d139; SATVI - d139 \\
6 & VI & NDSVI - d235 & \\
7 & Radar & RS2 VV & RS2 VH \\
8 & MS & R - d235 & B - d235; G - d235 \\
\hline
\end{tabular}


The accuracy statistics, including overall accuracy, class-based users' and producers' accuracy (UA and PA), and RF OOB error are presented in Table 4.13 for the Manitoba study area and Table 4.14 for the Alberta study area. For the Manitoba study area, only the top 4 variables are required to achieve a similar accuracy as using all 40 variables (McNemar's test; Appendix C). When the $4^{\text {th }}$ variable was removed from the classifier, accuracy dropped significantly. For Manitoba the top 4 variables included RS2 (VH), SWIR (d147), NDVI (d291), and NIR (d147).

For the Alberta study area, the top 5 variables by importance and correlation achieved a statistically similar accuracy result as using all 40 variables according to the McNemar's test results in Appendix C. In other words, after the $5^{\text {th }}$ variable was removed from the classification, accuracy results were significantly statistically different when compared to the classification using all 40 variables. The top 5 variables include NDVI Min, NDVI CoV, NIR (d139), SWIR2 (d139), and TCW (d139). The differences in the top variables are indicative of the geographic differences between the target classes, and highlight the regional variability (species composition, management) of rangeland and seeded forage in Canada. 
Table 4.13. Accuracy Statistics for Manitoba RF Variable Reduction Method

\begin{tabular}{|c|c|c|c|c|c|c|c|c|c|c|}
\hline $\begin{array}{l}\text { Number of } \\
\text { Variables }\end{array}$ & $\begin{array}{c}\text { Overall } \\
\text { Accuracy }\end{array}$ & $\begin{array}{c}\text { Cropland } \\
\text { PA }\end{array}$ & $\begin{array}{c}\text { Cropland } \\
\text { UA }\end{array}$ & $\begin{array}{c}\text { Rangeland } \\
\text { PA }\end{array}$ & $\begin{array}{c}\text { Rangeland } \\
\text { UA }\end{array}$ & $\begin{array}{c}\text { Seeded } \\
\text { Forage } \\
\text { PA }\end{array}$ & $\begin{array}{c}\text { Seeded } \\
\text { Forage } \\
\text { UA }\end{array}$ & $\begin{array}{l}\text { OOB } \\
\text { Error }\end{array}$ & $\begin{array}{c}\text { Difference } \\
\text { in Error } \\
(\mathrm{OA} \mathrm{-} \\
\text { OOB })\end{array}$ & $\begin{array}{l}\text { Cohen's } \\
\text { Kappa }\end{array}$ \\
\hline 40 & 88.48 & 98.48 & 97.37 & 60.47 & 80.00 & 86.99 & 77.44 & 90.66 & -2.18 & 0.81 \\
\hline 8 & 87.80 & 98.48 & 98.48 & 62.79 & 76.06 & 86.30 & 78.26 & 90.88 & -3.08 & 0.81 \\
\hline 7 & 88.48 & 98.48 & 98.48 & 61.63 & 74.65 & 86.30 & 78.26 & 90.77 & -2.29 & 0.81 \\
\hline 6 & 88.28 & 97.72 & 98.09 & 62.79 & 77.14 & 86.30 & 77.30 & 90.66 & -2.38 & 0.80 \\
\hline 5 & 87.20 & 97.34 & 98.08 & 61.63 & 76.81 & 86.99 & 76.97 & 90.46 & -3.26 & 0.79 \\
\hline 4 & 86.40 & 96.58 & 96.58 & 62.79 & 77.14 & 84.93 & 76.54 & 89.21 & -2.81 & 0.78 \\
\hline $3 *$ & 85.86 & 96.20 & 96.56 & 59.30 & 70.83 & 82.88 & 75.16 & 87.66 & -1.80 & 0.76 \\
\hline $2^{*}$ & 80.80 & 95.82 & 94.74 & 60.47 & 59.77 & 68.49 & 70.42 & 80.39 & 0.41 & 0.68 \\
\hline
\end{tabular}

Note; * significantly different $(p \leq 0.05)$ than the classification using all 40 variables.

Table 4.14. Accuracy Statistics for Alberta RF Variable Reduction Method.

\begin{tabular}{|c|c|c|c|c|c|c|c|c|c|c|}
\hline $\begin{array}{c}\text { Number of } \\
\text { Variables }\end{array}$ & $\begin{array}{c}\text { Overall } \\
\text { Accuracy }\end{array}$ & $\begin{array}{c}\text { Cropland } \\
\text { PA }\end{array}$ & $\begin{array}{c}\text { Cropland } \\
\text { UA }\end{array}$ & $\begin{array}{c}\text { Rangeland } \\
\text { PA }\end{array}$ & $\begin{array}{c}\text { Rangeland } \\
\text { UA }\end{array}$ & $\begin{array}{l}\text { Seeded } \\
\text { Forage } \\
\text { PA }\end{array}$ & $\begin{array}{l}\text { Seeded } \\
\text { Forage } \\
\text { UA }\end{array}$ & $\begin{array}{l}\text { OOB } \\
\text { Error }\end{array}$ & $\begin{array}{c}\text { Difference } \\
\text { in Error } \\
(\mathrm{OA}- \\
\mathrm{OOB})\end{array}$ & $\begin{array}{l}\text { Cohen's } \\
\text { Kappa }\end{array}$ \\
\hline 40 & 94.00 & 97.97 & 96.02 & 91.67 & 96.35 & 88.18 & 86.61 & 93.73 & 0.27 & 0.90 \\
\hline 8 & 93.20 & 97.56 & 96.39 & 89.58 & 95.56 & 88.18 & 83.62 & 92.70 & 0.50 & 0.89 \\
\hline 7 & 93.60 & 97.56 & 96.00 & 90.28 & 96.30 & 89.09 & 85.22 & 92.30 & 1.30 & 0.90 \\
\hline 6 & 93.2 & 97.15 & 95.60 & 89.58 & 95.56 & 89.09 & 85.22 & 91.97 & 1.23 & 0.89 \\
\hline 5 & 92.80 & 96.34 & 95.56 & 89.58 & 94.85 & 89.09 & 84.48 & 91.34 & 1.46 & 0.89 \\
\hline $4^{*}$ & 91.60 & 96.34 & 94.80 & 87.50 & 92.65 & 86.36 & 83.33 & 90.19 & 1.41 & 0.87 \\
\hline $3 *$ & 88.80 & 94.31 & 93.93 & 85.42 & 85.42 & 80.91 & 81.65 & 87.45 & 1.35 & 0.82 \\
\hline $2^{*}$ & 80.40 & 87.80 & 92.31 & 77.08 & 68.10 & 68.18 & 72.82 & 79.65 & 0.75 & 0.69 \\
\hline
\end{tabular}

Note; * significantly different $(p \leq 0.05)$ than the classification using all 40 variables. 


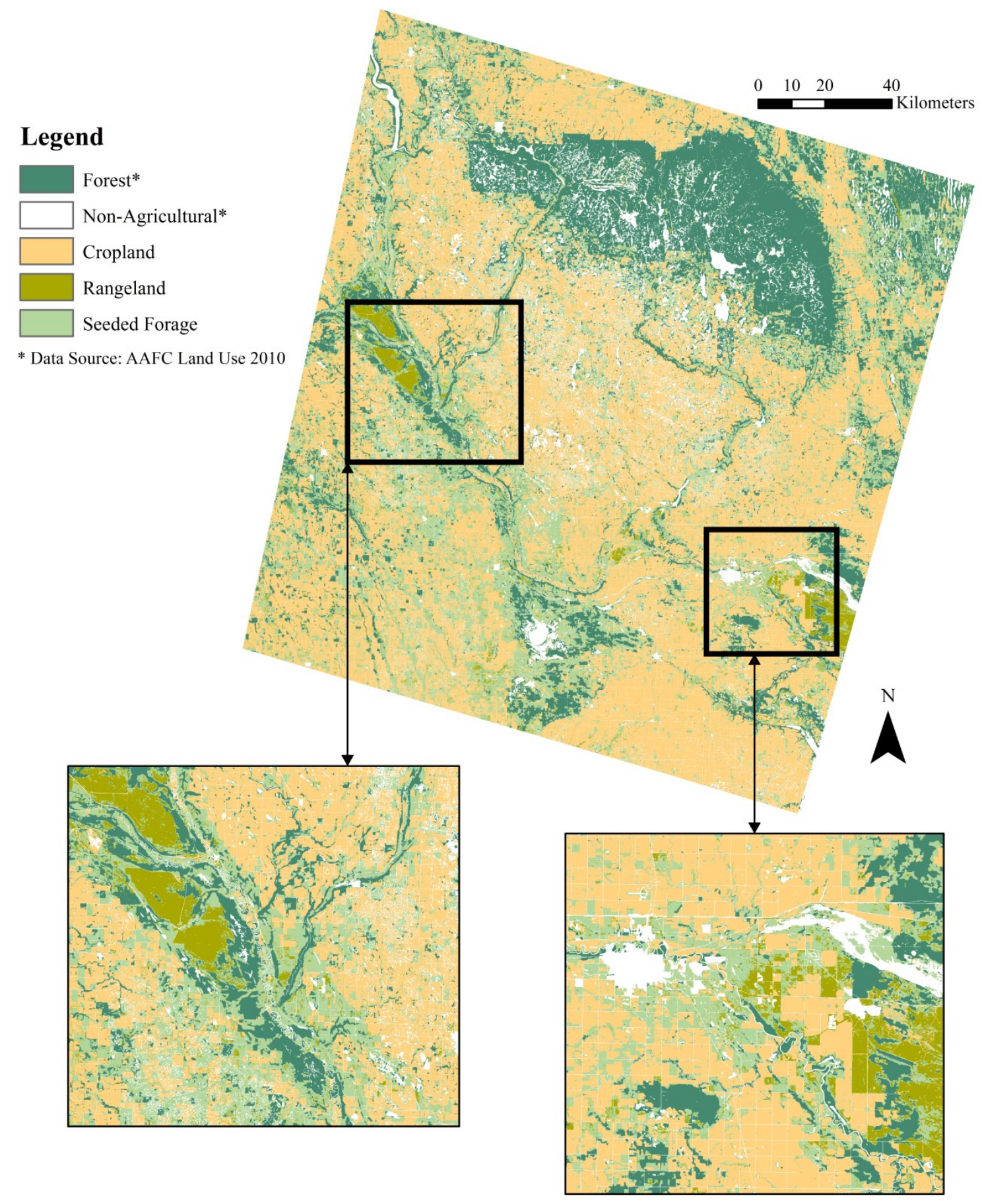

Figure 4.11. Classified map using top 8 important/uncorrelated variables for Manitoba. 


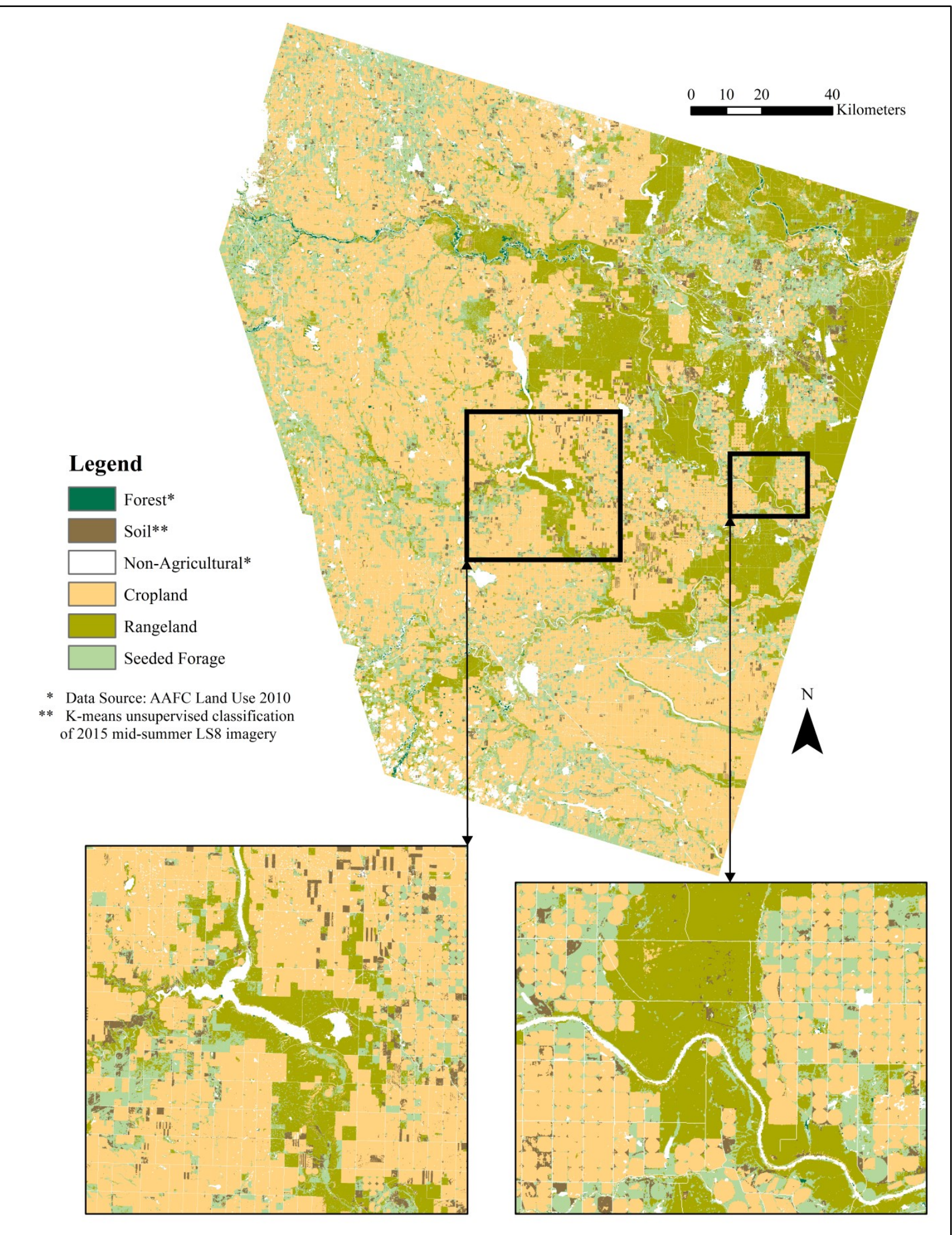

Figure 4.12. Classified map using top 8 important/uncorrelated variables for Alberta. 


\section{Chapter 5: Discussion}

Chapter 5 summarizes the key findings of this research and discusses the research outcomes in relation to the literature and research objectives. This chapter also summarizes the limitations of this research, followed by recommendations for future work in this study area.

\subsection{Discussion of Results}

The following section is a discussion of the results presented in Chapter 4, as they relate to the overall objectives outlined in Chapter 1.

\subsubsection{Random Forest Classification}

Of the single-date MS classifications, the spring date (d139) had the highest classification accuracy for the Alberta study area, followed closely by the late-summer (d235) MS image. The Manitoba data produced similar results, with the late-summer (d243) MS narrowly outperforming the spring image date (d147). The importance of these two acquisition periods is indicative of the phenological differences between the three classes. During the spring, rangeland and seeded forage are covered with photosynthetically active vegetation, while cropland is covered with bare soil or dead vegetation residue from the previous growing season. Late summer is another key phenological period for the growth season of grass species for both sites, as non-native seeded forage species $\left(\mathrm{C}_{3}\right)$ are more photosynthetically active in the warmer months of summer, while native $\left(\mathrm{C}_{4}\right)$ species are dormant (Volesky et al., 2003). Of the two-date MS classifications, the highest performing combination of dates (based on OA and OOB error) for Alberta was the spring and late-summer acquisitions. For the Manitoba study area, the spring and fall images performed best based on OA, however the spring and late-summer classification performed best when OOB error is considered. It is significant to note that when a third date of MS variables are added to the classification, the independent classification accuracy was 
improved to a significant degree, except when the late summer image (three-date) was added to the spring and fall MS (two-date) classification for the Manitoba study site. The random forest classifier is well suited to handling high dimensional and multi-source datasets (Breiman, 2001). For this reason, this study proves that it is better to include too much information than not enough, if processing power and time are not a significant constraint.

The producer's accuracy (PA) was significantly lower than UA for the Manitoba study area. This may be due to issues with the classification definitions in this region. A lower PA than UA means that reference data were not correctly classified and therefore there may be human errors in the reference dataset. The Manitoba study area was unique because there were a large number of sites in the reference data which were of Rangeland Subclass b) "Upland non-native grassland and reverted pasture." Manitoba had more fields which fell under this subclass than Alberta, because land abandonment and reverting to pasture from cropland is more common. This class was very hard to differentiate from seeded forage using the data collection methods required to survey such a large study area and may have been incorrectly classified from the road. Reverted pasture is abandoned pasture or agricultural land which has once been tilled, but has been reverted to grass and legume species through natural means over time, or by intentional seeding. Upland non-native grassland is considered land which has been invaded by non-native species. Although this subclass was within the rangeland class for this study, the transitional nature of this class, as well as the complex species composition makes it difficult to classify correctly, from both a remote sensing and an ecological perspective. Perhaps in future studies this class should be included in the seeded forage class as non-native (tame) species are present, or isolated as its own class. 
Vegetation indices did not perform significantly better as a substitute for MS data, and are computationally intensive. However, the addition of VI variables to the MS variables did yield an increase in OOB error, but not in OA for both study sites. When the error matrices were compared using the McNemar's test, the independent error differences between the comparing image dates were not significant. When the additional optical variables (VI and PhenNDVI) were added to the three-date MS classification, the classification accuracy was not significantly improved or decreased. The MS variables (B, G, R, NIR, SWIR1 \& SWIR2) captured all of the variability necessary for the RF classifier to perform.

Mid-summer RS2 did not perform well as a stand-alone data source in the RF classifier, however when it was added to the optical data, it significantly increased accuracy at the Manitoba study site when it was added to single and two-date MS classifications. No significant accuracy increase was achieved for the Alberta study area. The impact of the addition radar on classification performance in the Manitoba study area may be due to the area's higher moisture inputs. Climate Normals (1981-2010) indicate that on average Lethbridge, AB receives two thirds of the amount of rainfall that Brandon receives annually (Environment and Climate Change Canada, 2014). Radar alone did well at differentiating rangeland from forage and cropland; however, it performed poorly for the seeded forage and cropland classes for both study areas. The mid-summer acquisition date was a limitation of this study, and future research on additional acquisition dates for the Wide beam mode should be performed before ruling out this data source for rangeland and forage classification. Just as optical image acquisition has shown to be important in this study, the structural differences (backscatter) between rangeland and forage could be better captured at the beginning or end of the growing season. The results of this research support the results acquired by Smith \& Buckley (2010), who used finer resolution 
quad-polarized C-band RADARSAT-2 imagery to distinguish between rangeland and cultivated cropland. However, they also found that RS2 performed poorly at distinguishing rangeland from improved grassland when compared to optical imagery. This study used In addition, two speckle filters were compared for use in this study (Appendix A) and showed an improvement over unfiltered RS2 data; however it may be useful to explore additional speckle filters as they become available. Overall, cloud cover is a significant limiting factor for optical imagery, and this research shows there is some benefit of using single-pol (VV and VH) Wide beam mode RS2 imagery for large study areas when two or less cloud-free optical images are available, given RS2 imagery can be acquired (and not rejected for other prioritized clients) for the required times.

Random forest was the only classifier tested in this study. This is because it can be used to evaluate a large number of input variables, does not require parametric data, is known to outperform many other classifiers, and it has simple parameterization. OOB error (internal estimate of the RF algorithm) is closely correlated to the independent accuracy rates derived from the independent test set. To conduct an independent accuracy assessment, typically $1 / 3$ of the reference data must be left out of the classification. Because the difference between RF OOB error and the independent overall accuracy was very small in all iterations of the classification, this supports the idea that OOB error could be substituted for an independent accuracy test in future research when methods are being tested and compared (Breiman, 2001). In addition to efficiency, another benefit is the $1 / 3$ of reference data which is typically withheld from the classifier can contribute to training the algorithm. 


\subsubsection{Variable Reduction Model}

This research determined that when using the RF classifier, very few variables can be used to achieve similar accuracy as using many multi-source variables. Overall accuracy was not significantly lower for the Manitoba area until only 3 variables were used. The most important variable for the Manitoba study area was a RS2 variable, but radar variables were of less importance at the Alberta study area. Because the rangeland and forage classes had less spectral separability at the Manitoba area, perhaps the structural sensitivity of RS2 backscatter is a better determinant than optical reflectance based variables in the parkland ecoregion. Of the optical multispectral variables, the spring SWIR2 (d147) was ranked second and the spring NIR (d149) was ranked fourth. These results show the importance of spring optical imagery for classifying rangeland and seeded forage, especially for information on the moisture content of soil and vegetation during this early period of the growing season. Of the VI variables, the only variable which ranked among the top 4 was fall NDVI (d291). One interpretation of this result is that similar to the beginning of the growing season, the photosynthetic activity of the dominant vegetation in rangeland and forage land cover classes during the end of the growing season are also different. This corresponds to the knowledge of phenological growth differences between tame and native grasses at the beginning and end of the growing season in the Canadian prairie region (Volesky et al., 2003).

As was previously mentioned, for the Alberta study area, RS2 variables did not make the top five needed to obtain an overall accuracy that was not statistically lower than using all 40 variables; however they were among the top eight most important and uncorrelated variables. The top two variables were both PhenNDVI variables derived from the time series of NDVI images. Of these, the most important was minimum NDVI (NDVI Min), which was highly 
correlated to Spring NDVI (d139). The CoV of NDVI during the growing season ranked second. As the results show, the stability of NDVI $(\mathrm{CoV})$ and the minimum value of NDVI throughout the growing season are both important for distinguishing rangeland from seeded forage. The LS8 multispectral bands ranked among the top five are the spring NIR and SWIR2 (d139). The Spring TCW (d139) is the fifth ranked variable for Alberta, and is an indicator of plant and soil moisture. As predicted, spring vegetation photosynthesis (NDVI, NIR, R) and vegetation/soil moisture content (SWIR, TCW) have a strong influence on classification accuracy for rangeland and seeded forage for both study areas.

The method of reducing variables by importance and correlation did not see an improvement in classification accuracy. The results show that in this application the RF algorithm is very well suited to classifying multi-source variables and is not prone to overfitting. Although no accuracy improvements were made by the variable reduction method, more computationally efficient classification models can be created with only a few variables. By using only the best five variables of 40 , the processing time was reduced by close to $90 \%$ while maintaining the same classification performance.

\subsection{Limitations and Future Work}

One limitation of this research was the temporal portability of the classification methodology. Unfortunately, due to cost and time limitations of collecting reference data, only one study year was tested. Additionally, the results of the classification and the most important variables were not similar for both study areas. A possible solution to the geographic portability of the proposed methodology would be to classify smaller areas of similar soil or ecoregions instead of having a large square study area; i.e. to spatially stratify the classification. This would reduce the variability within the training data due to landscape-level changes and potentially 
provide a more accurate classification. For example, reference data in areas with different moisture and elevation such as the foothills area to the west of the Alberta study area should be classified separately from the spatially separate dry mixed-grass sites to the east so as not to contaminate the reference data and reduce related classification inaccuracies. It is not recommended to build spectral/temporal signatures of rangeland and seeded forage classes to train future classifiers, as they differ significantly in species composition from dry to wet years. However, due to the permanent state (not included in cropland rotation) of rangeland and relatively fixed-state of seeded forage classes, reference data may be re-used in future years where significant spectral changes have not occurred.

Another limitation of this study was the spatial resolution of available EO data. It was difficult to accurately classify the subclasses of rangeland and seeded forage (pasture, hay) using $30 \mathrm{~m}$ resolution data. However, given the operational constraints of the overall project, which is to create an annual inventory of rangeland and forage for the Prairie region, using finer resolution data would introduce computational and cost issues.

A limitation of the RS2 data was the single mid-summer acquisition date, when RS2 data is known to perform better when acquired in spring and late summer for the rangeland class (Smith \& Buckley, 2011). With the upcoming launch of the RADARSAT Constellation Mission (RCM) and the proposed increased revisit period, further research needs to be conducted on the importance of acquisition dates, incidence angles, and beam modes for RADARSAT-2 for this application (Smith \& Buckley, 2016). There may hold potential for using multiple SAR scenes gathered at yet-unidentified key growing stages alongside single or multiple date optical imagery to further increase accuracy and reliability of operational rangeland and forage mapping at the national scale. Additional EO data types which could be explored in combination with multi- 
temporal optical data are hyperspectral and Light Detection and Ranging (LiDAR) systems. The feasibility of using these systems for a national scale would be limited to processing power and cost, however the additional spectral information afforded by hyperspectral data as well as the structural (canopy height and density) information provided by LiDAR, or higher resolution (spatial and temporal) SAR data could enhance capabilities in agricultural and rangeland LULC mapping and condition monitoring (Bork \& Su, 2007).

A prairie-wide annual inventory of rangeland and forage resources will not only support the beef and dairy industry, the inventory will be a useful tool for monitoring land cover conversion, such as loss of native rangeland and seeded forage to more intensive forms of agriculture. Conversion of rangeland and natural land cover by human activities is a key driver of biodiversity loss in the Prairies. Protecting essential wildlife breeding habitat, migratory routes and corridors from fragmentation will continue. Remote sensing, geomatics technology, and landscape ecology are ever-evolving tools for monitoring LULC change at many scales. 


\section{Chapter 6: Conclusion}

This study demonstrated the power of the random forest algorithm in classifying moderate-resolution multi-source EO data for rangeland and forage classes in the Canadian Prairie ecozone. Multi-temporal Landsat 8 OLI data performed very well on its own, without the use of additional derived optical variables or backscatter data from a single SAR acquisition. On its own, RADARSAT-2 backscatter data acquired in mid-summer was not effective at classifying rangeland and forage. On its own, RS2 performed better in the Alberta study area than in the Manitoba area, however the RS2 variables were the highest ranked variable of importance (MDA) for the Manitoba site when all variables (Optical and SAR) were included in a RF classification. Random forest is easily parameterized for land cover classifications, and classification stability was proven through multiple tests with non-parametric data from multiple sources in the iterative variable importance assessment and variable reduction process.

The conclusions of this research will support the development of accurate mapping of rangeland and seeded forage resources using earth observation over large areas. This information is critical for monitoring and supporting policy initiatives for protecting the ecological integrity and value of native rangeland and semi-natural perennial land cover from the impact of invasive species, land conversion, and resource development. 


\section{References}

Alberta Agriculture, Food and Rural Development. (2004). Beneficial management practices: Environmental manual for Alberta cow/calf producers. Alberta Agriculture, Food and Rural Development, Agdex No. 420/28-2. http://www1.agric.gov.ab.ca/\$department/deptdocs.nsf/all/epw8724

Asbjornsen, H., Hernandez-Santana, V., Liebman, M.Z., Bayala, J., Chen, J., Helmers, M.J., ... Schulte, L.A. (2013). Targeting perennial vegetation is agricultural landscapes for enhancing ecosystem services. Agricultural and Biosystems Engineering Publications. Paper 374.

Bailey, A.W., McCartney, D., \& Schellenberg, M.P. (2010a). Management of Canadian prairie rangeland. AAFC No. 10144

Bailey, A.W., Schellenberg, M.P., McCartney, D., \& Bailey, P. (2010b). Politics, policy, settlers, and consequences for Canadian prairie grasslands: A range management perspective. Rangelands, 32(5), 17-25.

Belgiu, M. \& Dragut, L. (2016). Random forests in remote sensing: a review of applications and future directions. ISPRS Journal of Photogrammetry and Remote Sensing, 114, 24-31.

Biag, M.H.A., Shang, L., Shuai, T., \& Tong, Q. (2014). Derivation of a tasselled cap transformation based on Landsat 8 at-satellite reflectance. Remote Sensing Letters, 5(5), 423-431.

Bolanos, S., Stiff, D., Brisco, B., \& Pietroniro, A. (2016). Operational surface water detectionand monitoring using Radarsat 2. Remote Sensing, 8(4), 285-302.

Bork, E.W., \& Su, J.G. (2007). Integrating LIDAR data and multispectral imagery for enhanced classification of rangeland vegetation: A meta analysis. Remote Sensing of Environment, 111(1), 11-24.

Boyd, J., \& Banzhaf, S. (2007). What are ecosystem services? The need for standardized environmental accounting units. Ecological Economics, 63, 616-626.

Bradley, R.C., Brown, J.F., VanderZee, D., Loveland, T.R., Merchant, J.W., \& Ohlen, D.O. (1994). Measuring phenological variability from satellite imagery. Journal of Vegetation Science, 5, 703-714.

Breiman, L. (1996). Bagging predictors. Machine Learning, 24, 123-140.

Breiman, L. (2001). Random forests. Machine Learning, 45, 5-32. 
Bruynooghe, J., \& Macdonald, R. (2008). Managing Saskatchewan rangeland, (Reved.), Saskatchewan. Agriculture and Agri-Food Canada. http://www.saskforage.ca/publications/ManagingRangeland.pdf

Buckley, J.R. (2004). Enhanced classification of prairie landscapes using simulated RADARSAT-2 imagery. Canadian Journal of Remote Sensing, 30(3), 510-516.

Chan, K.M.A., Shaw, M.R., Cameron, D.R., Underwood, E.C., \& Daily, G.C. (2006). Conservation planning for ecosystem services. PLoS Biology, 4(11), 2138-2152.

Chen, D., Stow, D.A., \& Gong, P. (2004). Examining the effect of spatial resolution and texture window size on classification accuracy: an urban environment case. International Journal of Remote Sensing, 25(11), 2177-2192.

Christiansen, E.A. (1979). The Wisconsinan deglaciation of southern Saskatchewan and adjacent areas. Canadian Journal of Earth Science, 16(4), 913-938.

Cohen, J. (1960). A coefficient of agreement for nominal scales. Educational and Psychological Measurement, 20(1), 37-46.

Congalton, R.G. (1991). A review of assessing the accuracy of classifications of remotely sensed data. Remote Sensing of Environment, 37, 35-46.

Crist, E.P. \& Cicone R.C. (1984). A physically-based transformation of thematic mapper data the TM Tasseled Cap. IEEE Transactions on Geoscience and Remote Sensing, 22(3), 256263.

Crist, E.P., \& Kauth, R.J. (1986). The tasseled cap de-mystified. Photogrammetric Engineering and Remote Sensing, 52, 81-86.

Davidson, A. (2002) Integrating field sampling and remotely sensed data for monitoring the function and composition of northern Mixed Grass prairie. A thesis submitted in conformity with the requirements for the Degree of Doctor of Philosophy, Graduate Department of Geography, University of Toronto. National Library of Canada. Ottawa, Canada. 222 pp.

Dean, C. (2005). Monitoring of pastoral rangeland condition in the southern northern territory (Australia) by remote sensing - Status and prospects. Proceedings of the 1st International Conference on Remote Sensing and Geoinformation Processing in the Assessment and Monitoring of Land Degradation and Desertification, September 7-9 2005, Trier, Germany.151-158.

Deschamps, B., McNairn, H., Shang, J., \& Jiao, X. (2012). Towards operational radar-only crop type classification: comparison of a traditional decision tree with a random forest classifier. Canadian Journal of Remote Sensing, 38(1), 60-68. 
Dietterich, T. G., (1998). Approximate statistical tests for comparing supervised classification learning algorithms. Neural Computation, 10(7), 1895-1924.

Dingle Robertson, L. (2007). Land cover change mapping of eastern Ontario, 1995-2005 using object-based classification. MSc Thesis. Carleton University, Ottawa Ontario.

Dingle Robertson, L., \& King, D.J. 2011. Comparison of pixel- and object-based classification in land cover change mapping. International Journal of Remote Sensing, 32(6), 1505-1529.

DiTomaso, J.M. (2000). Invasive weeds in rangelands: Species, impacts, and management. Weed Science, 48(2), 255-265.

Duro, D.C., Franklin, S.E. \& Dube, M.G. (2012). A comparison of pixel-based and object-based image analysis with selected machine learning algorithms for the classification of agricultural landscapes using SPOT-5 HRG imagery. Remote Sensing of Environment, 118, 259-272.

Duro, D.C., Girard, J., King, D.J., Fahrig, L., Mitchell, S., Lindsay, K., \& Tischendorf, L. (2014). Predicting species diversity in agricultural environments using Landsat TM imagery. Remote Sensing of Environment, 144, 214-225.

Ecological Stratification Working Group. (1995). A National Ecological Framework for Canada. Agriculture and Agri-Food Canada, Research Branch, Centre for Land and Biological Resources Research and Environment Canada, State of the Environment Directorate, Ecozone Analysis Branch, Ottawa/Hull. 125 pp. Retrieved From http://sis.agr.gc.ca/cansis/publications/ecostrat/index.html

Elvidge, C.D., \& Lyon, R.J.P. (1985). Influence of rock-soil spectral variation on the assessment of green biomass. Remote Sensing of Environment, 17, 37-53.

Entz, M.H., Bullied, W.J., \& Katepa-Mupondwa, F. (1995). Rotational benefits of forage crops in Canadian prairie cropping systems. Journal of Production Agriculture, 8(4), 521-529.

Environment and Climate Change Canada (2014). Species at Risk Public Registry. Retrieved from: https://www.registrelep-sararegistry.gc.ca/

Environment and Climate Change Canada. (2014). 1987-2010 Climate Normals and Averages. Retrieved From http://climate.weather.gc.ca/climate_normals/index_e.html

Fisette, T., Chenier, R., Maloley, M., Gasser, PY. Huffman, T., White, L.... Elgarawany, A. (2006). Methodology for a Canadian agricultural land cover classification. Proceedings of the 1st International Conference on Object-based Image Analysis. July 4-5 2006, Salzburg, Austria. 
Fisette, T., Davidson, A., Daneshfar, B., Rollin, P., Aly, Z., \& Campbell, L. (2014). Annual space-based crop inventory for Canada: 2009-2014. International Geoscience and Remote Sensing Symposium. July 13-18 2014, Quebec City, Canada.

Foody, G.M. (2002). Status of land cover classification accuracy assessment. Remote Sensing of Environment, 80, 185-201.

Foody, G.M. (2004). Thematic map comparison: evaluating the statistical significance of differences in classification accuracy. Photogrammetric Engineering and Remote Sensing, 70(5), 627-633.

Foody, G.M., McCulloch, M.B., \& Yates, W.B. (2007), Crop classification from C-band polarimetric radar data. International Journal of Remote Sensing, 15(14), 2871-2885.

Fuhlendorf, S.D., \& Engle, D.M. (2001). Restoring heterogeneity on rangelands: ecosystem management based on evolutionary grazing patterns. BioScience, 51, 625-632.

Fuller, Les. (2010). Chernozemic soils of the prairie region of western Canada. Prairie Soils and Crops Journal, 3, 37-45.

Gagnon, L., \& Jouan, A. (1997). Speckle filtering of SAR images: A comparative study between complex-wavelet based and standard filters. SPIE Proceedings, 3169, 80-91.

Genuer, R., Poggi, J.M., \& Tuleau-Malot, C. (2010). Variable selection using random forests. Pattern Recognition Letters, 31, 2225-2236.

Gillen, R.L, Eckroat, J.A., \& McCollum, F.T. (2000). Vegetation response to stocking rate in southern mixedgrass prairie. Journal of Range Management, 53, 471-478.

Gislason, P.O., Benediktsson, J.A., \& Sveinsson, J.R. (2006). Random forests for land cover classification. Pattern Recognition Letters, 27, 294-300.

Gong, P., Marceau, D.J., \& Howarth, P.J. (1992). A comparison of spatial feature extraction algorithms for land-use classification with SPOT HRV data. Remote Sensing of Environment, 40, 137-151.

Goodin, D.G. \& Henebry, G.M. (1997). A technique for monitoring ecological disturbance in tallgrass prairie using seasonal NDVI trajectories and a discriminant function mixture model. Remote Sensing of the Environment, 61, 270-278.

Guo, X., Price, K.P., \& Stiles, J. (2003). Grasslands discriminant analysis using Landsat TM single and multitemporal data. Photogrammetric Engineering \& Remote Sensing, 69(11), $1255-1262$.

Hadjimitsis, D.G., Papadavid, G., Agapiou, A., Themistocleous, K., Hadjimitsis, M.G., Retalis, A.,... Clayton, C.R.I. (2010). Atmospheric correction for satellite remotely sensed data 
intended for agricultural applications: Impact on vegetation indices. Natural Hazards and Earth System Sciences, 10, 89-95.

Hagen, S. C., Heilman, P., Marsett, R., Torbick, N., Salas, W., Van Ravensway, J., \& Qi, J. (2012). Mapping total vegetation cover across western rangelands with moderateresolution imaging spectroradiometer data. Rangeland Ecology and Management, 65(5), 456-467.

Hall-Beyer, M. (2007). The GLCM Tutorial. Retrieved From http://www.fp.ucalgary.ca/mhallbey/tutorial.htm

Hao, P., Wang, L., \& Niu, Z. (2015). Comparison of hybrid classifiers for crop classification using normalized difference vegetation index time series: A case study for major crops in north Xinjiang, China. PLoS ONE, 10(9), e0137748.

Haralick, R.M., Shanmugam, K., \& Dinstein, I. (1973). Textural features for image classification. IEEE Transactions on Systems, Man, and Cybernetics, SMC-3(6), 610-621.

Harker, K.N., Baron, V.S., Chanasyk, D.S., Naeth, M.A., \& Stevenson, F.C. (2000). Grazing intensity effects on weed populations in annual and perennial pasture systems. Weed Science, 48(2), 231-238.

Hijmans, R. (2014). Raster: Geographic Data Analysis and Modeling; R package version 2.3. Retrieved From https://cran.r-project.org/web/packages/raster/index.html

Hively, W.D., Duiker, S., McCarty, G., \& Prabhakara, K. (2015). Remote sensing to monitor cover crop adoption in southeastern Pennsylvania. Journal of Soil and Water Conservation, $70(6), 340-352$.

Huete, A.R. (1988). A soil-adjusted vegetation index (SAVI). Remote Sensing of Environment, 25, 295-309.

Jefferson, R.G., Iwaasa, A.D., Schellenberg, M., \& Mcleod, J.G. (2013). Re-evaluation of native plant species for seeding and grazing by livestock on the semiarid prairie of western Canada. Prairie Forum, 38(1), 275-304.

Jensen, J.R. (2015). Introductory digital image processing: A remote sensing perspective ( $4^{\text {th }}$ ed.). Glenview, IL: Pearson Education, Inc.

Johnson, DM., \& Mueller, R. (2010). The 2009 cropland data layer. Photogrammetric Engineering and Remote Sensing, 11, 1201-1205.

Jones, H.G. \& Vaughan, R.A. (2010). Remote sensing of vegetation: Principles, techniques, and applications. Cambridge, UK: Cambridge University Press. 352 pp. 
Karl, J.W. \& Maurer, B.A. (2010). Multivariate correlations between imagery and field measurements across scales: comparing pixel aggregation and image segmentation. Landscape Ecology, 25, 591-605.

Kauth, R.J., \& Thomas, G.S. (1976). The tasselled cap - a graphic description of the spectraltemporal development of agricultural crops as seen by Landsat. Proceedings of the Symposium on Machine Processing of Remotely Sensed Data. June 29-July 1 1976, West Lafayette, IN. (4B)41-51.

Kelsey, K.C., \& Neff, J.C. (2014). Estimates of aboveground biomass from texture analysis of Landsat imagery. Remote Sensing, 6, 6407-6422.

Lauenroth, W.K., Coffin, D.P., Burke, I.C., \& Virginia, R.A. (1997). Interactions between demographic and ecosystem processes in a semi-arid and an arid grassland: a challenge for plant functional types. In T.M. Smith, H.H. Shugart, \& F.I. Woodward (Eds.), Plant functional types (pp. 234-254). Cambridge, UK: Cambridge University Press.

Lee, J.S. (1980). Digital image enhancement and noise filtering by use of local statistics. IEEE Transactions on Pattern Analysis and Machine Intelligence, 2(2), 165-168.

Lee, J.S. (1981). Refined filtering of image noise using local statistics. Computer Graphics and Image Processing, 15, 380-389.

Lee, J.S., Jurkevich, L., Dewaele, P., Wambacq, P., \& Oosterlinck, A. (1994). Speckle filtering of synthetic aperture radar images: A review. Remote Sensing Reviews, 8(4), 313-340.

Liaw, A., \& Wiener, M. (2002). Classification and regression by randomForest. $R$ News, 2, 18 22.

Li, G., Lu, D., Moran, E., \& Hetrick, S. (2011). Land-cover classification in a moist tropical region in Brazil with Landsat TM imagery. International Journal of Remote Sensing, $32(23), 8207-8230$.

Loupes, A., Touzi, R., \& Nezry, E. (1990). Adaptive speckle filters and scene heterogeneity. IEEE Transactions on Geoscience and Remote Sensing, 24(6), 992-1000.

Malhi, S.S., Gill, K.S., McCartney, D.H., \& Malmgren, R. (2004). Fertilizer management of forage crops in the Canadian Great Plains: A review. Recent Research Development in Crop Science, 1, 237-271.

Lu, D., Batistella, M., de Miranda, E.E., \& Moran, E. (2008). A comparative study of Landsat TM and SPOT HRG images for vegetation classification in the Brazilian Amazon. Photogrammetric Engineering and Remote Sensing, 74(3), 311-321 
MacDonald Dettwiler and Associates (2014, May 5). Radarsat-2 Product Description; RN-SP52-1238; Issue 1/11. Retrieved from http://mdacorporation.com/geospatial/international/satellites/RADARSAT-2

Manitoba Agriculture (2015, October 13). Crop Report: Issue 24, October 13, 2015. Retrieved from http://www.gov.mb.ca/agriculture/crops/seasonal-reports/crop-report-archive/201510-13-crop-report.html

Marsett, R.C., Qi, J., Heilman, P., Biedenbender, S.H., Watson, M.C., Amer, S., ,.. Goodrich, D. (2006). Remote sensing for grassland management in the arid southwest. Rangeland Ecology and Management, 5(9), 530-540.

Maynard, C.L., Lawrence, R.L., Nielsen, G.A. \& Decker, G. (2007). Ecological site descriptions and remotely sensed imagery as a tool for rangeland evaluation. Canadian Journal of Remote Sensing, 33(2), 109-115.

McCartney, D. (2011). Country pasture/forage resource profiles: Canada. Agriculture and Agric.-Food Canada, Lacombe, Alberta. Retrieved from http://www.fao.org/ag/AGP/AGPC/doc/Counprof/Canada/Canada.html

McNairn, H. \& Brisco, B. (2004). The application of C-band polarimetric SAR for agriculture: a review. Canadian Journal of Remote Sensing, 30(3), 525-542.

McNairn, H., Champagne, C., Shang, J., Holmstrom, D., \& Reichert, G. (2009). Integration of optical and Synthetic Aperture Radar (SAR) imagery for delivering operational annual crop inventories. ISPRS Journal of Photogrammetry and Remote Sensing, 64, 434-449.

McNemar, Q. (1947). Note on the sampling error of the difference between correlated proportions or percentages. Pshychometrika, 12, 153-157.

Millard, K., \& Richardson, M. (2015). On the importance of training data sample selection in random forest image classification: a case study in peatland ecosystem mapping. Remote Sensing, 7, 8489-8515.

Moran, P. (1950). Notes on Continuous Stochastic Phenomena. In Biometrika. 37(1-2), 17-23.

Morgan, J.P. (1995). Restoring Canada's native prairies. Argyle, MB: Prairie Habitats.

Mundava, C., Helmholtz, P., Schut, A.G.T., Corner, R., McAtee, B., \& Lamb, D.W. (2014). Evaluation of vegetation indices for rangeland biomass estimation in the Kimberly area of Western Australia. ISPRS Annals of the Photogrammetry, Remote Sensing and Spatial Information Sciences. September 29 - October 2 2014, Istanbul, Turkey.

Nixon, A., Iravani, M., Habib, T., \& White, S.R. (2015). Climate change and the provision of ecosystem services in Alberta: an initial assessment of impacts and adaptation strategies on Alberta's rangelands. Prepared for the ABMI Biodiversity Management and Climate 
Change Adaptation and Ecosystem Services Assessment projects. Retrieved from http://www.abmi.ca/home/publications/351-400/372.html?mode=detail\&page=3

Numata, I., Roberts, D.A., Chadwick, O.A., Schimel, J., Sampaio, F.R., Leonidas, F.C., Soares, J.V. (2007). Characterization of pasture biophysical properties and the impact of grazing intensity using remotely sensed data. Remote Sensing of Environment, 109(3), 314-327.

Olofsson, P., Foody, G.M., Herold, M., Stehman, S.V., Woodcock, C.E., \& Wulder, M.A. (2014). Good practices for estimating area and assessing accuracy of land change. Remote Sensing of Environment, 148, 42-57.

Ouma, Y.O., \& Tateishi, R. (2006). Optimization of second-order grey-level texture in highresolution imagery for statistical estimation of above-ground biomass. Journal of Environmental Informatics, 8(2), 70-85.

Paruelo, J.M., \& Lauenroth, W.K. (1996). Relative abundance of plant functional types in grasslands and shrublands of North America. Ecological Applications, 6, 1212-1224.

Peña-Barragán, J.M., Ngugi, M.K., Plant, R.E. \& Six, J. (2011). Object-based crop identification using multiple vegetation indices, textural features and crop phenology. Remote Sensing of Environment, 115(6), 1301-1316.

Peñuelas, J., Filella, I., Zhang, X., Llorens, L., Ogaya, R., Lloret, F., ... Terradas, J. (2004). Complex spatiotemporal phenological shifts as a response to rainfall changes. New Phytologist, 161(3), 837-846.

Prairie Conservation Forum. (January 2011). Alberta prairie conservation action plan: 2011 2015. Prairie Conservation Forum: Lethbridge, Alberta. 28 pp. Retrieved from http://www.albertapcf.org

Prishchepov, A.V., Radeloff, V.C., Dubinin, M., \& Alcantara, C. (2012). The effect of Landsat ETM/ETM+ image acquisition dates on the detection of agricultural land abandonment in eastern Europe. Remote Sensing of Environment, 126, 195-209.

Purevdorj, T.S., Tateishi, R., Ishiyama, T., \& Honda, Y. (2010). Relationships between percent vegetation cover and vegetation indices. International Journal of Remote Sensing, 19(18), 3519-3535.

Qi, J., Marsett, R., Heilman, P., Biedenbender, S., Moran, S., Goodrich, D., \& Weltz, M. (2002). RANGES improves satellite-based information and land cover assessments in southwest United States. Transactions of the American Geophysical Union, 83, 601-606.

R Core Team. (2014).R: A language and environment for statistical computing; $R$ Foundation for Statistical Computing: Vienna, Austria. 
Reed, B.C., Brown, J.F., VanderZee, D., Loveland, T.R. Merchant, J.W. \& Ohlen, D.O. (1994). Measuring phenological variability from satellite imagery. Journal of Vegetation Science, 5, 703-714.

Richter, R. (1996). A spatially adaptive fast atmospheric correction algorithm. International Journal of Remote Sensing, 17(6), 1201-1214.

Richter, R. (2008). Atmospheric-topographic correction for satellite imagery: ATCOR-2/3 user guide, version 6.4. German Aerospace Center: Wessling, Germany.

Rigge, M., Smart, A., Wylie, B., Gilmanov, T., \& Johnson, P. (2013). Linking phenology and biomass productivity in South Dakota mixed-grass prairie. Rangeland Ecology and Management, 66, 579-587.

Rodriguez-Galiano, V.F., Ghimire, B., Rogan, J., Chica-Olmo, M., \& Rigol-Sanchez, J.P. (2012). An assessment of the effectiveness of a random forest classifier for land-cover classification. ISPRS Journal of Photogrammetry and Remote Sensing, 67, 93-104.

Rouse, J.W., Jr., Haas, R.H., Schell, J.A., \& Deering, D.W. (1974). Monitoring vegetation systems in the Great Plains with ERTS. Third Earth Resources Technology Satellite-1 Symposium- Volume I: Technical Presentations. December 10-14 1973. Washington, D.C.

Rufin, P., Müller, H., Pflugmacher, D., \& Hostert, P. (2015). Land use intensity trajectories on Amazonian pastures derived from Landsat time series. International Journal of Applied Earth Observation and Geoinformation, 41, 1-10.

Schroeder, T.A., Cohen, W.B., Song, C., Canty, M.J., \& Yang, Z. (2006). Radiometric correction of multi-temporal Landsat data for characterization of early successional forest patterns in western Oregon. Remote Sensing of Environment, 103(1), 16-26.

Schuster, C., Schmidt, T., Conrad, C., Kleinschmit, B., \& Forster, M. (2015). Grassland habitat mapping by intra-annual time series analysis: Comparison of RapidEye and TerraSAR-X satellite data. International Journal of Applied Earth Observation and Geoinformation, 34, 25-34.

Serbin, G., Hunt Jr., E., Daughtry, C., McCarty, G., \& Doraiswamy, P. (2009). An improved ASTER index for remote sensing of crop residue, Remote Sensing, 1(4), 971-991.

Shi, Z., \& Fung, K.B. (1994). A comparison of digital speckle filters. International Geoscience and Remote Sensing Symposium: surface and atmospheric remote sensing: technologies, data analysis, and interpretation, August 8-12 1994. Pasadena, CA. 2129-2133

Shooshtarian, A. (2016, June 6). Alberta 2015 Crop Season in Review. Retrieved from http://www1.agric.gov.ab.ca/\$Department/deptdocs.nsf/all/sdd16003 
Skriver, H., Mattie, F., Satalino, G., Balenzano, A., Pauwels, V.R.N., Verhoest, N.E.C., \& Davidson, M. (2011). Crop classification using short-revisit multitemporal SAR data. IEEE Journal of Selected Topics in Applied Earth Observations and Remote Sensing, 4(2), 423431.

Smith, A.M., \& Buckley, J.R. (2011). Investigating RADARSAT-2 as a tool for monitoring grassland in western Canada. Canadian Journal of Remote Sensing, 37(1), 93-102.

Smith, A.M., \& Buckley, J.R. (2016). Optimizing remote sensing of native grasslands for monitoring and change detection. Geoscience and Remote Sensing Symposium (IGARSS), 2016 IEEE International. July 10 - July 15, 2016, Beijing, China.

Smith, A., Hill, M.J., \& Zhang, Y. (2015). Estimating ground cover in the mixed prairie grassland of southern Alberta using vegetation indices related to physiological function. Canadian Journal of Remote Sensing, 41, 51-66.

Society for Range Management. (1998). Glossary of terms used in range management, fourth edition. Edited by the Glossary Update Task Group, Thomas E. Bedell, Chairman.

Song, C., Woodcock, C.E., Seto, K.C., Lenney, M.P. \& Macomber, S.A. (2001). Landsat TM data: when and how to correct atmospheric effects. Remote Sensing of Environment, 75, $230-244$.

Sonobe, R., Tani, H., Wang, X., Kobayashi, N., \& Shimamura, H. (2014). Parameter tuning in the support vector machine and random forest and their performances in cross- and sameyear crop classification using TerraSAR-X. International Journal of Remote Sensing, 35(23), 7898-7909.

South, S., Qi, J., \& Lusch, D.P. (2004). Optimal classification methods for mapping agricultural tillage practices. Remote Sensing of Environment, 91, 90-97.

Stehman, S.V. (1996). Estimating the kappa coefficient and its variance under stratified random sampling, Photogrammetric Engineering \& Remote Sensing, 62, 401-407.

Statistics Canada. (2011). 2011 Census of population: Cartographic boundary file, Ottawa, ON. Retrieved from https://www12.statcan.gc.ca/census-recensement/2011/dp-pd/indexeng.cfm

Statistics Canada. (2006). Census of Agriculture. Retrieved from http://www.statcan.gc.ca/cara2006/index-eng.htm

Statistics Canada. (2011). Census of Agriculture. Retrieved from http://www.statcan.gc.ca/eng/ca2011/index 
Strobl, C., Boulesteix, A.L., Zeileis, A. \& Hothorn, T., (2007). Bias in random forest variable importance measures: Illustrations, sources and a solution. BMC Bioinformatics, 8(1), 120.

Swain, P. H., \& Davis, S. M. (1978). Remote sensing: The quantitative approach. New York: McGraw-Hill Publishers.

Tilman, D., Cassman, K.G., Matson, P.A., Naylor, R., \& Polasky, S. (2002). Agricultural sustainability and intensive production practices. Nature, 418, 671-677.

Todd, S.W., Hoffer, R.M., \& Milchunas, D.G. (1998). Biomass estimation on grazed and ungrazed rangelands using spectral indices. International Journal of Remote Sensing, 19, 427-438.

Tsalyuk, M., Kelly, M., Koy, K., Getz, W.M., \& Butterfield, H.S. (2015). Monitoring the impact of grazing on rangeland conservation easements using MODIS vegetation indices.

Rangeland Ecology and Management, 68, 173-185.

United States Geological Survey (USGS). (June 2015). Landsat 8 (L8) Data Users Handbook. Sioux Falls, South Dakota: U.S. Geological Survey. Retrieved from http://landsat.usgs.gov/18handbook.php

United States Geological Survey (USGS). (2016). Earth Explorer. Online: http://earthexplorer.usgs.gov/

Vaisey, J.S., \& Strankman, P. (1999). Prairie grasslands: an undervalued resource, grass cows and environmental management on the Canadian prairies. Great Plains Research, 9, 371395.

Vasquez, E.A., James, J.J., Monaco, T.A., \& Cummings, D.C. (2010). Invasive plants on rangelands: A global threat. Rangelands, 32, 3-5.

Volesky, J.D., Anderson, B.E., \& Nichols, J.T. (2003). Perennial forages for irrigated pasture. University of Nebraska Lincoln Extension Publications. Retrieved from http://extensionpublications.unl.edu/assets/html/g1502/build/g1502.htm

Waldner, F., Canto, G.S., \& Defourny, P. (2015). Automated annual cropland mapping using knowledge-based temporal features. ISPRS Journal of Photogrammetry and Remote Sensing, 110, 1-13.

Walker, J.J., de Beurs, K.M., \& Wynne, R.H. (2014). Dryland vegetation phenology across an elevation gradient in Arizona, USA, investigated with fused MODIS and Landsat data. Remote Sensing of Environment, 144, 85-97. 
Wang, C., Raymond Hunt Jr., E., Zhang, L., \& Guo, H. (2013). Phenology-assisted classification of $\mathrm{C}_{3}$ and $\mathrm{C}_{4}$ grasses in the U.S. Great Plains and their climate dependency with MODIS time series. Remote Sensing of Environment, 138, 90-101.

Wang, X., Vanden Bygaart, A.J., \& McConkey, B.C. (2014). Land management history of Canadian grasslands and the impact on soil carbon storage. Rangeland Ecology \& Management, 67(4), 333-343.

Waske, B., \& Braun, M. (2009). Classifier ensembles for land cover mapping using multitemporal SAR imagery. ISPRS Journal of Photogrammetry and Remote Sensing, 64, 450-457.

Weiser, R.L., Asrar, G., Miller, G.P., \& Kanemasu, E.T. (1986). Assessing grassland biophysical characteristics from spectral measurements. Remote Sensing of Environment, 20(2), 141152.

World Wildlife Fund (WWF). (2016). The Plowprint Report. WWF: Northern Great Plains Program. Retrieved from https://www.worldwildlife.org/projects/plowprint-report

Wulder, M.A., Masek, J.G., Cohen, W.B., Loveland, T.R., \& Woodcock, C.E., (2012). Opening the archive: how free data has enabled the science and monitoring promise of Landsat. Remote Sensing of Environment, 122, 2-10.

Zhang, X., Friedl, M.A., Schaaf, C.B., Strahler, A.H., Hodges, J.C.F., Gao, F., ... Huete, A. (2003). Monitoring vegetation phenology using MODIS. Remote Sensing of Environment, $84,471-475$.

Zheng, B., Campbell, J.B. \& de Beurs, K.M. 2012. Remote sensing of crop residue cover using multi-temporal Landsat imagery. Remote Sensing of Environment, 117, 177-183. 


\section{Appendices}

\section{APPENDIX A - Separability Analysis for Radar Speckle Filter Selection}

Table A.1 presents the results of the separability analysis (transformed divergence) of the unfiltered RS2 data, vs the two speckle filters (Lee and Enhanced Lee) with 3x3 and 5x5 window sizes.

Table A.1. Transformed Divergence of RS2 Speckle Filters

\begin{tabular}{|c|c|c|c|c|c|c|}
\hline \multirow{2}{*}{\multicolumn{2}{|c|}{ Alberta }} & \multicolumn{5}{|c|}{ Trans formed Diverge nce } \\
\hline & & Raw & Lee $3 \times 3$ & Lee $5 \times 5$ & Elee $3 \times 3$ & Elee $5 \times 5$ \\
\hline Seeded Forage & vs. Cropland & 0.0330 & 0.9125 & 0.9097 & 0.8626 & 1.0427 \\
\hline Rangeland & vs. Cropland & 0.2262 & 1.8951 & 1.9255 & 1.8869 & 1.9491 \\
\hline Rangeland & $\begin{array}{l}\text { vs. Seeded Forage } \\
\text { anitoba }\end{array}$ & 0.1035 & 0.6678 & 0.7644 & 0.6605 & 0.8321 \\
\hline Seeded Forage & vs. Cropland & 0.6847 & 0.9585 & 0.9713 & 0.9585 & 0.9726 \\
\hline Rangeland & vs. Cropland & 1.1981 & 1.5817 & 1.6673 & 1.5823 & 1.6665 \\
\hline Rangeland & vs. Seeded Forage & 0.0988 & 0.2109 & 0.3559 & 0.2133 & 0.3581 \\
\hline
\end{tabular}

Note: the transformed divergence separability measure yields values from 0 to 2 where 0 indicates complete overlap between the signatures of two classes, and 2 indicates complete separation. TD less than 1.0 indicates poor separability, and greater than 1.9 indicates good separability. 


\section{APPENDIX B - Classification Error Matrices and Accuracy Statistics}

The following tables consist of the summary accuracy statistics derived from the error matrices for each study area. Table A.2. presents the accuracy statistics (including Kappa and OOB error) for the Manitoba study area derived from the corresponding 34 error matrices

(Tables A.3. to A. 13.), while Table A.14. presents the accuracy statistics, including OOB error and Cohen's Kappa, for the 34 classifications performed for the Alberta study area (Tables A.15. to A.25.). For the following error matrices, each column of the matrix represents the instances in a predicted class while each row represents the instances in an actual class.

Table A.2. Classification Accuracy Statistics derived from the Error Matrices for the Manitoba Study Area.

\begin{tabular}{|c|c|c|c|c|c|c|c|c|c|c|c|c|}
\hline & Classification Variables & $\begin{array}{c}\text { Overall } \\
\text { Accuracy }\end{array}$ & $\begin{array}{c}\text { Cropland } \\
\text { PA }\end{array}$ & $\begin{array}{c}\text { Cropland } \\
\text { UA }\end{array}$ & $\begin{array}{c}\text { Rangeland } \\
\text { PA }\end{array}$ & $\begin{array}{l}\text { Rangeland } \\
\text { UA }\end{array}$ & $\begin{array}{c}\text { Seeded } \\
\text { Forage } \\
\text { PA }\end{array}$ & $\begin{array}{c}\text { Seeded } \\
\text { Forage } \\
\text { UA }\end{array}$ & $\begin{array}{c}\text { OOB } \\
\text { Error }\end{array}$ & $\begin{array}{c}\text { Diffe rence } \\
\text { in Error } \\
(\mathrm{OA}- \\
\text { OOB })\end{array}$ & $\begin{array}{c}\text { \# of } \\
\text { Variables }\end{array}$ & $\begin{array}{c}\text { Cohen's } \\
\text { Kappa }\end{array}$ \\
\hline \multirow[t]{18}{*}{ Optical (LS8) } & MS (1) - Spring & 84.85 & 95.82 & 96.18 & 54.65 & 74.60 & 82.88 & 71.18 & 83.40 & 1.45 & 6 & 0.75 \\
\hline & MS (1) - Late Summer & 85.86 & 97.72 & 95.90 & 59.30 & 70.83 & 80.14 & 75.48 & 85.48 & 0.38 & 6 & 0.76 \\
\hline & MS (1) - Fall & 80.61 & 94.68 & 88.93 & 48.84 & 68.85 & 73.97 & 70.13 & 82.68 & -2.07 & 6 & 0.67 \\
\hline & VI (1) - Spring & 82.22 & 93.54 & 93.89 & 58.14 & 62.50 & 76.03 & 72.55 & 81.43 & 0.79 & 4 & 0.70 \\
\hline & VI (1) - Late Summer & 82.42 & 98.48 & 93.17 & 47.67 & 62.12 & 73.97 & 71.52 & 83.09 & -0.67 & 4 & 0.70 \\
\hline & VI (1) - Fall & 78.59 & 91.63 & 87.96 & 47.67 & 60.29 & 73.29 & 69.93 & 82.78 & -4.19 & 4 & 0.64 \\
\hline & MS (2) - Spring \& Late Summer & 87.88 & 98.48 & 96.64 & 58.14 & 79.37 & 86.30 & 76.83 & 89.42 & -1.54 & 12 & 0.80 \\
\hline & MS (2) - Spring \& Fall & 88.89 & 97.34 & 96.97 & 67.44 & 82.86 & 86.30 & 78.26 & 88.69 & 0.20 & 12 & 0.81 \\
\hline & MS (2) - Late Summer \& Fall & 86.26 & 98.10 & 95.20 & 59.30 & 72.86 & 80.82 & 76.62 & 88.69 & -2.43 & 12 & 0.77 \\
\hline & MS (3) & 89.49 & 98.86 & 98.86 & 62.79 & 78.26 & 88.36 & 79.14 & 90.77 & -1.28 & 18 & 0.82 \\
\hline & MS (1) + VI (1) - Spring & 85.05 & 95.44 & 96.54 & 55.81 & 75.00 & 83.56 & 71.35 & 84.34 & 0.71 & 10 & 0.75 \\
\hline & MS (1) + VI (1) - Late Summer & 85.45 & 98.10 & 96.63 & 58.14 & 66.67 & 78.77 & 75.16 & 85.27 & 0.18 & 10 & 0.76 \\
\hline & MS (1) + VI (1) - Fall & 80.00 & 92.02 & 90.30 & 52.33 & 64.29 & 74.66 & 69.43 & 84.34 & -4.34 & 10 & 0.66 \\
\hline & MS (2) + VI (2) - Spring \& Late Summer & 88.08 & 98.10 & 97.73 & 58.14 & 78.13 & 87.67 & 76.65 & 89.83 & -1.75 & 20 & 0.80 \\
\hline & MS (2) + VI (2) - Spring \& Fall & 88.69 & 96.58 & 97.32 & 66.28 & 83.82 & 87.67 & 77.11 & 89.42 & -0.73 & 20 & 0.81 \\
\hline & MS (2) + VI (2) - Late Summer \& Fall & 86.67 & 98.48 & 95.22 & 59.30 & 75.00 & 81.51 & 76.77 & 89.32 & -2.65 & 20 & 0.77 \\
\hline & MS (3) + VI (3) & 89.29 & 98.86 & 98.86 & 62.79 & 77.14 & 87.67 & 79.01 & 90.98 & -1.69 & 30 & 0.82 \\
\hline & MS (3) + VI (3) + PhenNDVI & 88.69 & 98.86 & 98.11 & 60.47 & 78.79 & 86.99 & 77.44 & 89.94 & -1.25 & 38 & 0.81 \\
\hline Radar (RS2) & Radar & 68.48 & 88.21 & 85.61 & 38.37 & 39.76 & 50.68 & 52.48 & 67.84 & 0.64 & 2 & 0.47 \\
\hline \multirow{15}{*}{ Optical + Radar } & MS (1) + Radar - Spring & 86.67 & 95.82 & 96.55 & 60.47 & 80.00 & 85.62 & 73.96 & 86.94 & -0.27 & 8 & 0.78 \\
\hline & MS (1) + Radar - Late Summer & 87.07 & 97.72 & 95.90 & 55.81 & 76.19 & 86.30 & 76.83 & 87.97 & -0.90 & 8 & 0.78 \\
\hline & MS (1) + Radar - Fall & 84.65 & 95.82 & 94.03 & 60.47 & 74.29 & 78.77 & 73.25 & 85.06 & -0.41 & 8 & 0.74 \\
\hline & MS (2) + Radar - Spring and Late Summer & 88.69 & 97.72 & 98.09 & 61.63 & 80.30 & 88.36 & 77.25 & 90.26 & -1.57 & 14 & 0.81 \\
\hline & MS (2) + Radar - Spring and Fall & 88.69 & 97.34 & 97.34 & 62.79 & 83.08 & 88.36 & 77.25 & 90.25 & -1.56 & 14 & 0.81 \\
\hline & MS (2) + Radar - Late Summer and Fall & 89.09 & 99.24 & 96.31 & 63.95 & 80.88 & 85.62 & 80.13 & 90.87 & -1.78 & 14 & 0.82 \\
\hline & MS (3) + Radar & 89.49 & 98.86 & 98.48 & 63.95 & 78.57 & 87.67 & 79.50 & 91.70 & -2.21 & 20 & 0.82 \\
\hline & MS (1) + VI (1) + Radar - Spring & 86.87 & 96.20 & 96.20 & 62.79 & 79.41 & 84.25 & 75.00 & 87.66 & -0.79 & 12 & 0.83 \\
\hline & MS (1) + VI (1) + Radar - Late Summer & 86.67 & 98.10 & 95.91 & 56.98 & 75.38 & 83.56 & 75.78 & 88.90 & -2.23 & 12 & 0.79 \\
\hline & MS (1) + VI (1) + Radar - Fall & 84.85 & 96.20 & 94.40 & 59.30 & 73.91 & 79.45 & 73.42 & 84.96 & -0.11 & 12 & 0.84 \\
\hline & MS (2) + VI (2) + Radar - Spring \& Late Summer & 88.89 & 98.10 & 98.10 & 60.47 & 81.25 & 89.04 & 77.38 & 90.46 & -1.57 & 22 & 0.81 \\
\hline & MS (2) + VI (2) + Radar - Spring \& Fall & 89.09 & 97.72 & 97.35 & 65.12 & 82.35 & 87.67 & 78.53 & 89.94 & -0.85 & 22 & 0.82 \\
\hline & MS (2) + VI (2) + Radar - Late Summer \& Fall & 89.29 & 98.86 & 97.01 & 66.28 & 80.28 & 85.62 & 80.13 & 90.87 & -1.58 & 22 & 0.82 \\
\hline & MS (3) + VI (3) + Radar & 88.28 & 98.10 & 98.10 & 60.47 & 77.61 & 86.99 & 76.97 & 91.08 & -2.80 & 32 & 0.80 \\
\hline & MS (3) + VI (3) + PhenNDVI + Radar & 88.48 & 98.48 & 97.37 & 60.47 & 80.00 & 86.99 & 77.44 & 90.66 & -2.18 & 40 & 0.81 \\
\hline
\end{tabular}

Note: PA is the class-based Producer's Accuracy in percent (100\% - error of omission) while UA is the User's Accuracy in percent (100\% - error of commission). OOB error is the internal estimate of error from the RF classification. 
Table A.3. Manitoba single-date MS classification error matrices

\begin{tabular}{|lccccc|}
\hline & \multicolumn{5}{c|}{ MS (1) - Spring } \\
\cline { 2 - 5 } & Cropland & Rangeland & Seeded Forage & Total & User's Accuracy \\
\hline Cropland & $\mathbf{2 5 2}$ & 0 & 10 & 262 & $96.18 \%$ \\
Rangeland & 1 & $\mathbf{4 7}$ & 15 & 63 & $74.60 \%$ \\
Seeded Forage & 10 & 39 & $\mathbf{1 2 1}$ & 170 & $71.18 \%$ \\
Total & 263 & 86 & 146 & 495 & \\
\hline Producer's Accuracy & $95.82 \%$ & $54.65 \%$ & $82.88 \%$ & & \\
Overall Accuracy $=$ & $84.85 \%$ & & & & \\
OOB Error $=$ & $83.40 \%$ & & & & \\
Cohen's Kappa $=$ & 0.75 & & & & \\
\hline
\end{tabular}

\begin{tabular}{|lccccc|}
\hline & \multicolumn{5}{c|}{ MS (1) - Late Summer } \\
\cline { 2 - 5 } & Cropland & Rangeland & Seeded Forage & Total & User's Accuracy \\
\hline Cropland & $\mathbf{2 5 7}$ & 1 & 10 & 268 & $95.90 \%$ \\
Rangeland & 2 & $\mathbf{5 1}$ & 19 & 72 & $70.83 \%$ \\
Seeded Forage & 4 & 34 & $\mathbf{1 1 7}$ & 155 & $75.48 \%$ \\
Total & 263 & 86 & 146 & 495 & \\
\hline Producer's Accuracy & $97.72 \%$ & $59.30 \%$ & $80.14 \%$ & & \\
Overall Accuracy $=$ & $85.86 \%$ & & & & \\
OOB Error $=$ & $85.48 \%$ & & & & \\
Cohen's Kappa $=$ & 0.76 & & & & \\
\hline
\end{tabular}

\begin{tabular}{|lccccc|}
\hline & \multicolumn{5}{c|}{ MS (1) - Fall } \\
\cline { 2 - 5 } & Cropland & Rangeland & Seeded Forage & Total & User's Accuracy \\
\hline Cropland & $\mathbf{2 3 2}$ & 9 & 30 & 271 & $88.93 \%$ \\
Rangeland & 8 & $\mathbf{3 3}$ & 42 & 83 & $68.85 \%$ \\
Seeded Forage & 23 & 44 & $\mathbf{7 4}$ & 141 & $70.13 \%$ \\
Total & 263 & 86 & 146 & 495 & \\
\hline Producer's Accuracy & $94.68 \%$ & $48.84 \%$ & $73.97 \%$ & & \\
Overall Accuracy $=$ & $80.61 \%$ & & & & \\
OOB Error $=$ & $82.68 \%$ & & & & \\
Cohen's Kappa $=$ & 0.67 & & & & \\
\hline
\end{tabular}


Table A.4. Manitoba single-date VI classification error matrices

\begin{tabular}{|lccccc|}
\hline & \multicolumn{5}{c|}{ VI (1) - Spring } \\
\cline { 2 - 5 } & Cropland & Rangeland & Seeded Forage & Total & User's Accuracy \\
\hline Cropland & $\mathbf{2 4 6}$ & 4 & 12 & 262 & $93.89 \%$ \\
Rangeland & 7 & $\mathbf{5 0}$ & 23 & 80 & $62.50 \%$ \\
Seeded Forage & 10 & 32 & $\mathbf{1 1 1}$ & 153 & $72.55 \%$ \\
Total & 263 & 86 & 146 & 495 & \\
\hline Producer's Accuracy & $93.54 \%$ & $58.14 \%$ & $76.03 \%$ & & \\
Overall Accuracy $=$ & $82.22 \%$ & & & & \\
OOB Error $=$ & $81.43 \%$ & & & & \\
Cohen's Kappa $=$ & 0.70 & & & & \\
\hline
\end{tabular}

\begin{tabular}{|lccccc|}
\hline & \multicolumn{5}{c|}{ VI (1) - Late Summer } \\
\cline { 2 - 5 } & Cropland & Rangeland & Seeded Forage & Total & User's Accuracy \\
\hline Cropland & $\mathbf{2 5 9}$ & 5 & 14 & 278 & $93.17 \%$ \\
Rangeland & 1 & $\mathbf{4 1}$ & 24 & 66 & $62.12 \%$ \\
Seeded Forage & 3 & 40 & $\mathbf{1 0 8}$ & 151 & $71.52 \%$ \\
Total & 263 & 86 & 146 & 495 & \\
\hline Producer's Accuracy & $98.48 \%$ & $47.67 \%$ & $73.97 \%$ & & \\
Overall Accuracy $=$ & $82.42 \%$ & & & & \\
OOB Error $=$ & $83.09 \%$ & & & & \\
Cohen's Kappa $=$ & 0.70 & & & & \\
\hline
\end{tabular}

\begin{tabular}{|lccccc|}
\hline & \multicolumn{5}{c|}{ VI(1) - Fall } \\
\cline { 2 - 5 } & Cropland & Rangeland & Seeded Forage & Total & User's Accuracy \\
\hline Cropland & $\mathbf{2 4 1}$ & 11 & 22 & 274 & $87.96 \%$ \\
Rangeland & 10 & $\mathbf{4 1}$ & 17 & 68 & $60.29 \%$ \\
Seeded Forage & 12 & 34 & $\mathbf{1 0 7}$ & 153 & $69.93 \%$ \\
Total & 263 & 86 & 146 & 495 & \\
\hline Producer's Accuracy & $91.63 \%$ & $47.67 \%$ & $73.29 \%$ & & \\
Overall Accuracy $=$ & $78.59 \%$ & & & & \\
OOB Error $=$ & $82.78 \%$ & & & & \\
Cohen's Kappa $=$ & 0.64 & & & & \\
\hline
\end{tabular}


Table A.5. Manitoba single-date RS2 classification error matrix

\begin{tabular}{|lccccc|}
\hline & \multicolumn{5}{c|}{ Radar } \\
\cline { 2 - 5 } & Cropland & Rangeland & Seeded Forage & Total & Us er's Accuracy \\
\hline Cropland & $\mathbf{2 3 2}$ & 9 & 30 & 271 & $85.61 \%$ \\
Rangeland & 8 & $\mathbf{3 3}$ & 42 & 83 & $39.76 \%$ \\
Seeded Forage & 23 & 44 & $\mathbf{7 4}$ & 141 & $52.48 \%$ \\
Total & 263 & 86 & 146 & 495 & \\
\hline Producer's Accuracy & $88.21 \%$ & $38.37 \%$ & $50.68 \%$ & & \\
Overall Accuracy $=$ & $68.48 \%$ & & & & \\
OOB Error $=$ & $67.84 \%$ & & & & \\
Cohen's Kappa $=$ & 0.47 & & & & \\
\hline
\end{tabular}


Table A.6. Manitoba single-date MS \& VI classification error matrices

\begin{tabular}{|lccccc|}
\hline & \multicolumn{5}{c|}{ MS (1) + VI (1) - Spring } \\
\cline { 2 - 5 } & Cropland & Rangeland & Seeded Forage & Total & User's Accuracy \\
\hline Cropland & $\mathbf{2 5 1}$ & 0 & 9 & 260 & $96.54 \%$ \\
Rangeland & 1 & $\mathbf{4 8}$ & 15 & 64 & $75.00 \%$ \\
Seeded Forage & 11 & 38 & $\mathbf{1 2 2}$ & 171 & $71.35 \%$ \\
Total & 263 & 86 & 146 & 495 & \\
\hline Producer's Accuracy & $95.44 \%$ & $55.81 \%$ & $83.56 \%$ & & \\
Overall Accuracy $=$ & $85.05 \%$ & & & & \\
OOB Error $=$ & $84.34 \%$ & & & & \\
Cohen's Kappa $=$ & 0.75 & & & & \\
\hline
\end{tabular}

\begin{tabular}{|lccccc|}
\hline & \multicolumn{3}{c|}{ MS (1) + VI (1) - Late Summer } & \\
\cline { 2 - 5 } & Cropland & Rangeland & Seeded Forage & Total & User's Accuracy \\
\hline Cropland & $\mathbf{2 5 8}$ & 1 & 8 & 267 & $96.63 \%$ \\
Rangeland & 2 & $\mathbf{5 0}$ & 23 & 75 & $66.67 \%$ \\
Seeded Forage & 3 & 35 & $\mathbf{1 1 5}$ & 153 & $75.16 \%$ \\
Total & 263 & 86 & 146 & 495 & \\
\hline Producer's Accuracy & $98.10 \%$ & $58.14 \%$ & $78.77 \%$ & & \\
Overall Accuracy $=$ & $85.45 \%$ & & & & \\
OOB Error $=$ & $85.27 \%$ & & & & \\
Cohen's Kappa $=$ & 0.76 & & & & \\
\hline
\end{tabular}

\begin{tabular}{|lccccc|}
\hline & \multicolumn{5}{c|}{ MS (1) + VI (1) - Fall } \\
\cline { 2 - 5 } & Cropland & Rangeland & Seeded Forage & Total & Us er's Accuracy \\
\hline Cropland & $\mathbf{2 4 2}$ & 7 & 19 & 268 & $90.30 \%$ \\
Rangeland & 7 & $\mathbf{4 5}$ & 18 & 70 & $64.29 \%$ \\
Seeded Forage & 14 & 34 & $\mathbf{1 0 9}$ & 157 & $69.43 \%$ \\
Total & 263 & 86 & 146 & 495 & \\
\hline Producer's Accuracy & $92.02 \%$ & $52.33 \%$ & $74.66 \%$ & & \\
Overall Accuracy $=$ & $80.00 \%$ & & & & \\
OOB Error $=$ & $84.34 \%$ & & & & \\
Cohen's Kappa $=$ & 0.66 & & & & \\
\hline
\end{tabular}


Table A.7. Manitoba single-date MS \& RS2 classification error matrices

\begin{tabular}{|lccccc|}
\hline & \multicolumn{5}{c|}{ MS (1)+ Radar - Spring } \\
\cline { 2 - 5 } & Cropland & Rangeland & Seeded Forage & Total & User's Accuracy \\
\hline Cropland & $\mathbf{2 5 2}$ & 1 & 8 & 261 & $96.55 \%$ \\
Rangeland & 0 & $\mathbf{5 2}$ & 13 & 65 & $80.00 \%$ \\
Seeded Forage & 11 & 33 & $\mathbf{1 2 5}$ & 169 & $73.96 \%$ \\
Total & 263 & 86 & 146 & 495 & \\
\hline Producer's Accuracy & $95.82 \%$ & $60.47 \%$ & $85.62 \%$ & & \\
Overall Accuracy $=$ & $86.67 \%$ & & & & \\
OOB Error $=$ & $86.94 \%$ & & & & \\
Cohen's Kappa $=$ & 0.78 & & & & \\
\hline
\end{tabular}

\begin{tabular}{|lccccc|}
\hline & \multicolumn{5}{c|}{ MS (1)+ Radar - Late Summer } \\
\cline { 2 - 5 } & Cropland & Rangeland & Seeded Forage & Total & User's Accuracy \\
\hline Cropland & $\mathbf{2 5 7}$ & 4 & 7 & 268 & $95.90 \%$ \\
Rangeland & 2 & $\mathbf{4 8}$ & 13 & 63 & $76.19 \%$ \\
Seeded Forage & 4 & 34 & $\mathbf{1 2 6}$ & 164 & $76.83 \%$ \\
Total & 263 & 86 & 146 & 495 & \\
\hline Producer's Accuracy & $97.72 \%$ & $55.81 \%$ & $86.30 \%$ & & \\
Overall Accuracy $=$ & $87.07 \%$ & & & & \\
OOB Error $=$ & $87.97 \%$ & & & & \\
Cohen's Kappa $=$ & 0.78 & & & & \\
\hline
\end{tabular}

\begin{tabular}{|lccccc|}
\hline & \multicolumn{5}{c|}{ MS (1)+ Radar - Fall } \\
\cline { 2 - 5 } & Cropland & Rangeland & Seeded Forage & Total & User's Accuracy \\
\hline Cropland & $\mathbf{2 5 2}$ & 2 & 14 & 268 & $94.03 \%$ \\
Rangeland & 1 & $\mathbf{5 2}$ & 17 & 70 & $74.29 \%$ \\
Seeded Forage & 10 & 32 & $\mathbf{1 1 5}$ & 157 & $73.25 \%$ \\
Total & 263 & 86 & 146 & 495 & \\
\hline Producer's Accuracy & $95.82 \%$ & $60.47 \%$ & $78.77 \%$ & & \\
Overall Accuracy $=$ & $84.65 \%$ & & & & \\
OOB Error $=$ & $85.06 \%$ & & & & \\
Cohen's Kappa $=$ & 0.74 & & & & \\
\hline
\end{tabular}


Table A.8. Manitoba single-date $M S+V I+R S 2$ classification error matrices

\begin{tabular}{|lccccc|}
\hline & \multicolumn{3}{c|}{ MS (1)+VI(1)+ Radar - Spring } & \\
\cline { 2 - 5 } & Cropland & Rangeland & Seeded Forage & Total & User's Accuracy \\
\hline Cropland & $\mathbf{2 5 3}$ & 1 & 9 & 263 & $96.20 \%$ \\
Rangeland & 0 & $\mathbf{5 4}$ & 14 & 68 & $79.41 \%$ \\
Seeded Forage & 10 & 31 & $\mathbf{1 2 3}$ & 164 & $75.00 \%$ \\
Total & 263 & 86 & 146 & 495 & \\
\hline Producer's Accuracy & $96.20 \%$ & $62.79 \%$ & $84.25 \%$ & & \\
Overall Accuracy $=$ & $86.87 \%$ & & & & \\
OOB Error $=$ & $86.94 \%$ & & & & \\
Cohen's Kappa $=$ & 0.78 & & & & \\
\hline
\end{tabular}

\begin{tabular}{|lccccc|}
\hline & \multicolumn{3}{c|}{ MS (1) + VI (1) + Radar - Late Summer } & \\
\cline { 2 - 5 } & Cropland & Rangeland & Seeded Forage & Total & User's Accuracy \\
\hline Cropland & $\mathbf{2 5 8}$ & 2 & 9 & 269 & $95.91 \%$ \\
Rangeland & 1 & $\mathbf{4 9}$ & 15 & 65 & $75.38 \%$ \\
Seeded Forage & 4 & 35 & $\mathbf{1 2 2}$ & 161 & $75.78 \%$ \\
Total & 263 & 86 & 146 & 495 & \\
\hline Producer's Accuracy & $98.10 \%$ & $56.98 \%$ & $83.56 \%$ & & \\
Overall Accuracy $=$ & $86.67 \%$ & & & & \\
OOB Error $=$ & $87.97 \%$ & & & & \\
Cohen's Kappa $=$ & 0.77 & & & & \\
\hline
\end{tabular}

\begin{tabular}{|lccccc|}
\hline & \multicolumn{5}{c|}{ MS (1) + VI (1) + Radar - Fall } \\
\cline { 2 - 5 } & Cropland & Rangeland & Seeded Forage & Total & User's Accuracy \\
\hline Cropland & $\mathbf{2 5 3}$ & 2 & 13 & 268 & $94.40 \%$ \\
Rangeland & 1 & $\mathbf{5 1}$ & 17 & 69 & $73.91 \%$ \\
Seeded Forage & 9 & 33 & $\mathbf{1 1 6}$ & 158 & $73.42 \%$ \\
Total & 263 & 86 & 146 & 495 & \\
\hline Producer's Accuracy & $96.20 \%$ & $59.30 \%$ & $79.45 \%$ & & \\
Overall Accuracy $=$ & $84.85 \%$ & & & & \\
OOB Error $=$ & $85.06 \%$ & & & & \\
Cohen's Kappa $=$ & 0.74 & & & & \\
\hline
\end{tabular}


Table A.9. Manitoba two-date MS classification error matrices

\begin{tabular}{|lccccc|}
\hline & \multicolumn{5}{c|}{ MS (2) - Spring \& Fall } \\
\cline { 2 - 5 } & Cropland & Rangeland & Seeded Forage & Total & User's Accuracy \\
\hline Cropland & $\mathbf{2 5 6}$ & 0 & 8 & 264 & $96.97 \%$ \\
Rangeland & 0 & $\mathbf{5 8}$ & 12 & 70 & $82.86 \%$ \\
Seeded Forage & 7 & 28 & $\mathbf{1 2 6}$ & 161 & $78.26 \%$ \\
Total & 263 & 86 & 146 & 495 & \\
\hline Producer's Accuracy & $97.34 \%$ & $67.44 \%$ & $86.30 \%$ & & \\
Overall Accuracy $=$ & $88.89 \%$ & & & & \\
OOB Error $=$ & $88.69 \%$ & & & & \\
Cohen's Kappa $=$ & 0.81 & & & & \\
\hline
\end{tabular}

\begin{tabular}{|lccccc|}
\hline & \multicolumn{3}{c|}{ MS (2) - Spring \& Late Summer } & \\
\cline { 2 - 5 } & Cropland & Rangeland & Seeded Forage & Total & User's Accuracy \\
\hline Cropland & $\mathbf{2 5 9}$ & 0 & 9 & 268 & $96.64 \%$ \\
Rangeland & 2 & $\mathbf{5 0}$ & 11 & 63 & $79.37 \%$ \\
Seeded Forage & 2 & 36 & $\mathbf{1 2 6}$ & 164 & $76.83 \%$ \\
Total & 263 & 86 & 146 & 495 & \\
\hline Producer's Accuracy & $98.48 \%$ & $58.14 \%$ & $86.30 \%$ & & \\
Overall Accuracy $=$ & $87.88 \%$ & & & & \\
OOB Error $=$ & $89.42 \%$ & & & & \\
Cohen's Kappa $=$ & 0.80 & & & & \\
\hline
\end{tabular}

\begin{tabular}{|lccccc|}
\hline & \multicolumn{5}{c|}{ MS (2) - Late Summer \& Fall } \\
\cline { 2 - 5 } & Cropland & Rangeland & Seeded Forage & Total & User's Accuracy \\
\hline Cropland & $\mathbf{2 5 8}$ & 3 & 10 & 271 & $95.20 \%$ \\
Rangeland & 1 & $\mathbf{5 1}$ & 18 & 70 & $72.86 \%$ \\
Seeded Forage & 4 & 32 & $\mathbf{1 1 8}$ & 154 & $76.62 \%$ \\
Total & 263 & 86 & 146 & 495 & \\
\hline Producer's Accuracy & $98.10 \%$ & $59.30 \%$ & $80.82 \%$ & & \\
Overall Accuracy $=$ & $86.26 \%$ & & & & \\
OOB Error $=$ & $88.69 \%$ & & & & \\
Cohen's Kappa $=$ & 0.77 & & & & \\
\hline
\end{tabular}


Table A.10. Manitoba two-date MS \& VI classification error matrices

\begin{tabular}{|lccccc|}
\hline & \multicolumn{3}{c|}{ MS (2) + VI (2) - Spring \& Fall } & \\
\cline { 2 - 5 } & Cropland & Rangeland & Seeded Forage & Total & User's Accuracy \\
\hline Cropland & $\mathbf{2 5 4}$ & 0 & 7 & 261 & $97.32 \%$ \\
Rangeland & 0 & $\mathbf{5 7}$ & 11 & 68 & $83.82 \%$ \\
Seeded Forage & 9 & 29 & $\mathbf{1 2 8}$ & 166 & $77.11 \%$ \\
Total & 263 & 86 & 146 & 495 & \\
\hline Producer's Accuracy & $96.58 \%$ & $66.28 \%$ & $87.67 \%$ & & \\
Overall Accuracy $=$ & $88.69 \%$ & & & & \\
OOB Error $=$ & $89.42 \%$ & & & & \\
Cohen's Kappa $=$ & 0.81 & & & & \\
\hline
\end{tabular}

\begin{tabular}{|lccccc|}
\hline \multicolumn{4}{c}{ MS (2) + VI (2) - Spring \& Late Summer } & \\
\cline { 2 - 5 } & Cropland & Rangeland & Seeded Forage & Total & User's Accuracy \\
\hline Cropland & $\mathbf{2 5 8}$ & 0 & 6 & 264 & $97.73 \%$ \\
Rangeland & 2 & $\mathbf{5 0}$ & 12 & 64 & $78.13 \%$ \\
Seeded Forage & 3 & 36 & $\mathbf{1 2 8}$ & 167 & $76.65 \%$ \\
Total & 263 & 86 & 146 & 495 & \\
\hline Producer's Accuracy & $98.10 \%$ & $58.14 \%$ & $87.67 \%$ & & \\
Overall Accuracy $=$ & $88.08 \%$ & & & & \\
OOB Error $=$ & $89.83 \%$ & & & & \\
Cohen's Kappa $=$ & 0.80 & & & & \\
\hline
\end{tabular}

\begin{tabular}{|lccccc|}
\hline & \multicolumn{3}{c}{ MS (2) + VI (2) - Late Summer \& Fall } & \\
\cline { 2 - 5 } & Cropland & Rangeland & Seeded Forage & Total & User's Accuracy \\
\hline Cropland & $\mathbf{2 5 9}$ & 2 & 11 & 272 & $95.22 \%$ \\
Rangeland & 1 & $\mathbf{5 1}$ & 16 & 68 & $75.00 \%$ \\
Seeded Forage & 3 & 33 & $\mathbf{1 1 9}$ & 155 & $76.77 \%$ \\
Total & 263 & 86 & 146 & 495 & \\
\hline Producer's Accuracy & $98.48 \%$ & $59.30 \%$ & $81.51 \%$ & & \\
Overall Accuracy $=$ & $86.67 \%$ & & & & \\
OOB Error $=$ & $89.32 \%$ & & & & \\
Cohen's Kappa $=$ & 0.77 & & & & \\
\hline
\end{tabular}


Table A.11. Manitoba two-date MS \& VI $+R S 2$ classification error matrices

\begin{tabular}{|lccccc|}
\hline & \multicolumn{3}{c}{ MS (2)+ VI (2) + Radar - Spring \& Fall } & \\
\cline { 2 - 5 } & Cropland & Rangeland & Seeded Forage & Total & User's Accuracy \\
\hline Cropland & $\mathbf{2 5 7}$ & 1 & 6 & 264 & $97.35 \%$ \\
Rangeland & 0 & $\mathbf{5 6}$ & 12 & 68 & $82.35 \%$ \\
Seeded Forage & 6 & 29 & $\mathbf{1 2 8}$ & 163 & $78.53 \%$ \\
Total & 263 & 86 & 146 & 495 & \\
\hline Producer's Accuracy & $97.72 \%$ & $65.12 \%$ & $87.67 \%$ & & \\
Overall Accuracy $=$ & $89.09 \%$ & & & & \\
OOB Error $=$ & $89.94 \%$ & & & & \\
Cohen's Kappa $=$ & 0.82 & & & & \\
\hline
\end{tabular}

\begin{tabular}{|lccccc|}
\hline & \multicolumn{2}{c}{ MS (2)+VI (2) + Radar - Spring \& Late Summer } & \\
\cline { 2 - 5 } & Cropland & Rangeland & Seeded Forage & Total & User's Accuracy \\
\hline Cropland & $\mathbf{2 5 8}$ & 0 & 5 & 263 & $98.10 \%$ \\
Rangeland & 1 & $\mathbf{5 2}$ & 11 & 64 & $81.25 \%$ \\
Seeded Forage & 4 & 34 & $\mathbf{1 3 0}$ & 168 & $77.38 \%$ \\
Total & 263 & 86 & 146 & 495 & \\
\hline Producer's Accuracy & $98.10 \%$ & $60.47 \%$ & $89.04 \%$ & & \\
Overall Accuracy $=$ & $88.89 \%$ & & & & \\
OOB Error $=$ & $90.46 \%$ & & & & \\
Cohen's Kappa $=$ & 0.81 & & & & \\
\hline
\end{tabular}

\begin{tabular}{|lccccc|}
\hline & \multicolumn{2}{c}{ MS (2) + VI (2) + Radar - Late Summer \& Fall } & \\
\cline { 2 - 5 } & Cropland & Rangeland & Seeded Forage & Total & User's Accuracy \\
\hline Cropland & $\mathbf{2 6 0}$ & 1 & 7 & 268 & $97.01 \%$ \\
Rangeland & 0 & $\mathbf{5 7}$ & 14 & 71 & $80.28 \%$ \\
Seeded Forage & 3 & 28 & $\mathbf{1 2 5}$ & 156 & $80.13 \%$ \\
Total & 263 & 86 & 146 & 495 & \\
\hline Producer's Accuracy & $98.86 \%$ & $66.28 \%$ & $85.62 \%$ & & \\
Overall Accuracy $=$ & $89.29 \%$ & & & & \\
OOB Error $=$ & $90.87 \%$ & & & & \\
Cohen's Kappa $=$ & 0.82 & & & & \\
\hline
\end{tabular}


Table A.12. Manitoba three-date classification error matrices (part 1)

\begin{tabular}{|lccccc|}
\hline & \multicolumn{5}{c|}{ MS (3) } \\
\cline { 2 - 5 } & Cropland & Rangeland & Seeded Forage & Total & User's Accuracy \\
\hline Cropland & $\mathbf{2 6 0}$ & 0 & 3 & 263 & $98.86 \%$ \\
Rangeland & 1 & $\mathbf{5 4}$ & 14 & 69 & $78.26 \%$ \\
Seeded Forage & 2 & 32 & $\mathbf{1 2 9}$ & 163 & $79.14 \%$ \\
Total & 263 & 86 & 146 & 495 & \\
\hline Producer's Accuracy & $98.86 \%$ & $62.79 \%$ & $88.36 \%$ & & \\
Overall Accuracy $=$ & $89.49 \%$ & & & & \\
OOB Error $=$ & $90.77 \%$ & & & & \\
Cohen's Kappa $=$ & 0.82 & & & & \\
\hline
\end{tabular}

\begin{tabular}{|lccccc|}
\hline & \multicolumn{5}{c|}{ MS (3) + VI (3) } \\
\cline { 2 - 5 } & Cropland & Rangeland & Seeded Forage & Total & Us er's Accuracy \\
\hline Cropland & $\mathbf{2 6 0}$ & 0 & 3 & 263 & $98.86 \%$ \\
Rangeland & 1 & $\mathbf{5 4}$ & 15 & 70 & $77.14 \%$ \\
Seeded Forage & 2 & 32 & $\mathbf{1 2 8}$ & 162 & $79.01 \%$ \\
Total & 263 & 86 & 146 & 495 & \\
\hline Producer's Accuracy & $98.86 \%$ & $62.79 \%$ & $87.67 \%$ & & \\
Overall Accuracy $=$ & $89.29 \%$ & & & & \\
OOB Error $=$ & $90.98 \%$ & & & & \\
Cohen's Kappa $=$ & 0.82 & & & & \\
\hline
\end{tabular}

\begin{tabular}{|lccccc|}
\hline & \multicolumn{5}{c|}{ MS (3) + Radar } \\
\cline { 2 - 5 } & Cropland & Rangeland & Seeded Forage & Total & User's Accuracy \\
\hline Cropland & $\mathbf{2 6 0}$ & 0 & 4 & 264 & $98.48 \%$ \\
Rangeland & 1 & $\mathbf{5 5}$ & 14 & 70 & $78.57 \%$ \\
Seeded Forage & 2 & 31 & $\mathbf{1 2 8}$ & 161 & $79.50 \%$ \\
Total & 263 & 86 & 146 & 495 & \\
\hline Producer's Accuracy & $98.86 \%$ & $63.95 \%$ & $87.67 \%$ & & \\
Overall Accuracy $=$ & $89.49 \%$ & & & & \\
OOB Error $=$ & $91.70 \%$ & & & & \\
Cohen's Kappa $=$ & 0.82 & & & & \\
\hline
\end{tabular}


Table A.13. Manitoba three-date classification error matrices (part 2)

\begin{tabular}{|lccccc|}
\hline & \multicolumn{5}{c|}{ MS (3) + VI (3) + Radar } \\
\cline { 2 - 5 } & Cropland & Rangeland & Seeded Forage & Total & User's Accuracy \\
\hline Cropland & $\mathbf{2 5 8}$ & 0 & 5 & 263 & $98.10 \%$ \\
Rangeland & 1 & $\mathbf{5 2}$ & 14 & 67 & $77.61 \%$ \\
Seeded Forage & 4 & 34 & $\mathbf{1 2 7}$ & 165 & $76.97 \%$ \\
Total & 263 & 86 & 146 & 495 & \\
\hline Producer's Accuracy & $98.10 \%$ & $60.47 \%$ & $86.99 \%$ & & \\
Overall Accuracy $=$ & $88.28 \%$ & & & & \\
OOB Error $=$ & $91.08 \%$ & & & & \\
Cohen's Kappa $=$ & 0.80 & & & & \\
\hline
\end{tabular}

\begin{tabular}{|lccccc|}
\hline & \multicolumn{5}{c|}{ MS (3) + VI (3) + PhenNDVI } \\
\cline { 2 - 5 } & Cropland & Rangeland & Seeded Forage & Total & User's Accuracy \\
\hline Cropland & $\mathbf{2 6 0}$ & 0 & 5 & 265 & $98.11 \%$ \\
Rangeland & 0 & $\mathbf{5 2}$ & 14 & 66 & $78.79 \%$ \\
Seeded Forage & 3 & 34 & $\mathbf{1 2 7}$ & 164 & $77.44 \%$ \\
Total & 263 & 86 & 146 & 495 & \\
\hline Producer's Accuracy & $98.86 \%$ & $60.47 \%$ & $86.99 \%$ & & \\
Overall Accuracy $=$ & $88.69 \%$ & & & & \\
OOB Error $=$ & $89.94 \%$ & & & & \\
Cohen's Kappa $=$ & 0.81 & & & & \\
\hline
\end{tabular}

\begin{tabular}{|lccccc|}
\hline & \multicolumn{3}{c|}{ MS (3) + VI (3) + PhenNDVI+ Radar } & \\
\cline { 2 - 5 } & Cropland & Rangeland & Seeded Forage & Total & User's Accuracy \\
\hline Cropland & $\mathbf{2 5 9}$ & 0 & 7 & 266 & $97.37 \%$ \\
Rangeland & 1 & $\mathbf{5 2}$ & 12 & 65 & $80.00 \%$ \\
Seeded Forage & 3 & 34 & $\mathbf{1 2 7}$ & 164 & $77.44 \%$ \\
Total & 263 & 86 & 146 & 495 & \\
\hline Producer's Accuracy & $98.48 \%$ & $60.47 \%$ & $86.99 \%$ & & \\
Overall Accuracy $=$ & $88.48 \%$ & & & & \\
OOB Error $=$ & $90.66 \%$ & & & & \\
Cohen's Kappa $=$ & 0.81 & & & & \\
\hline
\end{tabular}


Table A.14. Classification Accuracy Statistics derived from the Error Matrices for the Alberta Study Area.

\begin{tabular}{|c|c|c|c|c|c|c|c|c|c|c|c|c|}
\hline & Classification Variables & $\begin{array}{c}\text { Overall } \\
\text { Accuracy }\end{array}$ & $\begin{array}{c}\text { Cropland } \\
\text { PA }\end{array}$ & $\begin{array}{c}\text { Cropland } \\
\text { UA }\end{array}$ & $\begin{array}{c}\text { Rangeland } \\
\text { PA }\end{array}$ & $\begin{array}{c}\text { Rangeland } \\
\text { UA }\end{array}$ & $\begin{array}{c}\text { Seeded } \\
\text { Forage } \\
\text { PA }\end{array}$ & $\begin{array}{c}\text { Seeded } \\
\text { Forage } \\
\text { UA }\end{array}$ & $\begin{array}{l}\text { OOB } \\
\text { Error }\end{array}$ & $\begin{array}{c}\text { Diffe rence } \\
\text { in Error } \\
\text { (OA - } \\
\text { OOB) }\end{array}$ & $\begin{array}{c}\text { \# of } \\
\text { Variables }\end{array}$ & $\begin{array}{c}\text { Cohen's } \\
\text { Kappa }\end{array}$ \\
\hline \multirow[t]{18}{*}{ Optical (LS8) } & MS (1) - Spring & 88.80 & 90.65 & 92.53 & 90.97 & 93.57 & 81.82 & 75.63 & 89.12 & -0.32 & 6 & 0.82 \\
\hline & MS (1) - Mid Summer & 86.40 & 93.50 & 86.47 & 88.89 & 94.12 & 67.27 & 75.51 & 83.97 & 2.43 & 6 & 0.78 \\
\hline & MS (1) - Late Summer & 88.00 & 96.34 & 92.58 & 83.33 & 89.55 & 75.45 & 75.45 & 87.89 & 0.11 & 6 & 0.81 \\
\hline & VI (1) - Spring & 88.00 & 91.87 & 91.13 & 88.19 & 94.78 & 79.09 & 73.73 & 84.68 & 3.32 & 4 & 0.81 \\
\hline & VI (1) - Mid Summer & 84.60 & 95.93 & 84.59 & 88.89 & 88.28 & 53.64 & 77.63 & 81.80 & 2.80 & 4 & 0.75 \\
\hline & VI (1) - Late Summer & 86.80 & 94.72 & 94.33 & 84.03 & 83.45 & 72.73 & 74.07 & 88.43 & -1.63 & 4 & 0.79 \\
\hline & MS (2) - Spring \& Mid Summer & 90.60 & 95.12 & 93.98 & 89.58 & 94.16 & 81.82 & 78.95 & 91.00 & -0.40 & 12 & 0.85 \\
\hline & MS (2) - Spring \& Late Summer & 91.20 & 97.56 & 94.12 & 88.19 & 91.37 & 80.91 & 83.96 & 91.89 & -0.69 & 12 & 0.86 \\
\hline & MS (2) - Mid \& Late Summer & 89.80 & 95.53 & 92.16 & 88.19 & 94.07 & 79.09 & 79.09 & 87.68 & 2.12 & 12 & 0.84 \\
\hline & MS (3) & 92.80 & 96.75 & 95.58 & 90.97 & 95.62 & 86.36 & 83.33 & 92.53 & 0.27 & 18 & 0.88 \\
\hline & MS (1) + VI (1) - Spring & 88.40 & 91.06 & 91.80 & 89.58 & 94.85 & 80.91 & 74.17 & 90.56 & -2.16 & 10 & 0.82 \\
\hline & MS (1) + VI (1) - Mid Summer & 87.60 & 95.12 & 85.71 & 90.97 & 94.24 & 66.36 & 82.95 & 84.82 & 2.78 & 10 & 0.80 \\
\hline & MS (1) + VI (1) - Late Summer & 87.80 & 95.53 & 94.00 & 81.94 & 88.72 & 78.18 & 73.50 & 88.85 & -1.05 & 10 & 0.81 \\
\hline & MS (2) + VI (2) - Spring \& Mid Summer & 92.40 & 98.37 & 93.44 & 92.36 & 93.01 & 79.09 & 88.78 & 91.15 & 1.25 & 20 & 0.88 \\
\hline & MS (2) + VI (2) - Spring \& Late Summer & 91.40 & 96.75 & 94.82 & 87.50 & 94.74 & 84.55 & 80.17 & 91.84 & -0.44 & 20 & 0.86 \\
\hline & MS (2) + VI (2) - Mid \& Late Summer & 92.00 & 96.75 & 94.44 & 88.89 & 94.81 & 85.45 & 83.19 & 89.94 & 2.06 & 20 & 0.87 \\
\hline & MS (3) + VI (3) & 92.60 & 97.97 & 95.26 & 89.58 & 95.56 & 84.55 & 83.04 & 93.17 & -0.57 & 30 & 0.88 \\
\hline & MS (3) + VI (3) + PhenNDVI & 93.60 & 97.97 & 96.40 & 90.97 & 95.62 & 87.27 & 84.96 & 92.47 & 1.13 & 38 & 0.90 \\
\hline Radar (RS2) & Radar & 75.80 & 87.80 & 76.60 & 84.72 & 87.77 & 37.27 & 51.90 & 74.62 & 1.18 & 2 & 0.60 \\
\hline \multirow[t]{15}{*}{ Optical + Radar } & MS (1) + Radar - Spring & 88.60 & 91.46 & 93.36 & 90.28 & 93.53 & 80.00 & 73.33 & 91.19 & -2.59 & 8 & 0.82 \\
\hline & MS (1) + Radar - Mid Summer & 88.00 & 92.28 & 88.33 & 90.97 & 95.62 & 74.55 & 77.36 & 85.47 & 2.53 & 8 & 0.81 \\
\hline & MS (1) + Radar - Late Summer & 88.20 & 95.12 & 92.86 & 85.42 & 92.48 & 76.36 & 73.04 & 88.19 & 0.01 & 8 & 0.81 \\
\hline & MS (2) + Radar - Spring \& Mid Summer & 91.40 & 96.34 & 92.58 & 90.97 & 96.32 & 80.91 & 82.41 & 91.93 & -0.53 & 14 & 0.86 \\
\hline & MS (2) + Radar - Spring \& Late Summer & 91.80 & 97.15 & 94.84 & 89.58 & 94.16 & 82.73 & 81.98 & 93.10 & -1.30 & 14 & 0.87 \\
\hline & MS (2) + Radar - Mid \& Late Summer & 90.00 & 95.93 & 92.91 & 87.50 & 94.03 & 80.00 & 78.57 & 89.54 & 0.46 & 14 & 0.84 \\
\hline & MS (3) + Radar & 92.20 & 96.75 & 94.82 & 90.97 & 95.62 & 83.64 & 82.14 & 92.87 & -0.67 & 20 & 0.88 \\
\hline & MS (1) + VI (1) + Radar - Spring & 89.00 & 91.46 & 93.36 & 89.58 & 94.85 & 82.73 & 73.98 & 90.47 & -1.47 & 12 & 0.83 \\
\hline & MS (1) + VI (1) + Radar - Mid Summer & 86.80 & 92.68 & 88.03 & 88.19 & 94.07 & 71.82 & 74.53 & 85.88 & 0.92 & 12 & 0.79 \\
\hline & MS (1) + VI (1) + Radar - Late Summer & 89.80 & 95.93 & 93.65 & 85.42 & 92.48 & 81.82 & 78.26 & 90.24 & -0.44 & 12 & 0.84 \\
\hline & MS (2) + VI (2) + Radar - Spring \& Mid Summer & 92.60 & 98.37 & 93.80 & 91.67 & 94.96 & 80.91 & 86.41 & 92.68 & -0.08 & 22 & 0.88 \\
\hline & MS (2) + VI (2) + Radar - Spring \& Late Summer & 92.60 & 97.56 & 96.00 & 89.58 & 94.16 & 85.45 & 83.19 & 92.10 & 0.50 & 22 & 0.88 \\
\hline & MS (2) + VI (2) + Radar - Mid \& Late Summer & 91.80 & 96.75 & 95.58 & 88.19 & 94.07 & 85.45 & 81.03 & 91.57 & 0.23 & 22 & 0.87 \\
\hline & MS (3) + VI (3) + Radar & 93.40 & 98.78 & 95.67 & 89.58 & 95.56 & 86.36 & 85.59 & 92.52 & 0.88 & 32 & 0.89 \\
\hline & MS (3) + VI (3) + PhenNDVI + Radar & 94.00 & 97.97 & 96.02 & 91.67 & 96.35 & 88.18 & 86.61 & 93.73 & 0.27 & 40 & 0.90 \\
\hline
\end{tabular}

Note: PA is the class-based Producer's Accuracy (error of omission) while UA is the User's Accuracy (error of commission). OOB error is the internal estimate of error from the RF classification. 
Table A.15. Alberta single-date MS classification error matrices

\begin{tabular}{|lccccc|}
\hline & \multicolumn{5}{c|}{ MS (1) - Spring } \\
\cline { 2 - 5 } & Cropland & Rangeland & Seeded Forage & Total & User's Accuracy \\
\hline Cropland & $\mathbf{2 2 3}$ & 5 & 13 & 241 & $92.53 \%$ \\
Rangeland & 2 & $\mathbf{1 3 1}$ & 7 & 140 & $93.57 \%$ \\
Seeded Forage & 21 & 8 & $\mathbf{9 0}$ & 119 & $75.63 \%$ \\
Total & 246 & 144 & 110 & 500 & \\
\hline Producer's Accuracy & $90.65 \%$ & $90.97 \%$ & $81.82 \%$ & & \\
Overall Accuracy $=$ & $88.80 \%$ & & & & \\
OOB Error $=$ & $89.12 \%$ & & & & \\
Cohen's Kappa $=$ & 0.82 & & & & \\
\hline
\end{tabular}

\begin{tabular}{|lccccc|}
\hline & \multicolumn{5}{c|}{ MS (1) - Mid Summer } \\
\cline { 2 - 5 } & Cropland & Rangeland & Seeded Forage & Total & User's Accuracy \\
\hline Cropland & $\mathbf{2 3 0}$ & 7 & 29 & 266 & $86.47 \%$ \\
Rangeland & 1 & $\mathbf{1 2 8}$ & 7 & 136 & $94.12 \%$ \\
Seeded Forage & 15 & 9 & $\mathbf{7 4}$ & 98 & $75.51 \%$ \\
Total & 246 & 144 & 110 & 500 & \\
\hline Producer's Accuracy & $93.50 \%$ & $88.89 \%$ & $67.27 \%$ & & \\
Overall Accuracy $=$ & $86.40 \%$ & & & & \\
OOB Error $=$ & $83.97 \%$ & & & & \\
Cohen's Kappa $=$ & 0.78 & & & & \\
\hline
\end{tabular}

\begin{tabular}{|lccccc|}
\hline & \multicolumn{5}{c|}{ MS (1) - Late Summer } \\
\cline { 2 - 5 } & Cropland & Rangeland & Seeded Forage & Total & Us er's Accuracy \\
\hline Cropland & $\mathbf{2 3 7}$ & 6 & 13 & 256 & $92.58 \%$ \\
Rangeland & 0 & $\mathbf{1 2 0}$ & 14 & 134 & $89.55 \%$ \\
Seeded Forage & 9 & 18 & $\mathbf{8 3}$ & 110 & $75.45 \%$ \\
Total & 246 & 144 & 110 & 500 & \\
\hline Producer's Accuracy & $96.34 \%$ & $83.33 \%$ & $75.45 \%$ & & \\
Overall Accuracy $=$ & $88.00 \%$ & & & & \\
OOB Error $=$ & $87.89 \%$ & & & & \\
Cohen's Kappa $=$ & 0.81 & & & & \\
\hline
\end{tabular}


Table A.16. Alberta single-date VI classification error matrices

\begin{tabular}{|lccccc|}
\hline & \multicolumn{5}{c|}{ VI (1) - Spring } \\
\cline { 2 - 5 } & Cropland & Rangeland & Seeded Forage & Total & User's Accuracy \\
\hline Cropland & $\mathbf{2 2 6}$ & 5 & 17 & 248 & $91.13 \%$ \\
Rangeland & 1 & $\mathbf{1 2 7}$ & 6 & 134 & $94.78 \%$ \\
Seeded Forage & 19 & 12 & $\mathbf{8 7}$ & 118 & $73.73 \%$ \\
Total & 246 & 144 & 110 & 500 & \\
\hline Producer's Accuracy & $91.87 \%$ & $88.19 \%$ & $79.09 \%$ & & \\
Overall Accuracy $=$ & $88.00 \%$ & & & & \\
OOB Error $=$ & $84.68 \%$ & & & & \\
Cohen's Kappa $=$ & 0.81 & & & & \\
\hline
\end{tabular}

\begin{tabular}{|lccccc|}
\hline & \multicolumn{5}{c|}{ VI (1) - Mid Summer } \\
\cline { 2 - 5 } & Cropland & Rangeland & Seeded Forage & Total & Us er's Accuracy \\
\hline Cropland & $\mathbf{2 3 6}$ & 8 & 35 & 279 & $84.59 \%$ \\
Rangeland & 1 & $\mathbf{1 2 8}$ & 16 & 145 & $88.28 \%$ \\
Seeded Forage & 9 & 8 & $\mathbf{5 9}$ & 76 & $77.63 \%$ \\
Total & 246 & 144 & 110 & 500 & \\
\hline Producer's Accuracy & $95.93 \%$ & $88.89 \%$ & $53.64 \%$ & & \\
Overall Accuracy $=$ & $84.60 \%$ & & & & \\
OOB Error $=$ & $81.80 \%$ & & & & \\
Cohen's Kappa $=$ & 0.75 & & & & \\
\hline
\end{tabular}

\begin{tabular}{|lccccc|}
\hline & \multicolumn{5}{c|}{ VI(1) - Late Summer } \\
\cline { 2 - 5 } & Cropland & Rangeland & Seeded Forage & Total & User's Accuracy \\
\hline Cropland & $\mathbf{2 3 3}$ & 4 & 10 & 247 & $94.33 \%$ \\
Rangeland & 4 & $\mathbf{1 2 1}$ & 20 & 145 & $83.45 \%$ \\
Seeded Forage & 9 & 19 & $\mathbf{8 0}$ & 108 & $74.07 \%$ \\
Total & 246 & 144 & 110 & 500 & \\
\hline Producer's Accuracy & $94.72 \%$ & $84.03 \%$ & $72.73 \%$ & & \\
Overall Accuracy $=$ & $86.80 \%$ & & & & \\
OOB Error $=$ & $88.43 \%$ & & & & \\
Cohen's Kappa $=$ & 0.79 & & & & \\
\hline
\end{tabular}


Table A.17. Alberta single-date RS2 classification error matrix

\begin{tabular}{|lccccc|}
\hline & \multicolumn{5}{c|}{ Radar } \\
\cline { 2 - 5 } & Cropland & Rangeland & Seeded Forage & Total & User's Accuracy \\
\hline Cropland & $\mathbf{2 1 6}$ & 10 & 56 & 282 & $76.60 \%$ \\
Rangeland & 4 & $\mathbf{1 2 2}$ & 13 & 139 & $87.77 \%$ \\
Seeded Forage & 26 & 12 & $\mathbf{4 1}$ & 79 & $51.90 \%$ \\
Total & 246 & 144 & 110 & 500 & \\
\hline Producer's Accuracy & $87.80 \%$ & $84.72 \%$ & $37.27 \%$ & & \\
Overall Accuracy $=$ & $75.80 \%$ & & & & \\
OOB Error $=$ & $74.62 \%$ & & & & \\
Cohen's Kappa $=$ & 0.60 & & & & \\
\hline
\end{tabular}


Table A.18. Alberta single-date MS \& VI classification error matrices

\begin{tabular}{|c|c|c|c|c|c|}
\hline & \multicolumn{4}{|c|}{ MS (1) + VI (1) - Spring } & \multirow[b]{2}{*}{ User's Accuracy } \\
\hline & Cropland & Rangeland & Seeded Forage & Total & \\
\hline Cropland & 224 & 5 & 15 & 244 & $91.80 \%$ \\
\hline Rangeland & 1 & 129 & 6 & 136 & $94.85 \%$ \\
\hline Seeded Forage & 21 & 10 & 89 & 120 & $74.17 \%$ \\
\hline Total & 246 & 144 & 110 & 500 & \\
\hline Producer's Accuracy & $91.06 \%$ & $89.58 \%$ & $80.91 \%$ & & \\
\hline Overall Accuracy $=$ & $88.40 \%$ & & & & \\
\hline OOB Error = & $90.56 \%$ & & & & \\
\hline Cohen's Kappa = & 0.82 & & & & \\
\hline
\end{tabular}

\begin{tabular}{|lccccc|}
\hline & \multicolumn{3}{c|}{ MS (1) + VI (1) - Mid Summer } & \\
\cline { 2 - 5 } & Cropland & Rangeland & Seeded Forage & Total & User's Accuracy \\
\hline Cropland & $\mathbf{2 3 4}$ & 9 & 30 & 273 & $85.71 \%$ \\
Rangeland & 1 & $\mathbf{1 3 1}$ & 7 & 139 & $94.24 \%$ \\
Seeded Forage & 11 & 4 & $\mathbf{7 3}$ & 88 & $82.95 \%$ \\
Total & 246 & 144 & 110 & 500 & \\
\hline Producer's Accuracy & $95.12 \%$ & $90.97 \%$ & $66.36 \%$ & & \\
Overall Accuracy $=$ & $87.60 \%$ & & & & \\
OOB Error $=$ & $84.82 \%$ & & & & \\
Cohen's Kappa $=$ & 0.80 & & & & \\
\hline
\end{tabular}

\begin{tabular}{|lccccc|}
\hline & \multicolumn{3}{c|}{ MS (1) + VI (1) - Late Summer } & \\
\cline { 2 - 5 } & Cropland & Rangeland & Seeded Forage & Total & User's Accuracy \\
\hline Cropland & $\mathbf{2 3 4}$ & 9 & 30 & 273 & $85.71 \%$ \\
Rangeland & 1 & $\mathbf{1 3 1}$ & 7 & 139 & $94.24 \%$ \\
Seeded Forage & 11 & 4 & $\mathbf{7 3}$ & 88 & $82.95 \%$ \\
Total & 246 & 144 & 110 & 500 & \\
\hline Producer's Accuracy & $95.12 \%$ & $90.97 \%$ & $66.36 \%$ & & \\
Overall Accuracy $=$ & $87.60 \%$ & & & & \\
OOB Error $=$ & $88.85 \%$ & & & & \\
Cohen's Kappa $=$ & 0.81 & & & & \\
\hline
\end{tabular}


Table A.19. Alberta single-date MS $+R S 2$ classification error matrices

\begin{tabular}{|lccccc|}
\hline & \multicolumn{5}{c|}{ MS (1) + Radar - Spring } \\
\cline { 2 - 5 } & Cropland & Rangeland & Seeded Forage & Total & User's Accuracy \\
\hline Cropland & $\mathbf{2 2 5}$ & 3 & 13 & 241 & $93.36 \%$ \\
Rangeland & 0 & $\mathbf{1 3 0}$ & 9 & 139 & $93.53 \%$ \\
Seeded Forage & 21 & 11 & $\mathbf{8 8}$ & 120 & $73.33 \%$ \\
Total & 246 & 144 & 110 & 500 & \\
\hline Producer's Accuracy & $91.46 \%$ & $90.28 \%$ & $80.00 \%$ & & \\
Overall Accuracy $=$ & $88.60 \%$ & & & & \\
OOB Error $=$ & $91.19 \%$ & & & & \\
Cohen's Kappa $=$ & 0.82 & & & & \\
\hline
\end{tabular}

\begin{tabular}{|lccccc|}
\hline & \multicolumn{3}{c|}{ MS (1) + Radar - Mid Summer } & \\
\cline { 2 - 5 } & Cropland & Rangeland & Seeded Forage & Total & User's Accuracy \\
\hline Cropland & $\mathbf{2 2 5}$ & 3 & 13 & 241 & $93.36 \%$ \\
Rangeland & 0 & $\mathbf{1 3 0}$ & 9 & 139 & $93.53 \%$ \\
Seeded Forage & 21 & 11 & $\mathbf{8 8}$ & 120 & $73.33 \%$ \\
Total & 246 & 144 & 110 & 500 & \\
\hline Producer's Accuracy & $91.46 \%$ & $90.28 \%$ & $80.00 \%$ & & \\
Overall Accuracy $=$ & $88.60 \%$ & & & & \\
OOB Error $=$ & $85.47 \%$ & & & & \\
Cohen's Kappa $=$ & 0.81 & & & & \\
\hline
\end{tabular}

\begin{tabular}{|lccccc|}
\hline & \multicolumn{3}{c|}{ MS (1) + Radar - Late Summer } & \\
\cline { 2 - 5 } & Cropland & Rangeland & Seeded Forage & Total & User's Accuracy \\
\hline Cropland & $\mathbf{2 3 4}$ & 2 & 16 & 252 & $92.86 \%$ \\
Rangeland & 0 & $\mathbf{1 2 3}$ & 10 & 133 & $92.48 \%$ \\
Seeded Forage & 12 & 19 & $\mathbf{8 4}$ & 115 & $73.04 \%$ \\
Total & 246 & 144 & 110 & 500 & \\
\hline Producer's Accuracy & $95.12 \%$ & $85.42 \%$ & $76.36 \%$ & & \\
Overall Accuracy $=$ & $88.20 \%$ & & & & \\
OOB Error $=$ & $88.19 \%$ & & & & \\
Cohen's Kappa $=$ & 0.81 & & & & \\
\hline
\end{tabular}


Table A.20. Alberta single-date MS + VI \& RS2 classification error matrices

\begin{tabular}{|lccccc|}
\hline & \multicolumn{3}{c|}{ MS (1) + VI (1) + Radar - Spring } & \\
\cline { 2 - 5 } & Cropland & Rangeland & Seeded Forage & Total & User's Accuracy \\
\hline Cropland & $\mathbf{2 2 7}$ & 8 & 22 & 257 & $88.33 \%$ \\
Rangeland & 0 & $\mathbf{1 3 1}$ & 6 & 137 & $95.62 \%$ \\
Seeded Forage & 19 & 5 & $\mathbf{8 2}$ & 106 & $77.36 \%$ \\
Total & 246 & 144 & 110 & 500 & \\
\hline Producer's Accuracy & $92.28 \%$ & $90.97 \%$ & $74.55 \%$ & & \\
Overall Accuracy $=$ & $88.00 \%$ & & & & \\
OOB Error $=$ & $90.47 \%$ & & & & \\
Cohen's Kappa $=$ & 0.82 & & & & \\
\hline
\end{tabular}

\begin{tabular}{|lccccc|}
\hline & \multicolumn{3}{c}{ MS (1) + VI (1) + Radar - Mid Summer } & \\
\cline { 2 - 5 } & Cropland & Rangeland & Seeded Forage & Total & Us er's Accuracy \\
\hline Cropland & $\mathbf{2 2 8}$ & 8 & 23 & 259 & $88.03 \%$ \\
Rangeland & 0 & $\mathbf{1 2 7}$ & 8 & 135 & $94.07 \%$ \\
Seeded Forage & 18 & 9 & $\mathbf{7 9}$ & 106 & $74.53 \%$ \\
Total & 246 & 144 & 110 & 500 & \\
\hline Producer's Accuracy & $92.68 \%$ & $88.19 \%$ & $71.82 \%$ & & \\
Overall Accuracy $=$ & $86.80 \%$ & & & & \\
OOB Error $=$ & $85.88 \%$ & & & & \\
Cohen's Kappa $=$ & 0.79 & & & & \\
\hline
\end{tabular}

\begin{tabular}{|lccccc|}
\hline & \multicolumn{3}{c}{ MS (1)+VI (1) + Radar - Late Summer } & \\
\cline { 2 - 5 } & Cropland & Rangeland & Seeded Forage & Total & Us er's Accuracy \\
\hline Cropland & $\mathbf{2 3 6}$ & 5 & 11 & 252 & $93.65 \%$ \\
Rangeland & 1 & $\mathbf{1 2 3}$ & 9 & 133 & $92.48 \%$ \\
Seeded Forage & 9 & 16 & $\mathbf{9 0}$ & 115 & $78.26 \%$ \\
Total & 246 & 144 & 110 & 500 & \\
\hline Producer's Accuracy & $95.93 \%$ & $85.42 \%$ & $81.82 \%$ & & \\
Overall Accuracy $=$ & $89.80 \%$ & & & & \\
OOB Error $=$ & $90.24 \%$ & & & & \\
Cohen's Kappa $=$ & 0.84 & & & & \\
\hline
\end{tabular}


Table A.21. Alberta two-date MS classification error matrices

\begin{tabular}{|lccccc|}
\hline & \multicolumn{3}{c|}{ MS (2) - Spring \& Late Summer } & \\
\cline { 2 - 5 } & Cropland & Rangeland & Seeded Forage & Total & Us er's Accuracy \\
\hline Cropland & $\mathbf{2 4 0}$ & 6 & 9 & 255 & $94.12 \%$ \\
Rangeland & 0 & $\mathbf{1 2 7}$ & 12 & 139 & $91.37 \%$ \\
Seeded Forage & 6 & 11 & $\mathbf{8 9}$ & 106 & $83.96 \%$ \\
Total & 246 & 144 & 110 & 500 & \\
\hline Producer's Accuracy & $97.56 \%$ & $88.19 \%$ & $80.91 \%$ & & \\
Overall Accuracy $=$ & $91.20 \%$ & & & & \\
OOB Error $=$ & $91.89 \%$ & & & & \\
Cohen's Kappa $=$ & 0.86 & & & & \\
\hline
\end{tabular}

\begin{tabular}{|lccccc|}
\hline & \multicolumn{3}{c|}{ MS (2) - Spring \& Mid Summer } & \\
\cline { 2 - 5 } & Cropland & Rangeland & Seeded Forage & Total & User's Accuracy \\
\hline Cropland & $\mathbf{2 3 4}$ & 1 & 14 & 249 & $93.98 \%$ \\
Rangeland & 2 & $\mathbf{1 2 9}$ & 6 & 137 & $94.16 \%$ \\
Seeded Forage & 10 & 14 & $\mathbf{9 0}$ & 114 & $78.95 \%$ \\
Total & 246 & 144 & 110 & 500 & \\
\hline Producer's Accuracy & $95.12 \%$ & $89.58 \%$ & $81.82 \%$ & & \\
Overall Accuracy $=$ & $90.60 \%$ & & & & \\
OOB Error $=$ & $91.00 \%$ & & & & \\
Cohen's Kappa $=$ & 0.85 & & & & \\
\hline
\end{tabular}

\begin{tabular}{|lccccc|}
\hline & \multicolumn{5}{c|}{ MS (2) - Mid \& Late Summer } \\
\cline { 2 - 5 } & Cropland & Rangeland & Seeded Forage & Total & User's Accuracy \\
\hline Cropland & $\mathbf{2 3 5}$ & 4 & 16 & 255 & $92.16 \%$ \\
Rangeland & 1 & $\mathbf{1 2 7}$ & 7 & 135 & $94.07 \%$ \\
Seeded Forage & 10 & 13 & $\mathbf{8 7}$ & 110 & $79.09 \%$ \\
Total & 246 & 144 & 110 & 500 & \\
\hline Producer's Accuracy & $95.53 \%$ & $88.19 \%$ & $79.09 \%$ & & \\
Overall Accuracy $=$ & $89.80 \%$ & & & & \\
OOB Error $=$ & $87.68 \%$ & & & & \\
Cohen's Kappa $=$ & 0.84 & & & & \\
\hline
\end{tabular}


Table A.22. Alberta two-date MS + VI classification error matrices

\begin{tabular}{|lccccc|}
\hline \multicolumn{5}{c}{ MS (2) + VI (2) - Spring \& Late Summer } & \\
\cline { 2 - 5 } & Cropland & Rangeland & Seeded Forage & Total & User's Accuracy \\
\hline Cropland & $\mathbf{2 3 8}$ & 2 & 11 & 251 & $94.82 \%$ \\
Rangeland & 1 & $\mathbf{1 2 6}$ & 6 & 133 & $94.74 \%$ \\
Seeded Forage & 7 & 16 & $\mathbf{9 3}$ & 116 & $80.17 \%$ \\
Total & 246 & 144 & 110 & 500 & \\
\hline Producer's Accuracy & $96.75 \%$ & $87.50 \%$ & $84.55 \%$ & & \\
Overall Accuracy $=$ & $91.40 \%$ & & & & \\
OOB Error $=$ & $91.84 \%$ & & & & \\
Cohen's Kappa $=$ & 0.86 & & & & \\
\hline
\end{tabular}

\begin{tabular}{|lccccc|}
\hline & \multicolumn{3}{c}{ MS (2) + VI (2) - Spring \& Mid Summer } & \\
\cline { 2 - 5 } & Cropland & Rangeland & Seeded Forage & Total & User's Accuracy \\
\hline Cropland & $\mathbf{2 4 2}$ & 2 & 15 & 259 & $93.44 \%$ \\
Rangeland & 2 & $\mathbf{1 3 3}$ & 8 & 143 & $93.01 \%$ \\
Seeded Forage & 2 & 9 & $\mathbf{8 7}$ & 98 & $88.78 \%$ \\
Total & 246 & 144 & 110 & 500 & \\
\hline Producer's Accuracy & $98.37 \%$ & $92.36 \%$ & $79.09 \%$ & & \\
Overall Accuracy $=$ & $92.40 \%$ & & & & \\
OOB Error $=$ & $91.15 \%$ & & & & \\
Cohen's Kappa $=$ & 0.88 & & & & \\
\hline
\end{tabular}

\begin{tabular}{|lccccc|}
\hline & \multicolumn{3}{c|}{ MS (2) + VI (2) - Mid \& Late Summer } & \\
\cline { 2 - 5 } & Cropland & Rangeland & Seeded Forage & Total & User's Accuracy \\
\hline Cropland & $\mathbf{2 3 8}$ & 5 & 9 & 252 & $94.44 \%$ \\
Rangeland & 0 & $\mathbf{1 2 8}$ & 7 & 135 & $94.81 \%$ \\
Seeded Forage & 8 & 11 & $\mathbf{9 4}$ & 113 & $83.19 \%$ \\
Total & 246 & 144 & 110 & 500 & \\
\hline Producer's Accuracy & $96.75 \%$ & $88.89 \%$ & $85.45 \%$ & & \\
Overall Accuracy $=$ & $92.00 \%$ & & & & \\
OOB Error $=$ & $89.94 \%$ & & & & \\
Cohen's Kappa $=$ & 0.87 & & & & \\
\hline
\end{tabular}


Table A.23. Alberta two-date MS $+V I \& R S 2$ classification error matrices

\begin{tabular}{|lccccc|}
\hline & \multicolumn{2}{c}{ MS (2) + VI (2) + Radar - Spring \& Late Summer } & \\
\cline { 2 - 5 } & Cropland & Rangeland & Seeded Forage & Total & Us er's Accuracy \\
\hline Cropland & $\mathbf{2 4 0}$ & 2 & 8 & 250 & $96.00 \%$ \\
Rangeland & 0 & $\mathbf{1 2 9}$ & 8 & 137 & $94.16 \%$ \\
Seeded Forage & 6 & 13 & $\mathbf{9 4}$ & 113 & $83.19 \%$ \\
Total & 246 & 144 & 110 & 500 & \\
\hline Producer's Accuracy & $97.56 \%$ & $89.58 \%$ & $85.45 \%$ & & \\
Overall Accuracy $=$ & $92.60 \%$ & & & & \\
OOB Error $=$ & $92.10 \%$ & & & & \\
Cohen's Kappa $=$ & 0.88 & & & & \\
\hline
\end{tabular}

\begin{tabular}{|lccccc|}
\hline & \multicolumn{2}{c}{ MS (2) + VI (2) + Radar - Spring \& Mid Summer } & \\
\cline { 2 - 5 } & Cropland & Rangeland & Seeded Forage & Total & User's Accuracy \\
\hline Cropland & $\mathbf{2 4 2}$ & 1 & 15 & 258 & $93.80 \%$ \\
Rangeland & 1 & $\mathbf{1 3 2}$ & 6 & 139 & $94.96 \%$ \\
Seeded Forage & 3 & 11 & $\mathbf{8 9}$ & 103 & $86.41 \%$ \\
Total & 246 & 144 & 110 & 500 & \\
\hline Producer's Accuracy & $98.37 \%$ & $91.67 \%$ & $80.91 \%$ & & \\
Overall Accuracy $=$ & $92.60 \%$ & & & & \\
OOB Error $=$ & $92.68 \%$ & & & & \\
Cohen's Kappa $=$ & 0.88 & & & & \\
\hline
\end{tabular}

\begin{tabular}{|lccccc|}
\hline & \multicolumn{2}{c}{ MS (2) + VI (2) + Radar - Mid \& Late Summer } & \\
\cline { 2 - 5 } & Cropland & Rangeland & Seeded Forage & Total & User's Accuracy \\
\hline Cropland & $\mathbf{2 3 8}$ & 3 & 8 & 249 & $95.58 \%$ \\
Rangeland & 0 & $\mathbf{1 2 7}$ & 8 & 135 & $94.07 \%$ \\
Seeded Forage & 8 & 14 & $\mathbf{9 4}$ & 116 & $81.03 \%$ \\
Total & 246 & 144 & 110 & 500 & \\
\hline Producer's Accuracy & $96.75 \%$ & $88.19 \%$ & $85.45 \%$ & & \\
Overall Accuracy $=$ & $91.80 \%$ & & & & \\
OOB Error $=$ & $91.57 \%$ & & & & \\
Cohen's Kappa $=$ & 0.87 & & & & \\
\hline
\end{tabular}


Table A.24. Alberta three-date classification error matrices (part 1)

\begin{tabular}{|lccccc|}
\hline & \multicolumn{5}{c|}{ MS (3) } \\
\cline { 2 - 5 } & Cropland & Rangeland & Seeded Forage & Total & User's Accuracy \\
\hline Cropland & $\mathbf{2 3 8}$ & 1 & 10 & 249 & $95.58 \%$ \\
Rangeland & 1 & $\mathbf{1 3 1}$ & 5 & 137 & $95.62 \%$ \\
Seeded Forage & 7 & 12 & $\mathbf{9 5}$ & 114 & $83.33 \%$ \\
Total & 246 & 144 & 110 & 500 & \\
\hline Producer's Accuracy & $96.75 \%$ & $90.97 \%$ & $86.36 \%$ & & \\
Overall Accuracy $=$ & $92.80 \%$ & & & & \\
OOB Error $=$ & $92.53 \%$ & & & & \\
Cohen's Kappa $=$ & 0.88 & & & & \\
\hline
\end{tabular}

\begin{tabular}{|lccccc|}
\hline & \multicolumn{5}{c|}{ MS (3) + VI (3) } \\
\cline { 2 - 5 } & Cropland & Rangeland & Seeded Forage & Total & User's Accuracy \\
\hline Cropland & $\mathbf{2 4 1}$ & 1 & 11 & 253 & $95.26 \%$ \\
Rangeland & 0 & $\mathbf{1 2 9}$ & 6 & 135 & $95.56 \%$ \\
Seeded Forage & 5 & 14 & $\mathbf{9 3}$ & 112 & $83.04 \%$ \\
Total & 246 & 144 & 110 & 500 & \\
\hline Producer's Accuracy & $97.97 \%$ & $89.58 \%$ & $84.55 \%$ & & \\
Overall Accuracy $=$ & $92.60 \%$ & & & & \\
OOB Error $=$ & $93.17 \%$ & & & & \\
Cohen's Kappa $=$ & 0.88 & & & & \\
\hline
\end{tabular}

\begin{tabular}{|lccccc|}
\hline & \multicolumn{5}{c|}{ MS (3)+ Radar } \\
\cline { 2 - 5 } & Cropland & Rangeland & Seeded Forage & Total & User's Accuracy \\
\hline Cropland & $\mathbf{2 3 8}$ & 1 & 12 & 251 & $94.82 \%$ \\
Rangeland & 0 & $\mathbf{1 3 1}$ & 6 & 137 & $95.62 \%$ \\
Seeded Forage & 8 & 12 & $\mathbf{9 2}$ & 112 & $82.14 \%$ \\
Total & 246 & 144 & 110 & 500 & \\
\hline Producer's Accuracy & $96.75 \%$ & $90.97 \%$ & $83.64 \%$ & & \\
Overall Accuracy $=$ & $92.20 \%$ & & & & \\
OOB Error $=$ & $92.87 \%$ & & & & \\
Cohen's Kappa $=$ & 0.88 & & & & \\
\hline
\end{tabular}


Table A.25. Alberta three-date classification error matrices (part 2)

\begin{tabular}{|lccccc|}
\hline & \multicolumn{5}{c|}{ MS (3) + VI (3) + Radar } \\
\cline { 2 - 5 } & Cropland & Rangeland & Seeded Forage & Total & User's Accuracy \\
\hline Cropland & $\mathbf{2 4 3}$ & 1 & 10 & 254 & $95.67 \%$ \\
Rangeland & 1 & $\mathbf{1 2 9}$ & 5 & 135 & $95.56 \%$ \\
Seeded Forage & 2 & 14 & $\mathbf{9 5}$ & 111 & $85.59 \%$ \\
Total & 246 & 144 & 110 & 500 & \\
\hline Producer's Accuracy & $98.78 \%$ & $89.58 \%$ & $86.36 \%$ & & \\
Overall Accuracy $=$ & $93.40 \%$ & & & & \\
OOB Error $=$ & $92.52 \%$ & & & & \\
Cohen's Kappa $=$ & 0.89 & & & & \\
\hline
\end{tabular}

\begin{tabular}{|lccccc|}
\hline & \multicolumn{3}{c|}{ MS (3) + VI (3) + PhenNDVI } & \\
\cline { 2 - 5 } & Cropland & Rangeland & Seeded Forage & Total & User's Accuracy \\
\hline Cropland & $\mathbf{2 4 1}$ & 1 & 8 & 250 & $96.40 \%$ \\
Rangeland & 0 & $\mathbf{1 3 1}$ & 6 & 137 & $95.62 \%$ \\
Seeded Forage & 5 & 12 & $\mathbf{9 6}$ & 113 & $84.96 \%$ \\
Total & 246 & 144 & 110 & 500 & \\
\hline Producer's Accuracy & $97.97 \%$ & $90.97 \%$ & $87.27 \%$ & & \\
Overall Accuracy $=$ & $93.60 \%$ & & & & \\
OOB Error $=$ & $92.47 \%$ & & & & \\
Cohen's Kappa $=$ & 0.90 & & & & \\
\hline
\end{tabular}

\begin{tabular}{|lccccc|}
\hline & \multicolumn{3}{c|}{ MS (3)+ VI (3)+ PhenNDVI+ Radar } & \\
\cline { 2 - 5 } & Cropland & Rangeland & Seeded Forage & Total & User's Accuracy \\
\hline Cropland & $\mathbf{2 4 1}$ & 2 & 8 & 251 & $96.02 \%$ \\
Rangeland & 0 & $\mathbf{1 3 2}$ & 5 & 137 & $96.35 \%$ \\
Seeded Forage & 5 & 10 & $\mathbf{9 7}$ & 112 & $86.61 \%$ \\
Total & 246 & 144 & 110 & 500 & \\
\hline Producer's Accuracy & $97.97 \%$ & $91.67 \%$ & $88.18 \%$ & & \\
Overall Accuracy $=$ & $94.00 \%$ & & & & \\
OOB Error $=$ & $93.73 \%$ & & & & \\
Cohen's Kappa $=$ & 0.90 & & & & \\
\hline
\end{tabular}




\section{APPENDIX C - McNemar's Test Results}

Figures A.1. - A.5. show the results of the McNemar's Chi Square test where classification error matrices (reduced to a $2 \times 2$ contingency matrix) derived from the same independent test set are compared to determine if differences in classification accuracy are statistically significant.

\begin{tabular}{|c|c|c|c|c|c|c|c|c|c|c|c|c|c|}
\hline \multicolumn{7}{|c|}{ Manitoba } & \multicolumn{7}{|c|}{$\begin{array}{ll}\text { Alberta } \\
\end{array}$} \\
\hline $\begin{array}{l}\text { Case: } \\
\text { Control: }\end{array}$ & \multicolumn{6}{|c|}{$\begin{array}{l}\text { MS (2) - Spring and Fall } \\
\text { MS (3) }\end{array}$} & $\begin{array}{l}\text { Case: } \\
\text { Control: }\end{array}$ & \multicolumn{6}{|c|}{$\begin{array}{l}\text { MS (2) - Spring and Late Summer } \\
\text { MS (3) }\end{array}$} \\
\hline \multirow{4}{*}{ Case } & \multirow{4}{*}{$\begin{array}{l}+ \\
- \\
\text { Total }\end{array}$} & $\begin{array}{l}\text { Control } \\
+\end{array}$ & \multicolumn{2}{|c|}{ Total } & \multirow{4}{*}{$\begin{array}{l}\text { Chi squared: } \\
\text { p-value: }\end{array}$} & \multirow{4}{*}{$\begin{array}{l}0.364 \\
0.547\end{array}$} & \multirow{4}{*}{ Case } & \multirow{4}{*}{$\begin{array}{l}+ \\
- \\
\text { Total }\end{array}$} & \multicolumn{2}{|c|}{$\begin{array}{ll}\text { Control } & \\
+ & -\end{array}$} & Total & \multirow{4}{*}{$\begin{array}{l}\text { Chi squared: } \\
\text { p-value: }\end{array}$} & \multirow{4}{*}{$\begin{array}{l}4.083 \\
0.043\end{array}$} \\
\hline & & \begin{tabular}{|r|}
48 \\
\end{tabular} & 4 & 52 & & & & & 34 & 10 & 44 & & \\
\hline & & 7 & 436 & 443 & & & & & 2 & 454 & 456 & & \\
\hline & & 55 & 440 & 495 & & & & & 36 & 464 & 500 & & \\
\hline $\begin{array}{l}\text { Case: } \\
\text { Control: }\end{array}$ & \multicolumn{6}{|c|}{$\begin{array}{l}\text { MS (2) - Spring and Late Summer } \\
\text { MS (3) }\end{array}$} & $\begin{array}{l}\text { Case: } \\
\text { Control: }\end{array}$ & \multicolumn{6}{|c|}{$\begin{array}{l}\text { MS (2) - Spring and Mid Summer } \\
\text { MS (3) }\end{array}$} \\
\hline \multirow{4}{*}{ Case } & \multirow{4}{*}{$\begin{array}{l}+ \\
- \\
\text { Total }\end{array}$} & $\begin{array}{l}\text { Control } \\
+\quad\end{array}$ & \multicolumn{2}{|c|}{ Total } & \multirow{4}{*}{$\begin{array}{l}\text { Chi squared: } \\
\text { p-value: }\end{array}$} & \multirow{4}{*}{$\begin{array}{l}6.125 \\
0.013\end{array}$} & \multirow{4}{*}{ Case } & \multicolumn{2}{|c|}{ Control } & \multicolumn{2}{|r|}{ Total } & \multirow{4}{*}{$\begin{array}{l}\text { Chi squared: } \\
\text { p-value: }\end{array}$} & \multirow{4}{*}{$\begin{array}{l}9.091 \\
0.003\end{array}$} \\
\hline & & \begin{tabular}{|r|}
52 \\
\end{tabular} & 0 & 52 & & & & + & \begin{tabular}{|r|}
36 \\
\end{tabular} & 0 & 36 & & \\
\hline & & 8 & 435 & 443 & & & & - & 11 & 453 & 464 & & \\
\hline & & 60 & 435 & 495 & & & & Total & 47 & 453 & 500 & & \\
\hline $\begin{array}{l}\text { Case: } \\
\text { Control: }\end{array}$ & \multicolumn{6}{|c|}{$\begin{array}{l}\text { MS (2) - Late Summer and Fall } \\
\text { MS (3) }\end{array}$} & $\begin{array}{l}\text { Case: } \\
\text { Control: }\end{array}$ & \multicolumn{4}{|c|}{$\begin{array}{l}\text { MS (2) - Mid Summer and Late Summer } \\
\text { MS (3) }\end{array}$} & & \\
\hline \multirow{4}{*}{ Case } & \multirow{4}{*}{$\begin{array}{l}+ \\
- \\
\text { Total }\end{array}$} & $\begin{array}{l}\text { Control } \\
+\quad\end{array}$ & \multicolumn{2}{|c|}{ Total } & \multirow{4}{*}{$\begin{array}{l}\text { Chi squared: } \\
\text { p-value: }\end{array}$} & \multirow{4}{*}{$\begin{array}{r}14.063 \\
0.000\end{array}$} & & & $\begin{array}{ll}\text { Control } & \\
+\end{array}$ & & Total & & \\
\hline & & \begin{tabular}{|r|}
52 \\
\end{tabular} & 0 & 52 & & & Case & + & \begin{tabular}{|r|}
36 \\
\end{tabular} & 0 & 36 & Chi squared: & 13.067 \\
\hline & & 16 & 427 & 443 & & & & - & 15 & 449 & 464 & p-value: & 0.000 \\
\hline & & 68 & 427 & 495 & & & & Total & 51 & 449 & 500 & & \\
\hline
\end{tabular}

Figure A.1. McNemar's Chi-Square test comparing three-date MS classification to two-date MS classifications 


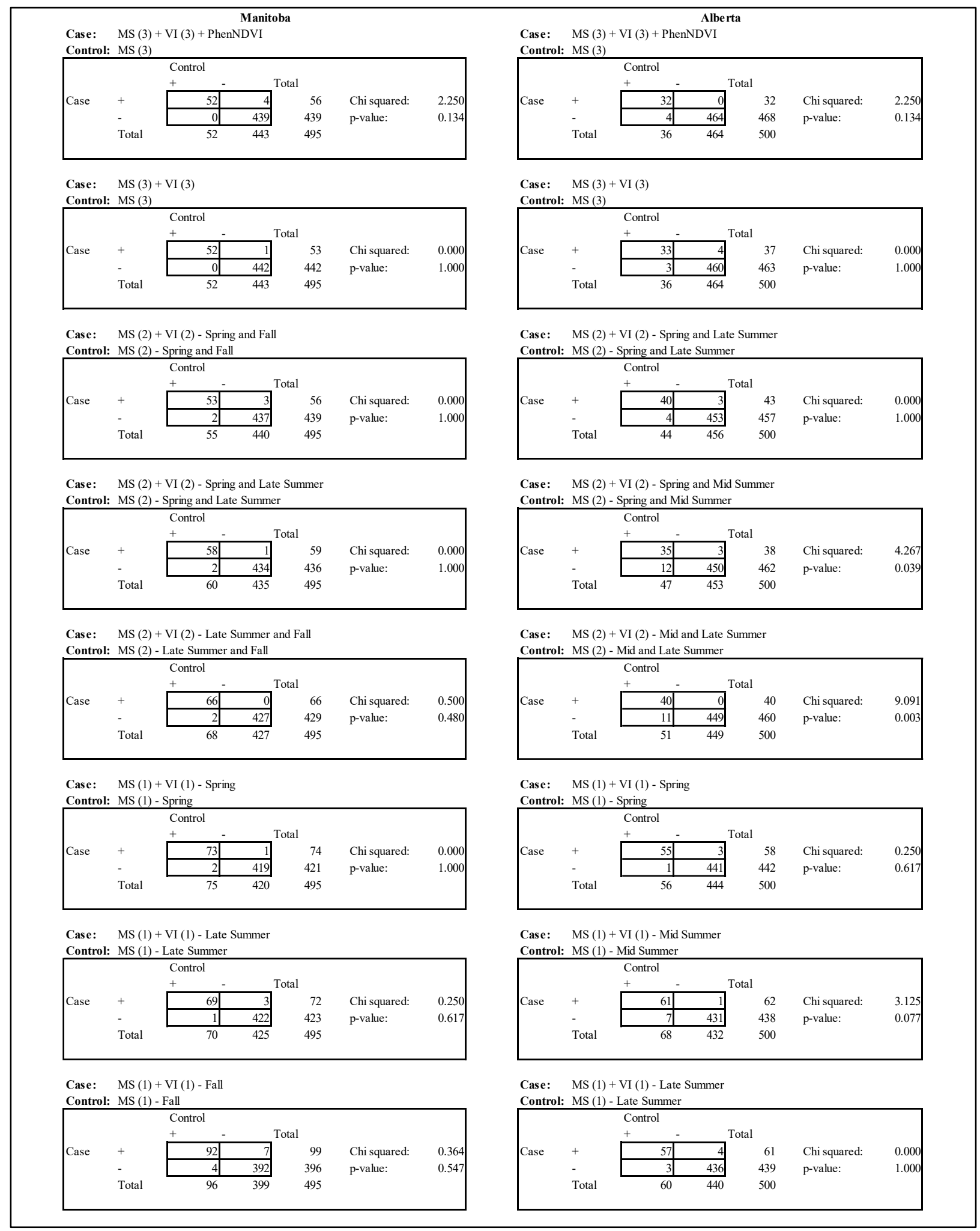

Figure A.2. McNemar's Chi-Square test comparing MS + VI classifications (1, 2, and 3-date) to MS classifications (1, 2 and 3-date) 


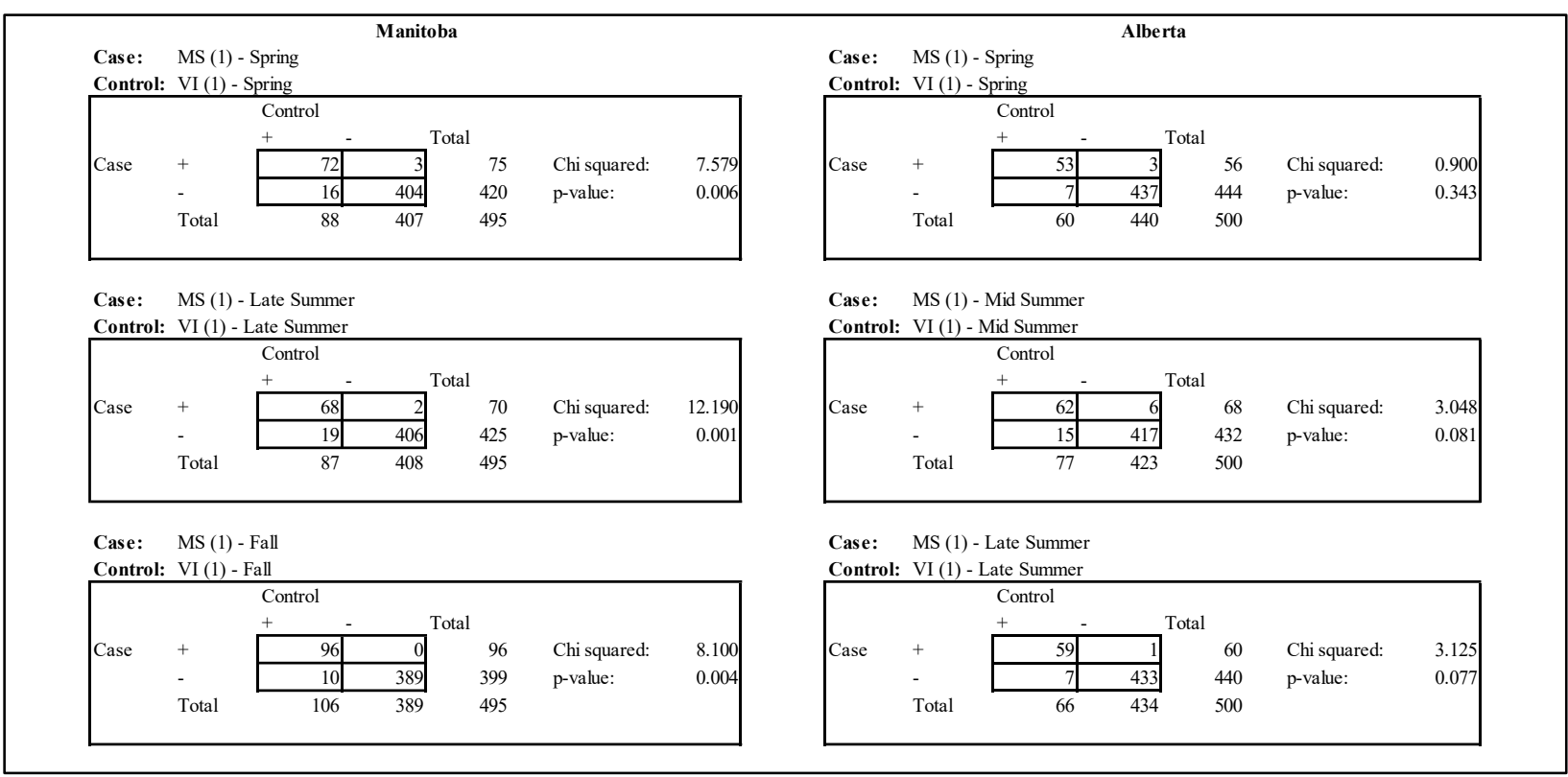

Figure A.3. McNemar's Chi-Square test comparing single-date MS classifications to single-date VI classifications. 


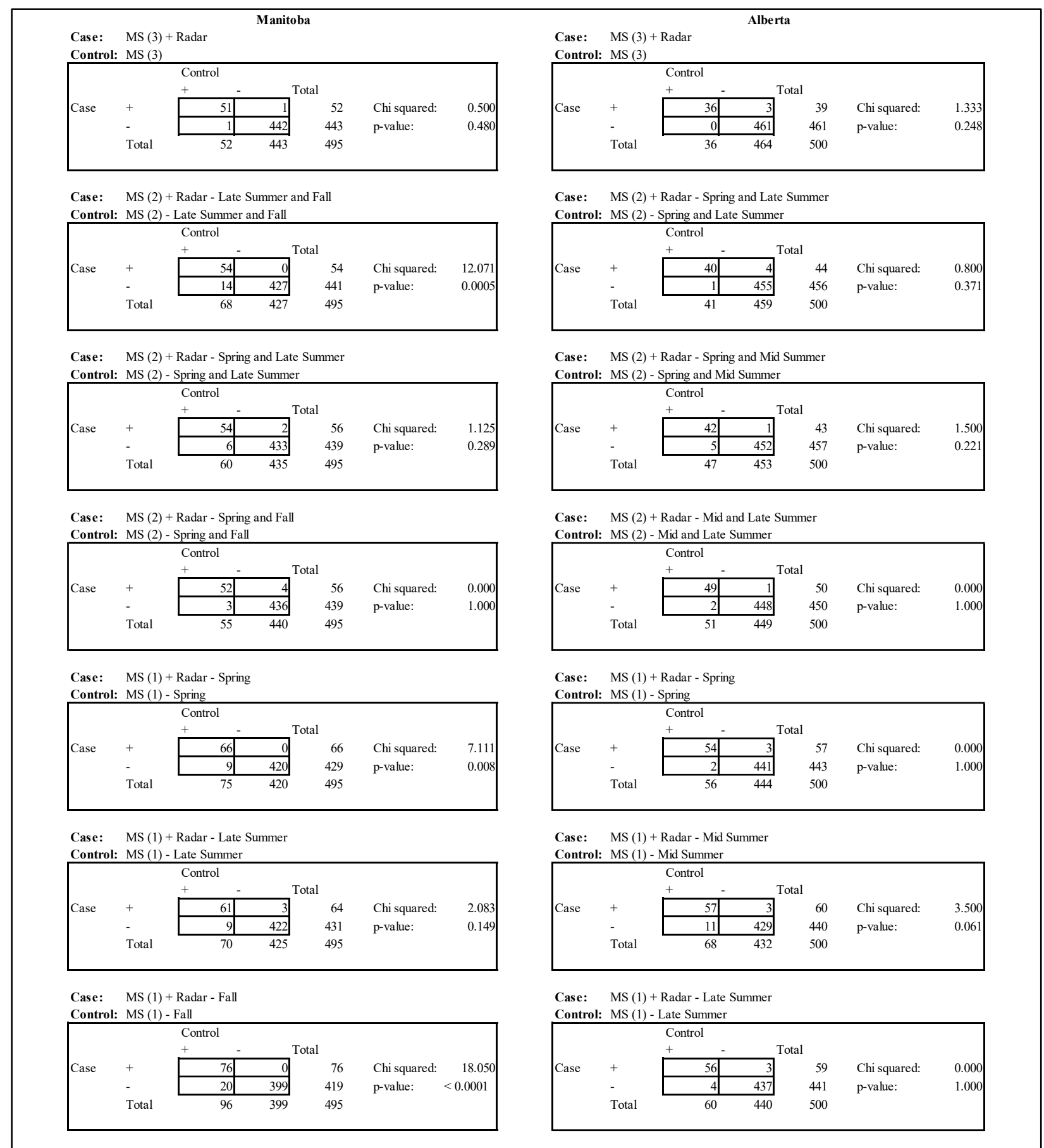

Figure A.4. McNemar's Chi-Square test comparing MS + RS2 classifications (1, 2, and 3-date) to MS classifications (1, 2 and 3-date) 


\begin{tabular}{|c|c|c|c|c|c|c|c|c|c|c|c|c|c|}
\hline $\begin{array}{l}\text { Case: } \\
\text { Control: }\end{array}$ & $\begin{array}{l}\text { MS (3) } \\
\text { MS (3) }\end{array}$ & $\begin{array}{l}\text { VI (3) + Phe } \\
\text { Radar }\end{array}$ & $\begin{array}{l}\text { Manit } \\
\text { DVI + }\end{array}$ & & & & $\begin{array}{l}\text { Case: } \\
\text { Control: }\end{array}$ & $\begin{array}{l}\text { MS (3) } \\
\text { MS (3) }\end{array}$ & $\begin{array}{l}\mathrm{VI}(3)+\mathrm{Phe} \\
\text { Radar }\end{array}$ & $\begin{array}{l}\text { Albe } \\
\text { DVI + }\end{array}$ & & & \\
\hline & & Control & & & & & & & Control & & & & \\
\hline Case & + & 5 & 5 & 57 & Chiscuared. & 32001 & Case & + & 30 & 0 & 30 & Chis cuared. & $7111 \mathrm{~K}$ \\
\hline & - & 0 & 438 & 438 & p-value: & 0.074 & & - & 9 & 461 & 470 & p-value: & 0.008 \\
\hline & Total & 52 & 443 & 495 & & & & Total & 39 & 461 & 500 & & \\
\hline $\begin{array}{l}\text { Case: } \\
\text { Control: }\end{array}$ & $\begin{array}{l}\text { MS (3) } \\
\text { MS (3) }\end{array}$ & $\mathrm{VI}(3)+\mathrm{Phe}$ & $\mathrm{DVI}+$ & & & & $\begin{array}{l}\text { Case: } \\
\text { Control: }\end{array}$ & $\begin{array}{l}\text { MS (3) } \\
\text { MS (3) }\end{array}$ & VI (3) + Phe & DVI + & & & \\
\hline & & $\begin{array}{l}\text { Control } \\
++\end{array}$ & & & & & & & $\begin{array}{l}\text { Control } \\
+\end{array}$ & & & & \\
\hline Case & + & \begin{tabular}{|l|}
52 \\
\end{tabular} & 0 & 52 & Chi squared: & 3.200 & Case & + & 30 & 0 & 30 & Chi squared: & 4.167 \\
\hline & - & 5 & 438 & 443 & p-value: & 0.074 & & - & 6 & 464 & 470 & p-value: & 0.041 \\
\hline & Total & 57 & 438 & 495 & & & & Total & 36 & 464 & 500 & & \\
\hline
\end{tabular}

Figure A.5. McNemar's Chi-Square test comparing three date classifications using all variables to the three-date MS classification and the three-date MS + RS2 classification 


\section{APPENDIX D - Mean Decrease in Accuracy for all Variables}

Figure A.28 displays the mean decrease in accuracy statistic (MDA) for the Manitoba study area, while Figure A.29 displays the MDA for the Alberta variables. The higher the MDA for a variable, the more the accuracy of the random forest classification decreases due to the exclusion (or permutation) of that variable, therefore variables with a large mean decrease in accuracy are more important for classification. 


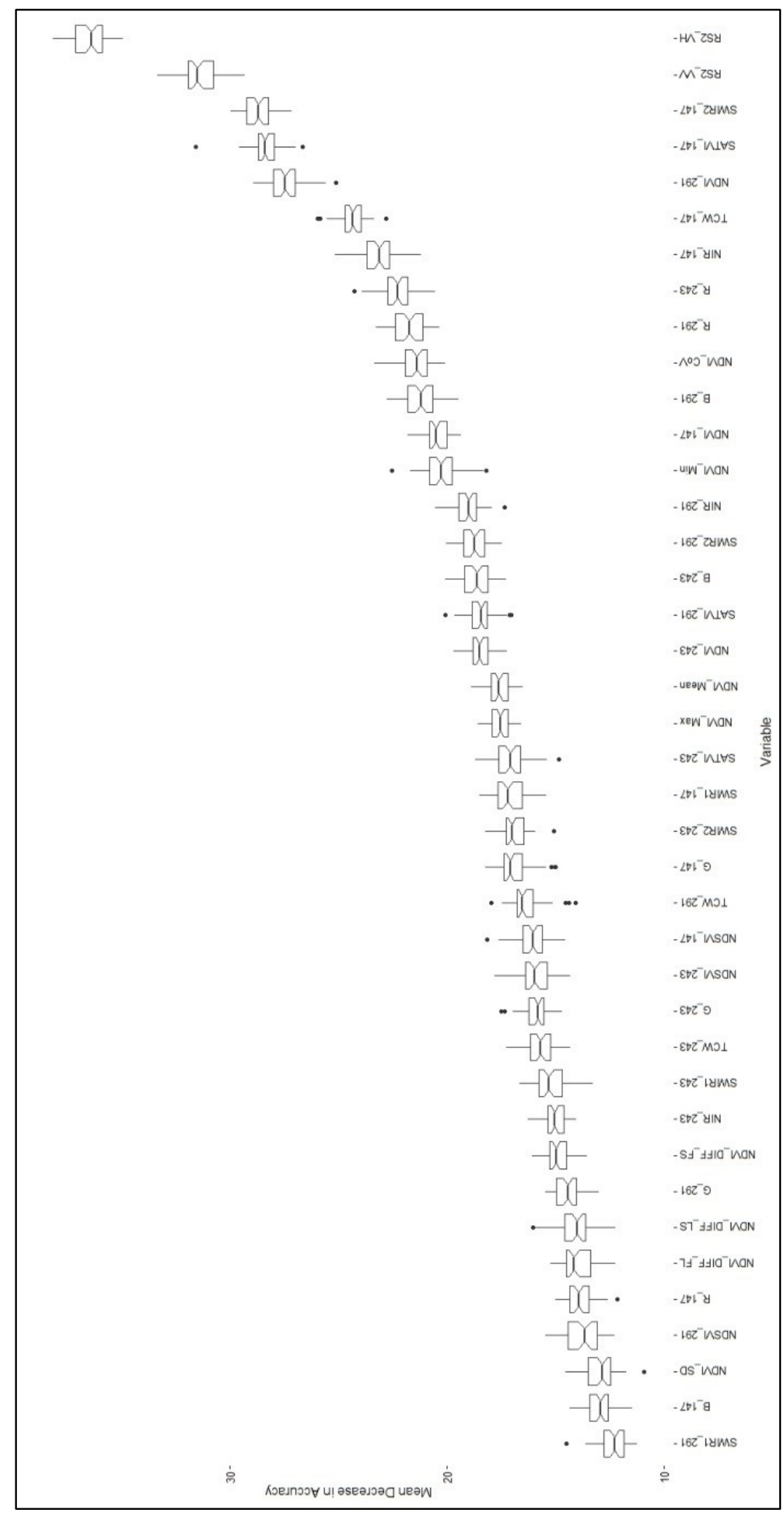

Figure A.6. MDA for all Manitoba variables (Optical + Radar) for 1 iteration of the RF classification 


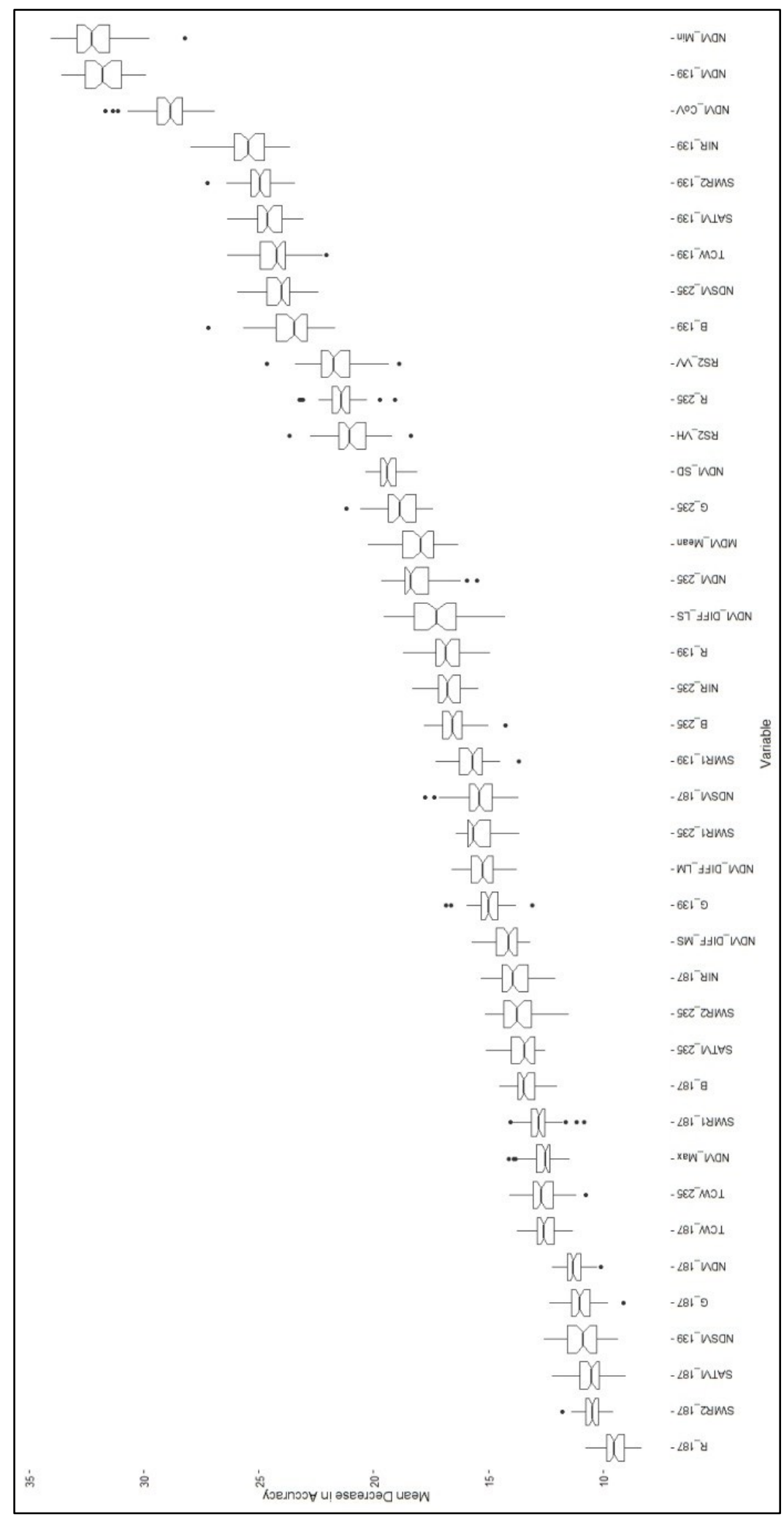

Figure A.7. MDA for all Alberta variables (Optical + Radar) for 1 iteration of the RF classification 


\section{APPENDIX E - Variable Correlation}

The following figures are the variable correlation tables comparing all variables using the Spearman correlation. Figures A.8 and A.9 present the spearman correlation coefficients, and the p-values, respectively for the Manitoba study data. Figures A.10 and A.11 present the spearman correlation coefficients, and the p-values, respectively for the Alberta study data 


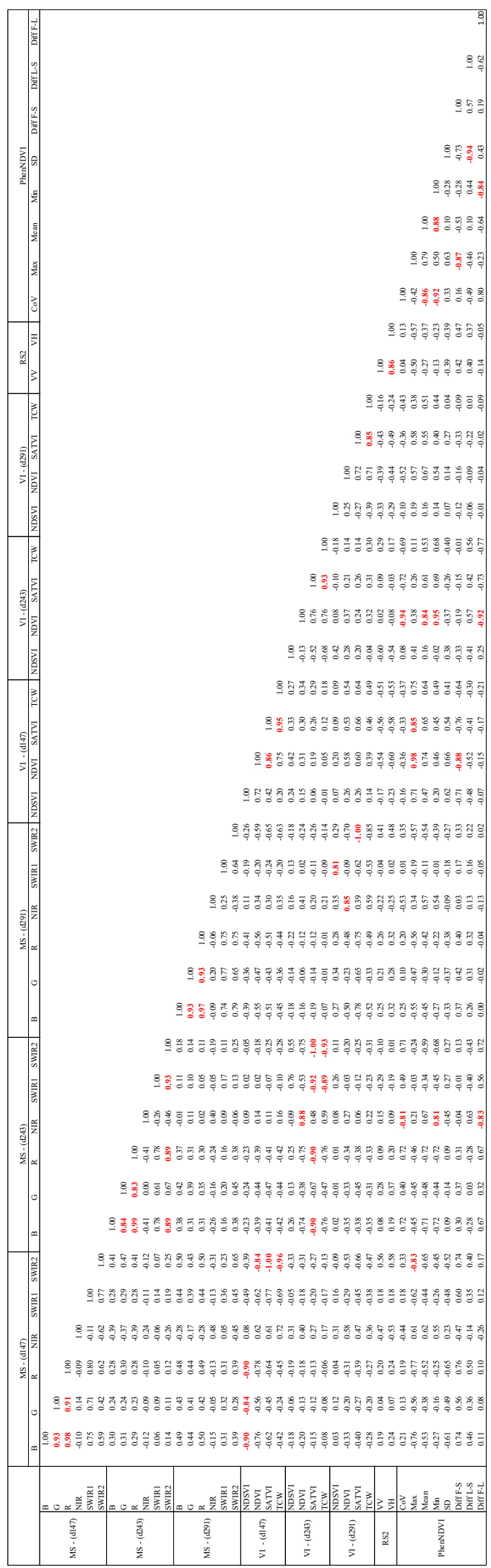

Figure A.8. Spearman correlation coefficients for all Manitoba variables 


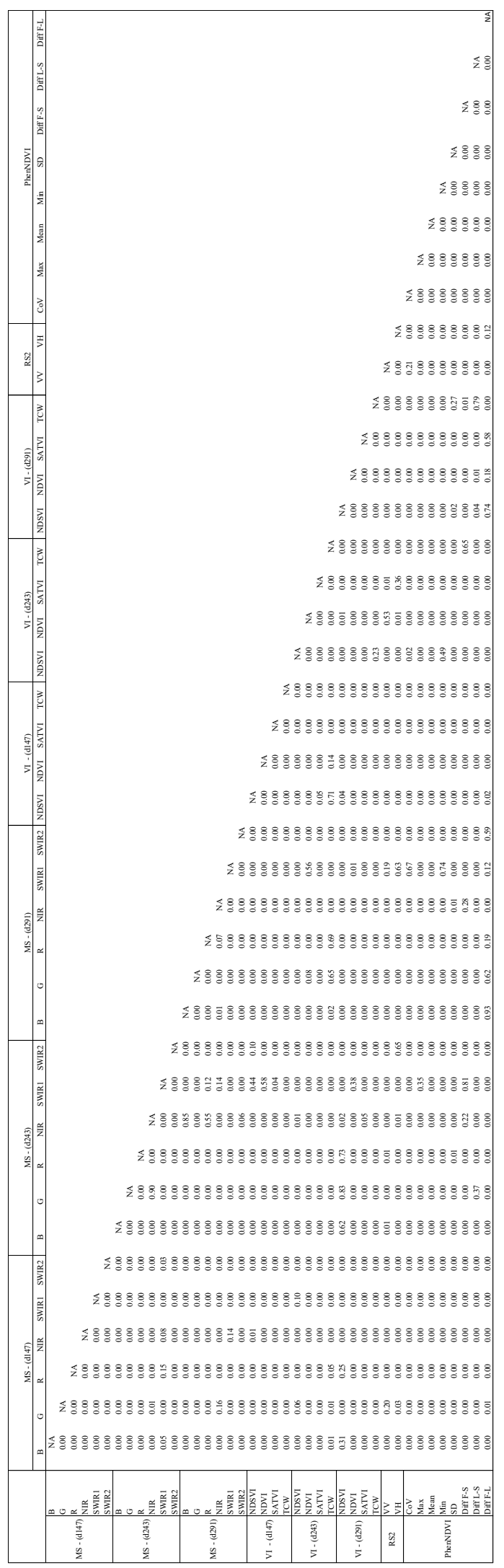

Figure A.9. Spearman correlation p-values for all Manitoba variables 


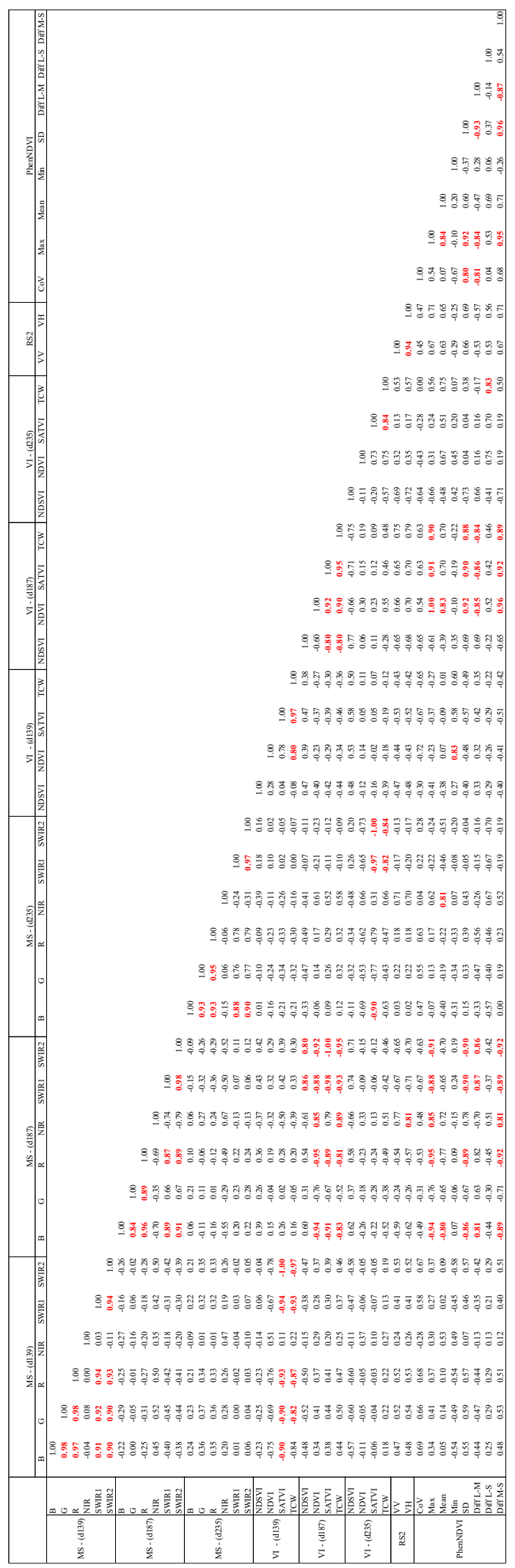

Figure A.10. Spearman correlation coefficients for all Alberta variables 


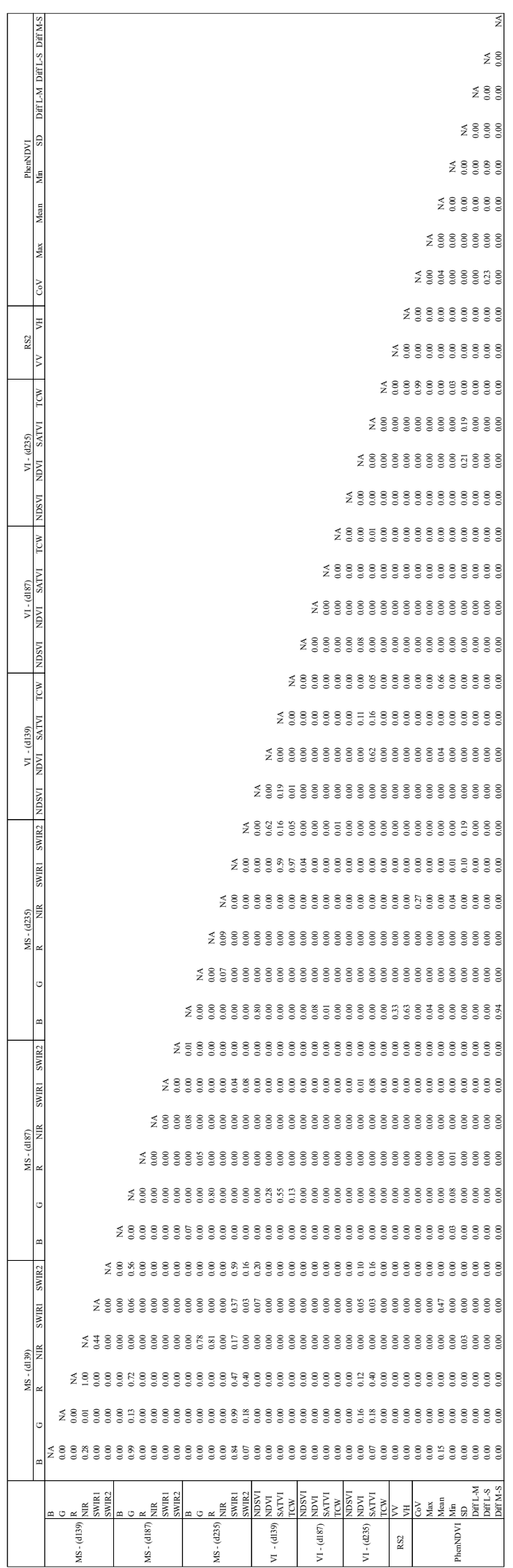

Figure A.11. Spearman correlation p-values for all Alberta variables 
